Instituto de Física

Universidade de São Paulo

\title{
Desenvolvimento de um gerador de nanopartículas e caracterização de nanopartículas de cobalto
}

\author{
Gabriel Teixeira Landi \\ Orientador: Prof. Dr. Antonio Domingues dos Santos
}

Dissertação apresentada ao Instituto de Física da

Universidade de São Paulo para a obtenção do

título de Mestre em Ciências.

\section{Comissão examinadora:}

Prof. Dr. Antonio Domingues dos Santos (IF-USP)

Profa. Dra. Rosângela Itri (IF-USP)

Prof. Dr. Varlei Rodrigues (UNICAMP) 
A toda a minha familia 


\section{Agradecimentos}

Gostaria primeiramente de agradecer ao meu orientador, Prof. Dr. Antonio Domingues dos Santos, não só pela paciência e competência mas principalmente pela amizade.

Em seguida, gostaria de agradecer a todas as pessoas que participaram deste trabalho:

- Sérgio, pela ajuda no desenvolvimento do sistema;

- Mariana, por me ajudar com absolutamente tudo;

- Professora Marcia Fantini e o Antonio Carlos, pelo auxílio com as medidas de raios X;

- Adir e Nildemar, pelas intermináveis análises de microscopia eletrônica e

- Paulo, por usinar tantas peças tão rapidamente.

Agradeço ao Gil e a Mariana pela amizade e convivência e aos novos alunos pelas incessantes e divertidas seções de café.

Um obrigado especial a minha família, por todos os momentos divertidos que passamos juntos. Hercio, Marília, Marcio, Gisela, Ricardo, Samantha, Toy e Quem.

Agradeço também aos meus amigos: Dead, Vina, Igor, Elton, Rebeca, Chico, Leo, Daniel, Super e Flávia, Timpa, Pivo e todos os outros.

Obrigado também pela amizade de todos: professora Marcia, professora Lucy, professor Daniel, professor Hercílio, professora Carmen, Marcelo, Leonardo, Fabiana, Regina, Renato. O pessoal da oficina mecânica, da criogenia. As moças da limpeza. Ao Iran e a Tatiana. 


\section{Resumo}

Neste trabalho, desenvolvemos um gerador de nanopartículas (NPs) como uma adaptação para um sistema de "magnetron sputtering". Com ele, somos capazes de produzir NPs de materiais diversos e codepositá-las em matrizes dielétricas ou metálicas.

A adaptação consiste em incluir uma região de alta pressão relativa de Ar no caminho do vapor atômico removido do alvo. A aglomeração ocorre termodinamicamente devido a diminuição da energia cinética após colisões com o gás. Desenvolvemos também, uma metodologia para colimar o fluxo de NPs dentro da região de alta pressão. A deposição é feita no substrato na forma de uma mancha com alguns milímetros de diâmetro e o tempo de preparação da amostra é significativamente curto.

Desenvolvemos um modelo fenomenológico para explicar a condensação e a colimação do nosso sistema. Este, apesar de não sofisticado, explica bem ambos os fenômenos e consegue prever o diâmetro das nanopartículas para certas condições.

Em paralelo ao desenvolvimento, produzimos e caracterizamos nanopartículas de cobalto. Da caracterização morfológica, através de microscopia eletrônica, concluímos que as NPs produzidas tem diâmetros médios de $10 \mathrm{~nm}$ com uma dispersão de $13 \%$.

Através de análises de retro-espalhamento Rutherford estudamos a distribuição do material sobre o substrato e observamos que este segue uma distribuição Gaussiana de espessuras. Além disso, devido a colimação, observamos que as taxas de deposição são da ordem de 50 vezes maiores que as taxas usuais de um sistema de "sputtering".

Estudos estruturais através de difração de raios $X$ mostraram que as nanopartículas são nanocristalinas e imagens em alta magnificação de microscopia eletrônica de transmissão comprovaram esta hipótese. Finalmente, estudos magnéticos mostraram que as NPs não possuem eixos preferenciais de magnetização.

Desenvolvemos condições padrões de operação e estabilizamos o sistema que atualmente produz amostras confiáveis e reprodutíveis. Além do Co, nanopartículas de Cu e SmCo foram produzidas em condições parecidas. A morfologia destas partículas foi investigadas por microscopia eletrônica e seus tamanhos se mostraram próximos dos das NPs de Co. Estes resultados ilustraram a universalidade do nosso sistema de deposição de nanopartículas. 


\section{Abstract}

We have developed a nanoparticle (NP) generator by adapting one of the sputtering guns on a magnetron sputtering system. With it, we are able to produce nanoparticles with different types of material.

The adaptation consists of including a high-pressure region in the path of the atomic vapor removed from the sputtering target. The condensation happens thermodynamically through the loss of kinetic energy that the atomic vapor suffers after collisions with the gas. We have also developed a methodology to collimate the flow of nanoparticles inside the high pressure region. The deposition on the substrate is in the form of a stain with a few millimeters in diameter. The sample preparation time is also relatively short.

We created a phenomenological model to explain both the condensation and collimation phenomena in our system. Despite being relatively simple, this model explain both quite well.

In parallel to the development of the system, we produced and characterized cobalt nanoparticles. From a morphological analysis, carried out using electron microscopy, we determined that the nanoparticles mean diameter is of about $10 \mathrm{~nm}$ with a dispersion of $13 \%$. Through Rutherford back-scattering analysis, we studied the thickness distribution of the sample along the substrate. We observed that it follows a Gaussian distribution. Also, because of the collimation of the material, the deposition rates are about 50 times higher than in a regular sputtering system.

Using $X$ ray diffraction we were able to determine that the NPs are nano-crystalline which is corroborated with high resolution transmission electron microscopy images. Finally, magnetic measurements showed that the nanoparticles do not have any preferential magnetization axis.

We developed standards of operations and stabilized the system. The samples we produce are trustworthy and reproducible. Besides $\mathrm{Co}, \mathrm{Cu}$ and SmCo NPs were produced using this system with conditions similar to the ones used on the Co NPs. Through morphological analysis, we determined that their sizes are also similar. These results illustrate the universality of our system. 


\section{Sumário}

1. Introdução 1

2. Técnicas experimentais 5

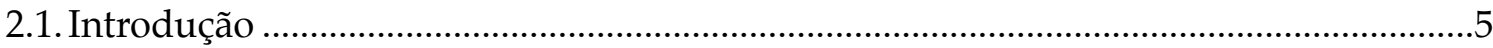

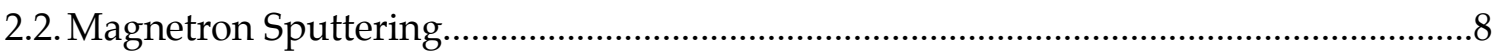

2.3. O gerador de nanopartículas .......................................................................................12

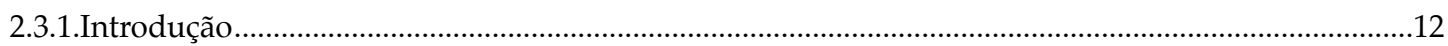

2.3.2.Parâmetros experimentais ...................................................................................................................13

2.3.3.Produção das amostras e controle da quantidade de material ................................................................14

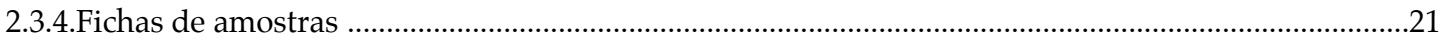

2.4. O processo de condensação ......................................................................................... 21

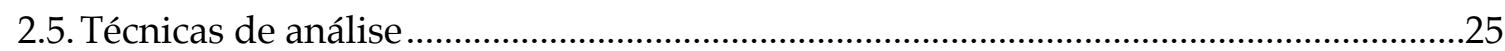

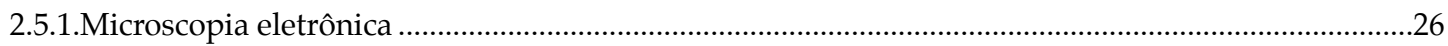

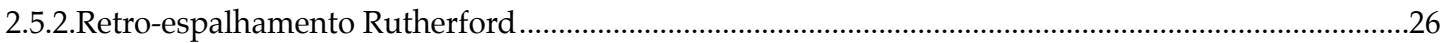

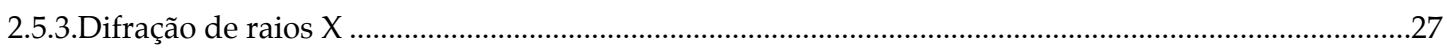

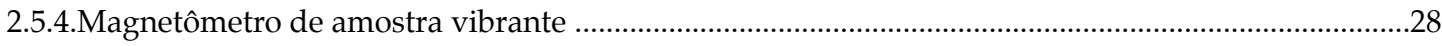

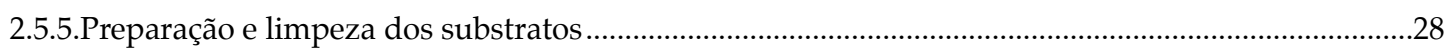

3. Resultados experimentais e análise dos dados 30

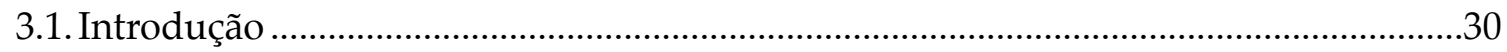

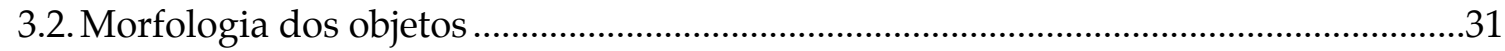

3.2.1.Influência do fluxo de gás sobre o tamanho dos aglomerados ..........................................................32

3.2.2.Influência da potência aplicada sobre o tamanho dos aglomerados .....................................................36

3.2.3.Algumas considerações sobre as amostras produzidas .......................................................................38

3.2.4. Variações no tamanho das nanopartículas .............................................................................................38 


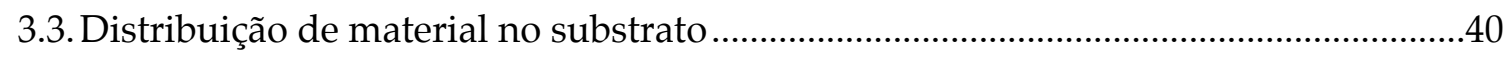

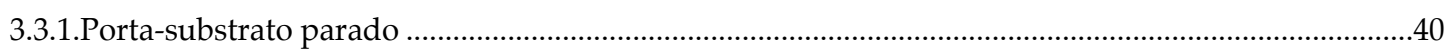

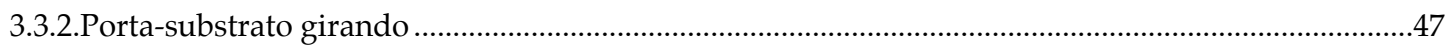

3.3.3.Discussões referentes a distribuição do material e as taxas de deposição ............................................50

3.3.4.Alguns comentários sobre codeposições .........................................................................................52

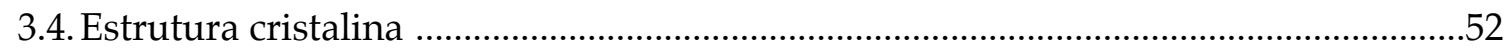

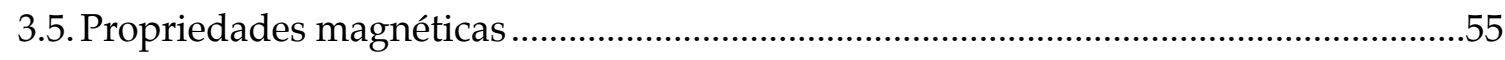

3.6. Considerações sobre o regime de colimação..................................................................57

3.7. Resultados para nanopartículas de $\mathrm{Cu}$ e SmCo............................................................58

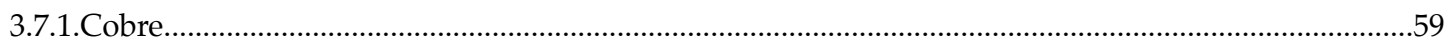

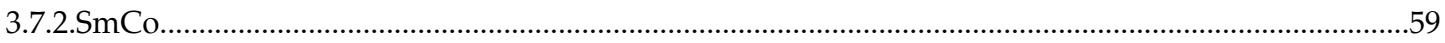

4. Conclusões 64

$\begin{array}{ll}\text { Bibliografia } & 69\end{array}$ 


\section{Introdução}

\section{Introdução e motivação}

Os avanços na área de ciência e tecnologia dos materiais tem como principal característica o crescente controle sobre estruturas de tamanho reduzido [1, 2], cujo comportamento não é nem o de átomos, nem o de sólidos, líquidos ou gases; mas algo intermediário.

Esta área de conhecimento é denominada nanociência ou nanotecnologia. Quebras de simetria, efeitos de confinamento e propriedades quânticas entram em vigor e atribuem aos materiais propriedades novas, interessantes e sofisticadas.

Argumenta-se que os principais avanços nesta área se deram devido as melhorias nas técnicas de análise [ $\underline{3}$ ] abrindo o caminho para diversos novos experimentos e para a investigação das propriedades de diferentes sistemas.

Seguindo o avanço nas técnicas de análise, novos métodos de produção de amostras foram desenvolvidos $[\underline{4}, \underline{5}]$ e métodos antigos foram aperfeiçoados. Tais podem ser divididos em duas categorias, normalmente denominadas "top-down" [ $\underline{6}, \underline{7}] \mathrm{e}$ "bottomup" $[\underline{8}, 9]$. Na primeira, parte-se de uma amostra macroscópica para obter a estrutura nanoscópica desejada ao passo que na segunda, parte-se de componentes atômicos e moleculares para alcançar este resultado.

Melhorias em ambos os métodos são fundamentais para buscar materiais com novas propriedades e com potenciais para aplicações. O uso de sistemas exóticos, combinados entre si de formas diversas, pode abrir caminho para efeitos nunca antes observados. Para obter as diferentes propriedades que buscamos nestes materiais, as características mais importantes de serem manipuladas são sua forma geométrica, sua composição química e sua estrutura cristalina (ou disposição atômica).

Entre as diversas classes de objetos nanométricos possíveis de serem produzidas, uma que é de grande interesse, tanto científico quanto tecnológico, é a das nanopartícu- 
las (NPs) $[\underline{10}, \underline{11}, \underline{12}, \underline{13}]$. Estas são caracterizadas por terem uma forma bem definida (esféricas, cúbicas, etc.) e uma distribuição de tamanhos conhecida.

Se restringindo apenas a esta área, a ramificação nos trabalhos ainda é extremamente vasta. Isso se deve ao número enorme de materiais com os quais as nanopartículas podem ser produzidas (polímeros, metais, óxidos metálicos, semicondutores, etc.) $[\underline{14}, \underline{15}, \underline{16}, \underline{17}, \underline{18}, \underline{19}]$ e a gama de técnicas produção que podem ser utilizadas.

\section{$\underline{\text { Objetivos }}$}

O principal objetivo deste trabalho foi desenvolver um gerador de nanopartículas capaz de produzir NPs de diferentes materiais que podem ser emberçadas em matrizes dielétricas ou metálicas. Ele servirá como ponte para a realização de muitos trabalhos interessantes; alguns já em andamento e outros ainda a serem iniciados.

Diversos destes trabalhos envolvem o uso de nanopartículas de cobalto que precisam ser previamente caracterizadas. Portanto, como um objetivo secundário, estudamos as propriedades gerais destas NPs.

\section{Técnicas experimentais}

Desenvolvemos, no Laboratório de Materiais Magnéticos (LMM) um gerador de nanopartículas baseado na técnica de "magnetron sputtering" ("bottom-up") [20]

Esta técnica, amplamente utilizada pela comunidade científica e pela industria na preparação de filmes finos e na metalização de objetos, foi adaptada (de forma não destrutiva) para comportar o nosso gerador. Ela consiste em um sistema de alto-vácuo onde insere-se uma atmosfera controlada de argônio. Através de uma diferença de potencial ioniza-se o gás na direção do alvo de interesse (auxiliado por imãs colocados sob ele). Ao colidir, o gás transfere energia para o alvo podendo remover material na forma de vapor atômico, que é por sua vez direcionado para um substrato.

De forma resumida, é possível entender o gerador de nanopartículas como uma câmara (normalmente denominada de "copo" devido a sua forma geométrica) preen- 
chida com uma atmosfera de argônio em alta pressão*. Ela é fixada na região por onde passa o vapor atômico produzido pelo "sputtering" e é selada, exceto por uma abertura de $2 \mathrm{~mm}$ de diâmetro na sua extremidade.

Assim, como o livre caminho médio é muito pequeno (da ordem de alguns $\mu \mathrm{m}$ ), o vapor atômico sofrerá diversas colisões com o gás perdendo uma fração de sua energia cinética a cada colisão. Com a diminuição da energia cinética ou seja, o resfriamento termodinâmico, ocorre a condensação do vapor atômico que se aglomera então em nanopartículas.

É pela pequena abertura na ponta do copo que as NPs e o gás são removidos em direção ao substrato (onde a pressão é da ordem de alguns mTorr). Devido aos altos valores de fluxo utilizados, há uma colimação das NPs resultando em uma deposição localizada e extremamente concentrada.

Nos tópicos 2.2 e 2.3 encontram-se descritos em detalhes a técnica de "magnetron sputtering" e a adaptação para o gerador de nanopartículas respectivamente.

Da forma como o sistema foi descrito, diversas considerações podem ser feitas: (1) as nanopartículas devem possuir simetria esférica; (2) a pressão dentro do copo, o seu comprimento (ou seja, o tamanho da região de alta pressão) e a quantidade de vapor atômico devem influenciar no tamanho e nas propriedades dos objetos e (3) o processo não deve depender do material utilizado (contanto que ele seja compatível com o "sputtering").

Todas estas previsões foram investigadas e estão detalhadamente discutidas ao longo do trabalho nos capítulos 2 e 3.

Para que tais investigações pudessem ser realizadas, uma gama de técnicas de análise foram necessárias. Entre elas, podemos mencionar microscopia eletrônica de transmissão e varredura, difração de raios $X$, magnetometria de amostra vibrante e retro-espalhamento Rutherford. Tais técnicas estão melhor descritas no tópico 2.5 juntamente com os procedimentos adotados na preparação dos substratos.

* Da ordem de I Torr a ser comparado com alguns mTorr utilizados em um sistema de "sputtering" usual. 


\section{Aplicações do sistema desenvolvido}

Com a adaptação que construímos, somos capazes de produzir nanopartículas de diferentes materiais e em diferentes condições. Além disso, somos capazes de codepositar as NPs com outros materiais ou recobrí-las para proteção (o sistema possui 4 canhões de "sputtering" e o gerador utiliza apenas 1).

Este trabalho teve como principal foco nanopartículas de cobalto $[\underline{21}, \underline{22}, \underline{23}, \underline{24}$, 25]. Estas foram utilizadas primeiramente para testes no desenvolvimento do equipamento. Junto com estes testes, estudamos suas propriedades morfológicas, estruturais e magnéticas (capítulo 3).

Além do cobalto, há um grande interesse de nossa parte em usar o mesmo sistema para produzir NPs de outros materiais. Até o momento, estudos paralelos foram realizados com alvos de $\mathrm{Cu}$ e $\mathrm{SmCo}_{5}$. Para ambos, verificamos a formação de nanopartículas (através de microscopia eletrônica de transmissão) exatamente nas mesmas condições que as utilizadas no Co (o que ajuda a confirmar a universalidade do processo de produção).

Para finalizar, gostaria de enunciar de forma sucinta quais as vantagens e desvantagens do sistema. Entre as vantagens, podemos mencionar:

- A eficácia na produção de amostras;

- O grande leque de materiais que podem ser utilizados;

- A codeposição das nanopartículas com outros materiais;

Entre as desvantagens:

- Não possuímos um controle sobre o tamanho das nanopartículas;

- Não é possível controlar suas formas;

- As nanopartículas estão sempre depositadas sobre um substrato não sendo trivial de dissolvê-las em meio aquoso. 


\section{Técnicas experimentais}

Baseando-se em técnicas de aglomeração de vapor atômico, um gerador de nanopartículas foi desenvolvido como uma adaptação de um sistema de "magnetron sputtering". Neste capítulo estão descritas as principais características do sistema utilizado juntamente com a metodologia por trás da geração dos aglomerados.

Após uma breve introdução sobre as técnicas experimentais (seção 2.1), encontrase uma descrição detalhada do sistema de "magnetron sputtering" (seção 2.2). Em seguida, segue uma descrição do gerador de nanopartículas incluindo os valores de trabalho e as técnicas experimentais para preparação de amostras (seção 2.3). Por fim, uma seção de caráter teórico tem o intuito de melhor situar as grandezas do nosso sistema (seção 2.4). O objetivo desta não é descrever a teoria por trás do processo de condensação mas apenas explicar, fenomenologicamente, o nosso sistema em particular.

Além disso, todas as técnicas de análise utilizadas estão descritas juntamente com os procedimentos para a preparação e limpeza dos substratos (seção 2.5).

\subsection{Introdução}

Em geral, duas rotas são utilizadas para a produção de nanopartículas: métodos químicos ou métodos físicos [11]. Nos métodos químicos a aglomeração é, na maioria dos casos, feita a partir da redução de certos compostos em soluções aquosas [12]. Resultados surpreendentes foram obtidos nos últimos anos, principalmente por [9] e [10], cujos trabalhos não só expõem formas de controlar o tamanho dos aglomerados mas também de controlar sua forma. 
As principais vantagens dos métodos químicos são a grande quantidade de material que podem produzir [13] e o alto controle no tamanho e forma das nanopartículas $[\underline{9}, \underline{10}]$. Em contrapartida, suas principais desvantagens surgem das mudanças significativas que o procedimento experimental exige cada vez que se deseja usar materiais diferentes. Além disso, há uma dificuldade intrínseca dos processos químicos de emberçar os aglomerados em matrizes (dielétricas ou metálicas), o que pode ser usado para evitar a oxidação das NPs ou atribuir a amostra propriedades interessantes.

Métodos físicos, por outro lado, estão comumente relacionados com a formação de aglomerados por processos energéticos ou explosivos. Um exemplo é a utilização de métodos de combustão para remover "pedaços" de alvos que já são em si nanopartículas [14]. Finalmente, partindo de métodos de evaporação atômica, é também possível produzir nanopartículas condensando o vapor atômico em tempo de vôo em sistemas de alto-vácuo $[\underline{15}, \underline{16}, \underline{17}, \underline{18}, \underline{19}, \underline{27}]$.

O sistema desenvolvido neste trabalho está relacionado com estas técnicas de aglomeração de vapor atômico e consiste em uma adaptação da técnica de "magnetron sputtering" [21] utilizada na produção de filmes finos. Para sistemas como o nosso, o processo de produção das NPs pode ser dividido em três etapas:

(1) Geração do vapor atômico do elemento ou liga de interesse;

(2) Condensação termodinâmica do vapor para a formação dos aglomerados;

(3) Remoção dos aglomerados e deposição no substrato.

Com relação a geração do vapor atômico, diversos métodos podem ser usados para substituir o sistema de "sputtering". Entre eles os principais são métodos de evaporação por laser [34], por feixe de elétrons [35] ou íons [36] e térmica [37].

As técnicas de condensação de vapor atômico tem suas origens na década de 70 [38]. Em sistemas parecidos com o nosso, o uso de diferentes gases (He, Ar, Xe) como elemento condensador é uma ferramenta muito comum de ser utilizada para modificar o tamanho das nanopartículas [풍. Devido as suas diferentes massas atômicas, a eficá- 
cia destes gases (todos inertes) em condensar as NPs varia fortemente. Neste trabalho, no entanto, optamos por utilizar apenas o Ar como elemento condensador. Tal decisão teve a vantagem de simplificar o sistema e a desvantagem de diminuir o nosso leque de ferramentas para modificar o tamanho das NPs.

A extração do material pode ser feita de diversas maneiras como, por exemplo, através de lentes aerodinâmicas ou eletrostáticas. No sistema que desenvolvemos nenhuma lente foi necessária pois a própria aerodinâmica do equipamento é capaz de colimar este material e removê-lo em direção ao substrato.

Como será melhor descrito nas seções subseqüentes, os aglomerados são gerados em tempo de vôo em sistemas de vácuo e, devido aos canhões auxiliares, podem ser imersos em matrizes dielétricas, metálicas ou multicamadas através da codeposição do material de interesse. Além disso, devido a uma colimação aerodinâmica dos aglomerados, taxas enormes de deposição (da ordem de $\mathrm{nm} / \mathrm{s}$ ) podem ser alcançadas. Isto corresponde a valores nunca antes observados em sistemas deste tipo, mesmo quando utilizados apenas na produção de filmes finos.

Comparativamente falando, as vantagens deste sistema com relação a outros métodos, sejam eles químicos ou físicos, podem ser destacadas como segue:

- Altíssimas taxas de deposição que, caso se queira, podem ser finamente controladas;

- Invariância da metodologia experimental para diferentes materiais tornando possível a produção de nanopartículas compostas de materiais exóticos, nunca antes utilizados nesta área de pesquisa;

- Imersão dos aglomerados em matrizes dielétricas ou metálicas, não só protegendo-os de corrosões como também possibilitando a construção de sistemas complexos com propriedades interessantes.

Por outro lado, entre as desvantagens temos que:

- Não possuímos um controle eficiente sobre o tamanho das NPs; 
- Devido a natureza estatística do processo, não é possível controlar a forma das NPs (como por exemplo NPs cúbicas $[\underline{10}, \underline{27}])$, sendo elas sempre esféricas;

\subsection{Magnetron Sputtering}

Antes que seja descrita a adaptação do sistema para comportar o gerador de nanopartículas, uma descrição do equipamento na sua forma usual se faz necessária.

Um sistema de "sputtering" comum consiste em uma câmara de alto-vácuo $\left(10^{-6}\right.$ a $10^{-8}$ Torr) que é preenchida com um gás inerte, tipicamente argônio, em pressões da ordem de $10^{-3}$ a $10^{-4}$ Torr. Em torno do alvo do elemento ou liga de interesse aplica-se um potencial que direciona os íons de Ar até ele. Há então a formação de um plasma auto-consistente que se mantêm enquanto o potencial for mantido [21]. Ao colidir com o alvo, os íons de Ar transferem energia para os átomos, podendo removê-los do material.

Com relação ao potencial, há dois tipos de fontes de tensão tipicamente utilizadas: fontes DC e fontes de radiofrequência (RF). Esta última é principalmente utilizada em materiais isolantes para evitar o acúmulo de cargas superficiais.

Em um sistema de "magnetron sputtering", como o utilizado neste trabalho, os canhões onde ficam os alvos possuem imãs que tendem a confinar o plasma na região próxima a ele. Este sistema gera taxas de deposição substancialmente maiores com maior reprodutibilidade, maior controle de espessura e uma melhor aderência no substrato. A figura 2.1 ilustra as principais partes de um canhão de "magnetron sputtering". Uma outra forma de esquematizá-lo está mostrada na figura 2.2.

O sistema utilizado neste trabalho foi um ATC 2000 da AJA Internacional localizado no Laboratório de Materiais Magnéticos (LMM) do Instituto de Física (IF) da Universidade de São Paulo (USP). Vide figura 2.3 para uma imagem panorâmica do sistema.

\footnotetext{
* Há uma gama de processos envolvidos nessas colisões, como a ejeção de elétrons secundários do alvo, desorção de gases, emissão de fótons, entre outros. Em particular, os elétrons secundários podem ionizar os átomos neutros de Ar gerando então um plasma estável.
} 

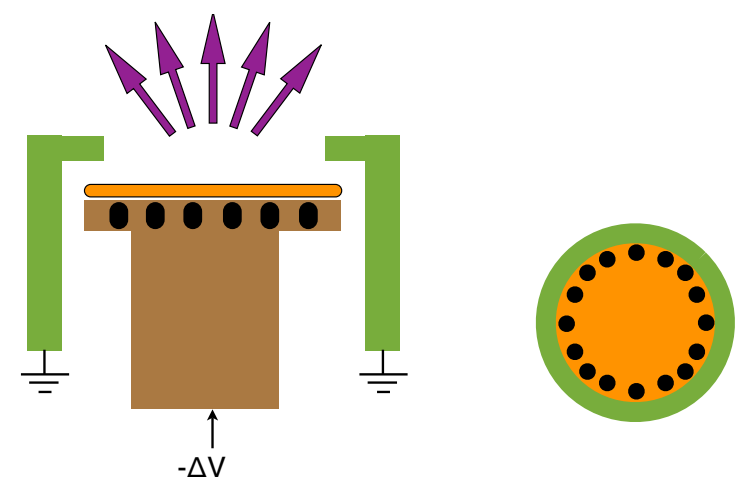

Fig. 2.1: esquema de um sistema de "magnetron sputtering". Em cores, a legenda de cada peça é marrom - canhão do sputtering, laranja - alvo, preto - imãs e verde - armadura aterrada.
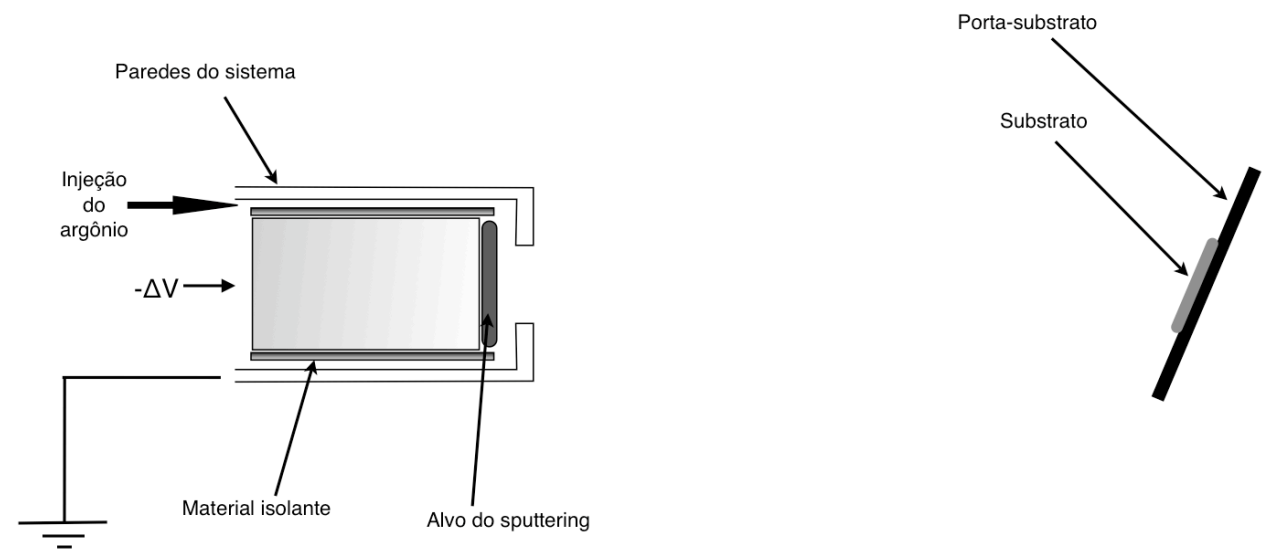

Fig 2.2: forma alternativa de esquematizar um canhão do sistema de "sputtering".

A câmara principal tem aproximadamente 90 litros e possui 4 canhões de deposição. Há também uma pequena câmara auxiliar, conectada a principal por uma válvula manual, que permite a troca dos substratos sem que seja preciso quebrar o vácuo desta última. O sistema de vácuo é composto por duas bombas turbo-moleculares, uma para a câmara principal com vazão nominal de 500 l/s (modelo TCP380) e outra para a câmara auxiliar com vazão nominal de 50 1/s (modelo TCP015). Finalmente, há também bombas mecânicas acopladas às bombas turbo-moleculares. A pressão de base do sistema é tipicamente da ordem de $10^{-7}$ Torr.

Com relação ao monitoramento das pressões, 3 medidores são utilizados na câmara principal: um sensor termoresistivo para a região de pré-vácuo, um "ion-gauge" para medidas de alto-vácuo e um medidor capacitivo (Baratron) de alta precisão para o controle da pressão durante o processo de deposição. A câmara auxiliar também possui 
um sensor termoresistivo e um “ion-gauge". Tipicamente, pressões da ordem de $10^{-7}$ Torr são atingidas em 12 horas na câmara principal e 30 minutos na câmara auxiliar.

Para os canhões de deposição, possuímos fontes DC e RF (13,56 MHz) com potências máximas de 500W. Os 4 canhões possuem entradas de gás e "shutters" (obturadores capazes de bloquear o fluxo de material direcionado ao substrato). Nada foi mencionado até então mas, além do Ar, há também a possibilidade de se utilizar $\mathrm{N}_{2}$ ou $\mathrm{O}_{2}$ como gás.

As taxas de deposição de cada material dependem tipicamente da pressão de Ar, da potência aplicada e do "sputtering yield", uma grandeza característica de cada material e do sistema em questão e que representa a susceptibilidade do material a ser removido do alvo (normalmente fornecida em átomos/íon). As taxas de deposição podem ser monitoradas in situ através de um cristal de quartzo oscilador associado a um equipamento microprocessado.

Conectado ao porta-substratos há um mecanismo de aquecimento composto por lâmpadas halógenas acopladas a um controlador de temperatura (modelo MIC-1160) capaz de aquecer as amostras durante a deposição. Há também a possibilidade de serem feitas deposições a baixas temperaturas utilizando nitrogênio líquido para resfriar o porta-substrato.

Com relação ao sistema de gases, possuímos um controlador adaptivo de pressão (modelo VAT PM-5) associado a uma válvula gaveta que liga a bomba turbo-molecular à câmara principal. Para a entrada dos gases, um controlador de fluxo de massa (modelo 1179A - MKS) é utilizado juntamente com um controlador de quatro canais (modelo 274C - MKS). Os gases utilizados possuem pureza de 99,9999\%.

Finalmente, o dispositivo onde o porta-substrato é rosqueado é conectado a um pequeno motor que possibilita que ele seja rotacionado sobre seu eixo. Como será visto adiante, tal ferramenta foi de extrema importância para que conseguíssemos controlar a concentração de NPs nas amostras. A velocidade do motor pode ser controlada e a altura do substrato com relação ao alvo variada em aproximadamente $5 \mathrm{~cm}$. 


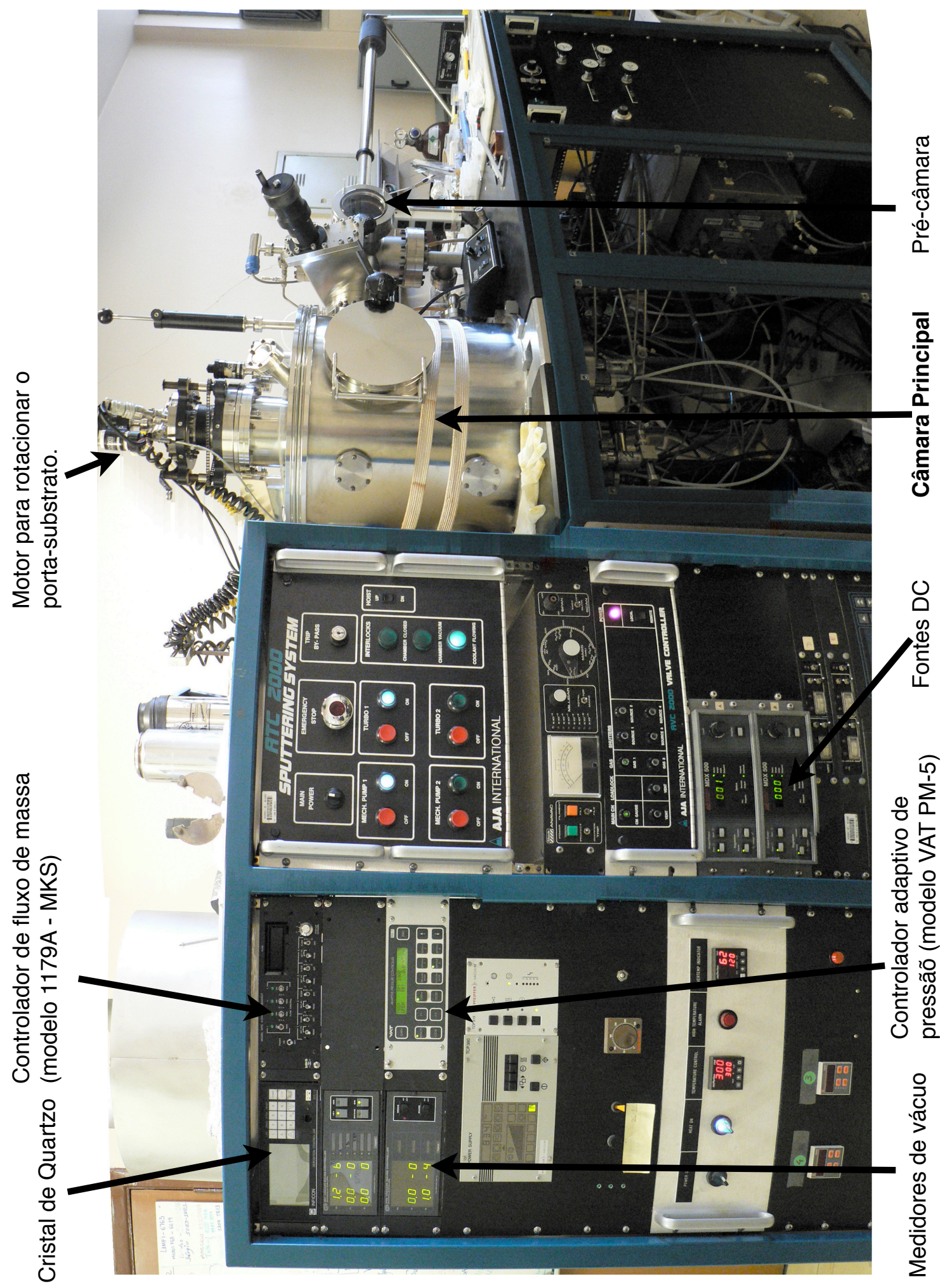

Fig. 2.3: imagem panorâmica do sistema de "sputtering" com os principais componentes estão destacados. 


\section{3. $O$ gerador de nanopartículas}

\subsubsection{Introdução}

A adaptação do sistema de "magnetron sputtering" para o gerador de nanopartículas é bastante simples. No entanto, há uma quantidade enorme de complicações e cuidados envolvidos e foi necessário mais de um ano para que o sistema pudesse ser considerado estável. Ao fim desta seção, encontra-se um parênteses do texto principal com o intuito de explicar a trajetória do seu desenvolvimento.

Em suma, a adaptação consiste em incluir ao longo da trajetória percorrida pelo vapor atômico (entre o alvo e o substrato) uma região com alta pressão relativa de $\mathrm{Ar}$ [17 18, 19]. A condensação dos aglomerados ocorre termodinamicamente através do resfriamento do vapor atômico devido a colisões com as moléculas do gás [39].

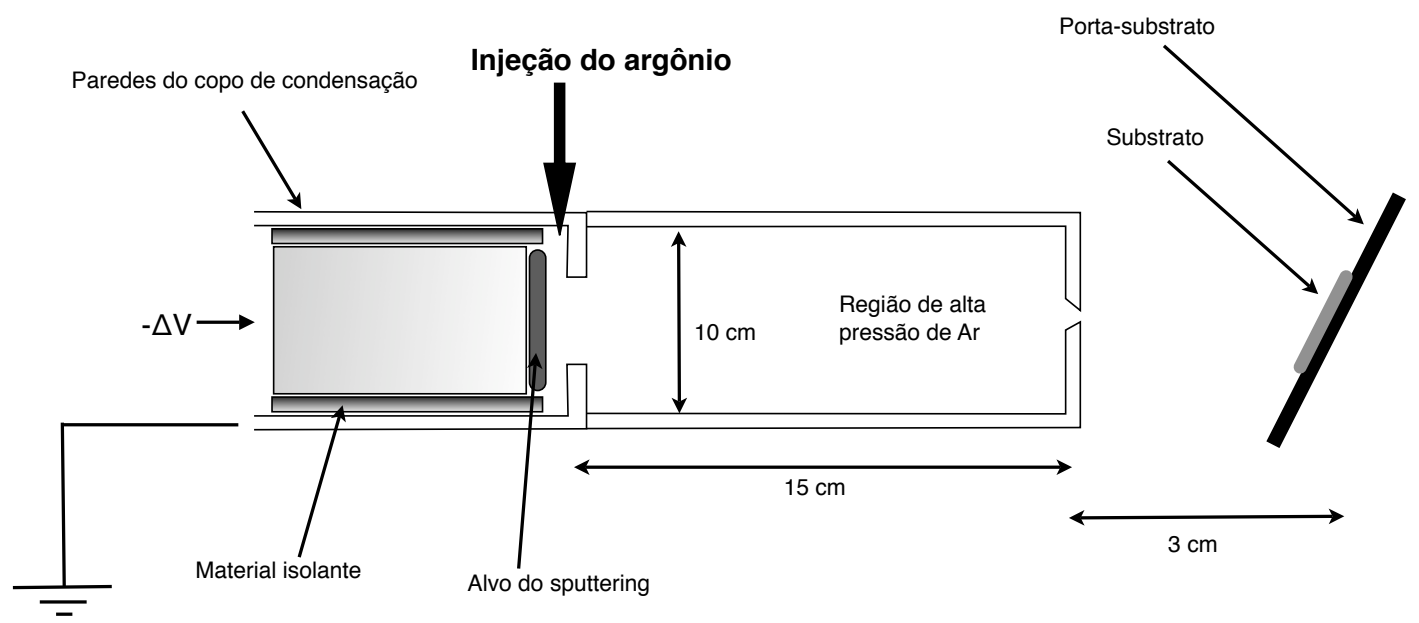

Fig 2.4: esquema da adaptação do sistema de "magnetron sputtering" para o gerador de nanopartículas.

Para isso, usamos um copo cilíndrico de $10 \mathrm{~cm}$ de diâmetro e $15 \mathrm{~cm}$ de comprimento colocado sobre o canhão onde se encontra o alvo de interesse. Por ser selado, exceto por uma abertura de $2 \mathrm{~mm}$ de diâmetro localizada na sua extremidade, a pressão dentro dele pode ser controlada e é significativamente mais alta que a pressão na câmara principal. Isso é feito usando um fluxo de Ar injetado na parte inferior desse copo, 
próximo do alvo, como mostra a figura 2.4. A entrada de Ar no canhão foi melhorada visando eliminar possíveis vazamentos que seriam altamente perniciosos à produção das nanopartículas (vide figura 2.2).

O elemento utilizado como alvo foi, na maioria dos casos, o cobalto. A montagem do sistema leva em torno de 4 horas e normalmente deixamos uma noite bombeando para atingir um bom vácuo.

\subsubsection{Parâmetros experimentais}

Tipicamente, usamos entre 20 e 100 sccm de fluxo de Ar e deixamos a válvula que liga o sistema às bombas de vácuo completamente aberta. Com isso, ajustando apenas o fluxo, variamos tanto a pressão na câmara principal quanto a pressão no copo. Neste último foi adaptado um medidor de vácuo próprio para poder medir sua pressão de forma independente. Os valores típicos resultantes são da ordem de 2 a 5 mTorr na câmara principal e 0,2 a 1,3 Torr no copo. O fluxo, a pressão na câmara e a pressão no copo são grandezas fundamentais do sistema e serão mencionadas extensivamente ao longo deste texto pois correspondem a parâmetros de controle das taxas de deposição. O gráfico da figura 2.5 mostra como variam a pressão na câmara e no copo em função do fluxo quando a válvula de controle do sistema de vácuo está completamente aberta.

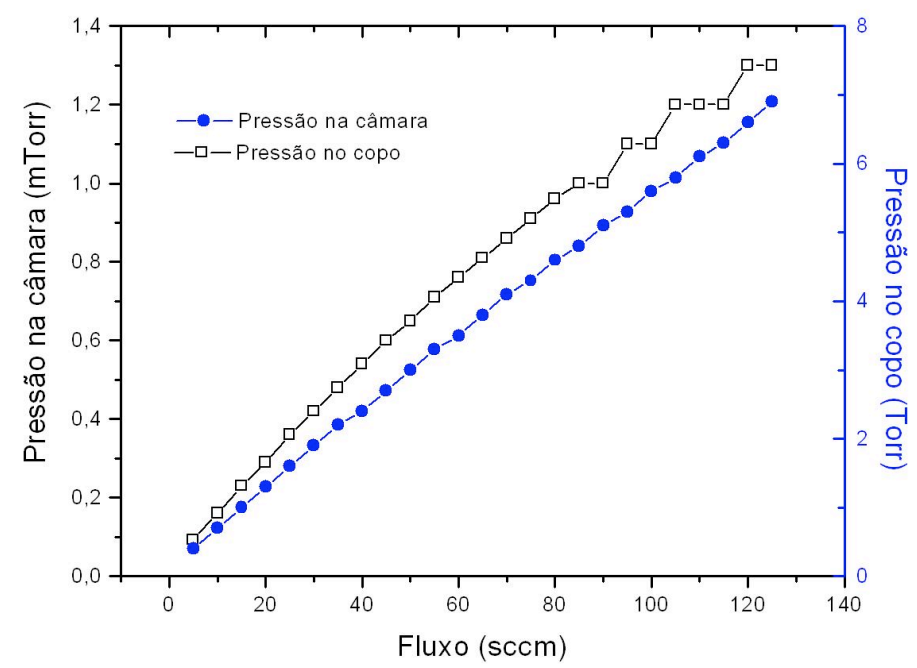

Fig. 2.5: variação das pressões no copo de condensação e na câmara principal em função do fluxo de gás para a válvula do sistema de vácuo completamente aberta. 
Os alvos utilizados são os mesmos do sistema de "magnetron sputtering", assim como as fontes de potência: DC para metais e RF para isolantes. Em particular, para os metais, as potências tipicamente utilizadas são da ordem de 10 a $100 \mathrm{~W}$ o que resulta em correntes que variam entre 50 e $400 \mathrm{~mA}$.

Após diversos testes e análises (que serão detalhadamente descritos nos capítulos seguintes) estabelecemos uma condição estável de trabalho a partir da qual, a grande maioria das amostras foram preparadas. Tal configuração está denotada na tabela 2.1 e foi escolhida após diversos testes e a partir dos seguintes princípios:

I. Uma potência não muito alta: pois como a pressão dentro do copo já é extremamente elevada, uma potência alta intensifica a degradação das peças do sistema. Por outro lado, potências muito baixas resultam em uma inibição das deposições.

II. Fluxo alto (sem passar de $100 \mathrm{sccm}$ ): pois fluxos baixos demais não são suficientes para remover o material do copo e fluxos altos demais também inibem a deposição, possivelmente devido a formação de regiões de altíssima turbulência.

\begin{tabular}{|c|c|c}
\hline Fluxo: $85 \mathrm{sccm}$ & Pressão no copo: 1 Torr & Pressão na câmara: 4.5 mTorr \\
\hline Potência: $30 \mathrm{~W}$ & Corrente: $\sim 105 \mathrm{~mA}$ & Voltagem: $\sim 290 \mathrm{~V}$
\end{tabular}

Tabela 2.1: condições padrões de operação para a otimização do sistema.

\subsubsection{Produção das amostras e controle da quantidade de material}

Devido a colimação de material, a deposição das nanopartículas é feita colimadamente e não de forma homogênea (como em um sistema de "sputtering" comum). Isto resulta em uma mancha de material no substrato, aproximadamente circular, de alguns milímetros de raio e com uma concentração maior de material no seu centro. Como será visto na seção 3.3, a quantidade de material decai seguindo uma distribuição Gaussiana a partir do centro. 
A largura desta mancha pode ser controlada modificando a distância entre a abertura do copo e o porta-substrato como ilustra a figura 2.6. A figura 2.7 ilustra manchas feitas por nanopartículas de Co sobre uma folha de papel sulfite* a diferentes distâncias (para que as manchas pudessem caber todas em uma mesma folha, foi necessário rodar levemente o porta-substrato a cada deposição). Como ilustrado na figura 2.6, pode-se notar na figura 2.7 que o diâmetro médio das manchas de fato aumenta com a distância copo-substrato.

Desta imagem nota-se também que a mancha não tem aparência metálica como se espera de um filme de cobalto mas é bastante escura. Isso pode ser atribuído ao caráter nanoparticulado do material que causa o espalhamento da luz.

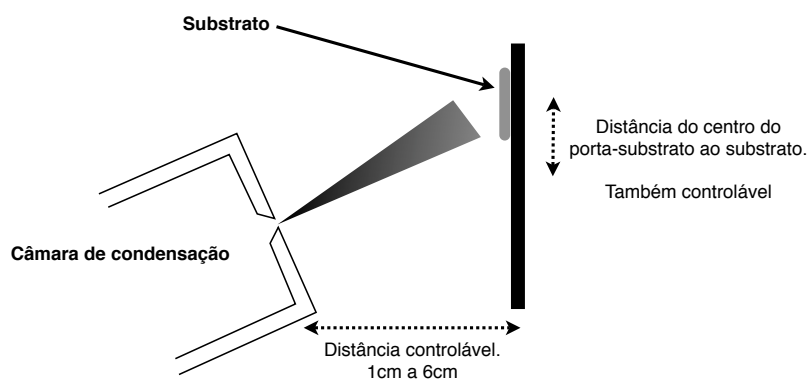

Fig. 2.6: esquema da abertura do feixe de nanopartículas em função da distância.

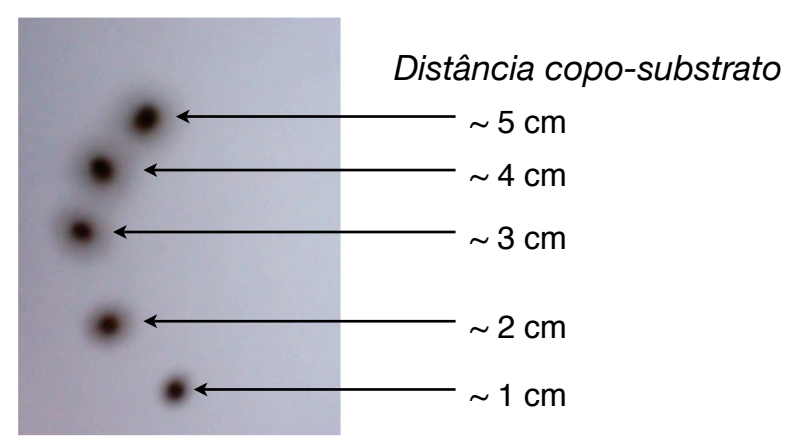

Fig. 2.7: manchas de NPs de cobalto depositadas sobre uma folha de papel. O espalhamento de material ao sair do copo de condensação pode ser evidenciado através do aumento do diâmetro da mancha conforme a distância copo-substrato aumenta.

\footnotetext{
* Papel sulfite comercial contêm substâncias fluorescentes para deixa-lo mais "branco". Assim, o contraste das nanopartículas sobre ele é mais evidente. Ao longo de todo o trabalho, utilizamos pequenos pedaços de papel sulfite para calibrar o sistema e medir se a deposição estava ocorrendo de forma adequada.
} 
Os valores das taxas de deposição deste sistema são expressivamente mais altos do que o de uma deposição comum de "sputtering" (da ordem de 50 vezes maior). Isto é evidente na imagem 2.7 uma vez que tais manchas correspondem a apenas alguns segundos de deposição.

Por outro lado, em diversas situações (como análises de microscopia ou codeposição com outros materiais), taxas menores são necessárias. Para resolver este problema usamos o fato de que, conectado ao porta-substrato, há um motor que permite que ele gire em torno do seu próprio eixo. Isso faz com que a mancha de material se distribua em torno de um círculo como ilustram as figuras 2.8 (a) e (b). Assim, prendendo o substrato desejado ao longo da circunferência e controlando a velocidade de giro do motor, podemos reduzir a taxa de deposição como desejarmos.

Como é possível notar na figura 2.8 (b), há uma região grande do substrato onde não são depositadas nanopartículas. Mas, qualquer tipo de codeposição atinge esta região com a mesma quantidade de material que a região onde estão as NPs. Ou seja, isso significa que é possível fazer amostras de controle que contenham exatamente o mesmo substrato, a mesma matriz e a mesma cobertura de proteção, mas que não contenham as nanopartículas.

Da figura 2.8 (a) é possível notar também que o diâmetro do anel diminui com a distância. Por outro lado, nota-se que a espessura do anel aumenta; como esperado (vide figuras 2.6 e 2.7). Finalmente, é importante mencionar que a variação do diâmetro com a distância não é linear. Isso fica claro ao observar que os anéis (ainda da figura 2.8 (a)) relativos a 4 e $5 \mathrm{~cm}$ se superpõem (da imagem eles talvez pareçam apenas um anel, mas olhando diretamente na folha de papel nota-se que são de fato dois).

A distância mínima entre o porta-substrato e a abertura do copo é de a aproximadamente $1 \mathrm{~cm}$. Em praticamente todas as amostras preparadas neste trabalho, fixamos como distância total aproximadamente $3 \mathrm{~cm}$. 


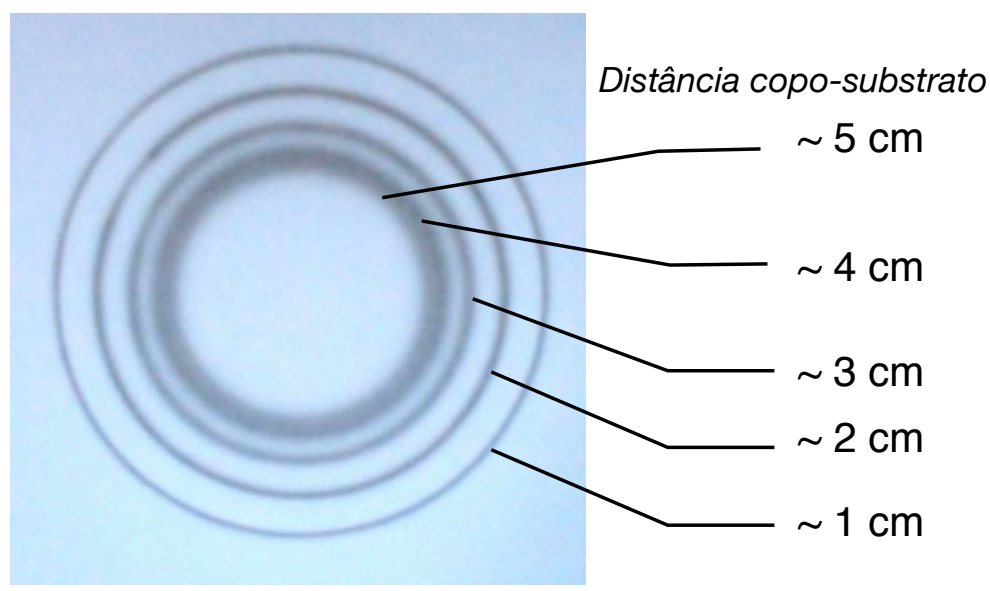

(a)

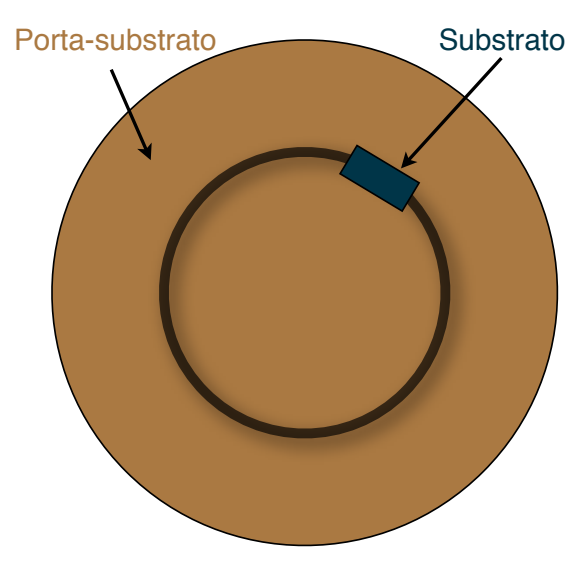

(b)

Fig. 2.8: metodologia adotada para diminuir a taxa de deposição. A deposição pontual mostrada na figura 2.6 pode ser transformada em uma circunferência ao fazer o porta-substrato rotacionar sobre o seu próprio eixo. (a) imagem real de nanopartículas de cobalto codepositadas sobre uma folha de papel e (b) diagrama de como posicionar o substrato.

Os substratos são colados no porta-substrato através de pequenos pedaços de fita kapton. No entanto, caso necessite-se fazer deposições com o porta-substrato aquecido $\left(300{ }^{\circ} \mathrm{C}\right)$, utilizamos pinças metálicas.

A priori, poderia-se esperar que seriamos capazes de obter estimativas sobre a taxa de deposição utilizando o cristal de quartzo. Mas, infelizmente isso não é possível. Há duas razões para isso. Em primeiro lugar, a eletrônica deste sistema subentende que a deposição é feita homogeneamente sobre todo o cristal (como em um sistema de "sputtering"), o que não é verdade no caso do gerador de nanopartículas. Isto faz com que os valores mostrados pelo cristal precisem ser interpretados. Em segundo lugar, a energia cinética das nanopartículas ao atingir o cristal é consideravelmente baixa pois corresponde a energia do escoamento do fluxo de gás. Assim, nota-se claramente que o material não se fixa no cristal desprendendo-se dele uma vez que ele está vibrando em alta frequência. Isso é traduzido no medidor como taxas de deposição negativas.

A solução para estimar a quantidade de material depositado no substrato é o retro-espalhamento Rutherford (RBS) que pode fornecer informações sobre o número de átomos depositados em diferentes regiões do substrato. É possível converter estes nú- 
meros em espessuras de amostra levando em consideração a densidade de massa do cobalto. Uma descrição aprofundada da técnica de RBS está feita na seção 2.5.2.

A boa colimação de material que somos capazes de obter veio com um preço. As partes laterais e inferiores do canhão correspondem a regiões de alta pressão com distâncias muito curtas entre as peças. Isto as torna susceptíveis à abertura de arcos fazendo com que o plasma do "sputtering" se estabeleça na região errada. Isso não só corrói as peças como inibe a remoção de material do alvo fazendo com que nada seja depositado no substrato.

Visando minimizar este problema, uma folha de kapton foi incorporada dentro do canhão de "sputtering" para melhorar a isolação elétrica entre o bloco contendo o alvo e a armadura externa do canhão.

Não encontramos até hoje, uma forma efetiva de resolver tal dificuldade. Por tal razão, foi necessário encontrar meios de contorná-la. Ou seja, meios de monitorar se havia ou não material sendo depositado no substrato. Após algumas semanas notamos que a corrente gerada pela fonte DC oscilava entre dois valores distintos e notamos também que estes valores estavam relacionados com a deposição, ou não, de material no substrato. Ou seja, relacionados com o fato do plasma abrir no lugar certo ou no lugar errado. A partir deste fato, monitorando a corrente é então possível saber se o sistema está operando corretamente ou não. Tal medida é fundamental para que as amostras sejam produzidas adequadamente, sendo sempre cuidadosamente adotada.

Uma outra forma de amenizar este problema é ligar o sistema lentamente. Ou seja, ligar a fonte DC em baixa potência (2 ou $3 \mathrm{~W}$ ) e com baixo fluxo (3 ou $4 \mathrm{sccm}$ ) e, em seguida, aumentar estes valores gradativamente até atingir os valores de trabalho.

\subsubsection{Trajetória do desenvolvimento do sistema}

Gostaria, nesta etapa, de fazer um parênteses do texto principal para discutir algo que, do ponto de vista da instrumentação, julgo ser de extrema importância: a trajetória do desenvolvimento do sistema. 
$\mathrm{Na}$ ausência do copo, o vapor atômico é removido do material e direcionado de forma aleatória em todas as direções. Assim, olhando para o sistema na forma mostrada na figura 2.4 é natural esperar que sairia dele apenas uma quantidade muito pequena de material; que corresponde ao vapor atômico removido exatamente na direção do furo.

É exatamente este o ponto que nos deu mais trabalho no desenvolvimento do sistema pois sempre víamos quantidades significativamente baixas de material sendo depositadas nos substratos. Mas, uma vez resolvido, o resultado foi bastante surpreendente pois conseguimos desenvolver uma metodologia para colimar o material aumentando significativamente a quantidade de NPs depositadas no substrato.

A solução para este problema veio após mais de 1 ano de trabalho e, não só ela transformou completamente o sistema, como abriu as portas para diversos estudos interessantes. Atualmente, a densidade de material depositado no substrato pode ser mais de 50 vezes maior do que a vista sem o copo de condensação (ou seja, em um sistema de "sputtering" comum).

Inicialmente usávamos um copo menor, tanto em diâmetro quanto em comprimento. Suas dimensões eram $5 \mathrm{~cm} \times 5 \mathrm{~cm}$. Além disso, a tubulação de gás entrava no copo pela região comumente usada no sistema de "sputtering". Após meses de trabalho, tornou-se claro que haviam dois problemas intrínsecos na otimização do sistema:

1. O copo tem de ter um comprimento suficientemente longo ou uma pressão suficientemente alta para que o vapor atômico condense em aglomerados. Em geral, é uma combinação destes dois fatores que tem que ser considerada;

2. O fluxo de gás tem que ser alto o suficiente para que o material, nanoparticulado ou não, consiga ser removido do copo, não se fixando nas suas paredes internas. 
Durante o inicio do desenvolvimento, não estávamos conseguindo nenhuma imagem (de microscopia) confiável das nanopartículas. Acreditamos isso ao fato do copo ser muito curto o que faria com que as nanopartículas formadas fossem muito pequenas e não pudessem ser visualizadas dentro da resolução dos aparelhos. Consequentemente, construímos um copo mais comprido, com $15 \mathrm{~cm}$, três vezes o comprimento do copo anterior. Os resultados ainda eram insatisfatórios.

Finalmente, passamos a acreditar que o problema era que as paredes do copo eram regiões de velocidade nula. Ou seja, que todo o material que nelas chegassem, nelas ficariam. Acreditávamos que era de suma importância modificar o sistema de uma forma tal que pelo menos uma certa quantidade de material não chegasse a parede. Ou seja, tal que esta fração fosse eficientemente desviada de sua trajetória original (uma discussão sobre se este argumento é correto ou não está feita na seção 2.4.3).

Inicialmente, para resolver este problema, pensamos em construir um copo mais largo, de $10 \mathrm{~cm}$ de diâmetro (mantendo os $15 \mathrm{~cm}$ de comprimento). Enquanto este estava sendo usinado, durante testes ainda com o copo fino e utilizando o cristal de quartzo para estimar a taxa de deposição, a solução foi encontrada.

Os fluxos típicos de gás que utilizávamos eram da ordem de 5 a $20 \mathrm{sccm}$ (sendo 20 sccm um valor já razoavelmente alto para o "sputtering"). Já sem idéias sobre o que fazer, passamos a aumentar o fluxo constantemente e monitorar a taxa de deposição (que costumava ser extremamente baixa). O que vi, para minha surpresa, foi que havia um limiar de fluxo em torno de $60 \mathrm{sccm}$ para o qual a taxa de deposição aumentava exponencialmente. Ou seja, um valor tal que o fluxo de gás era suficiente para impedir que o material chegasse às paredes, sendo então removido do copo e direcionado para o porta-substrato.

Pouco tempo depois, quando começamos a usar um copo mais largo, observamos que ainda havia um limiar de fluxo para ocorrer a deposição mas este era menor que o anterior. 


\subsubsection{Fichas de amostras}

Ao longo do capítulo 3, informações sobre amostras relevantes a discussão em questão serão resumidas na forma de fichas de deposição. Abaixo encontra-se um exemplo dessas fichas com dados usuais. A forma como as informações estão dispostas em cada uma delas varia dependendo da amostra, de forma a melhor expor os dados que forem relevantes.

FICHA \#

\begin{tabular}{|c|c|c|c|}
\hline $\begin{array}{l}\text { INFORMAÇÕES } \\
\text { GERAIS }\end{array}$ & $\begin{array}{l}\text { GRANDEZAS DO } \\
\text { SISTEMA }\end{array}$ & $\begin{array}{l}\text { CONDIÇÕES DO } \\
\text { ALVO }\end{array}$ & $\begin{array}{l}\text { CONDIÇÕES DA } \\
\text { DEPOSIÇÃO }\end{array}$ \\
\hline $\begin{array}{l}\text { Material: Cobalto } \\
\text { Objetivos: ... }\end{array}$ & $\begin{array}{l}\text { Fluxo: } 85 \text { sccm } \\
\text { Pressão no copo: } 1 \\
\text { Torr } \\
\text { Pressão na câmara: } \\
4.5 \text { mTorr }\end{array}$ & $\begin{array}{l}\text { Potência: } 30 \mathrm{~W} \\
\text { Corrente: } ~ 105 \mathrm{~mA} \\
\text { Voltagem: } \sim 290 \mathrm{~V}\end{array}$ & $\begin{array}{l}\text { Tempo: } 10 \text { min } \\
\text { Substrato: Silício } \\
\text { Porta-substrato: } \\
\text { rodando } \\
\text { Distância PS - } \\
\text { Copo: } 3 \mathrm{~cm}\end{array}$ \\
\hline
\end{tabular}

\subsection{O processo de condensação}

Uma descrição aprofundada de como ocorre o processo de condensação do vapor atômico é significativamente complexa podendo compor um estudo a parte. Usualmente, usa-se da mecânica quântica para descrever as probabilidades de haver a formação de ligações químicas entre átomos e aglomerados [누] .

Esta seção, no entanto, tem o intuito de discutir algumas propriedades e grandezas do sistema afim de melhor situar o problema. Para fins ilustrativos, a figura 2.9 descreve de forma simplificada como ocorre o processo de condensação das nanopartículas.

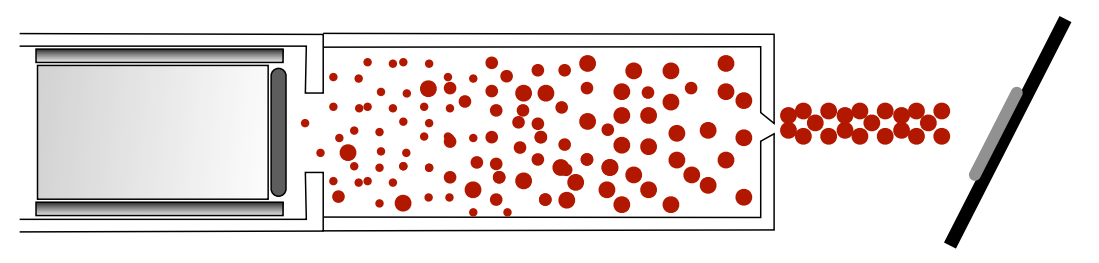

Fig. 2.9: ilustração de como ocorre o processo de condensação das NPs dentro do copo de condensação. 
O livre caminho médio $(\mathbf{l c m})$ em um sistema composto de um gás monoatômico pode ser estimado através da relação

$$
\lambda=\frac{k_{B} T}{\sqrt{2} \pi P d^{2}},
$$

onde T é a temperatura do sistema, $\mathrm{P}$ a pressão, d o diâmetro atômico médio do gás e $\mathrm{k}_{\mathrm{B}}$ a constante de Boltzmann que vale $\mathrm{k}_{\mathrm{B}} \approx 1,4 \times 10^{-23} \mathrm{JK}^{-1}$.

Considerando as condições padrões de operação descritas na tabela 2.1, temos que 85 sccm de fluxo de gás gera 1 Torr de pressão dentro do copo. Suponhamos que o fluxo seja estanque e lamelar de tal forma que o gás esteja aproximadamente em equilíbrio e parado. À temperatura ambiente, utilizando o diâmetro covalente do argônio que vale $2,5 \AA$, estes dados podem ser traduzidos através da relação acima como um livre caminho médio de:

$$
\lambda \approx 10 \mu \mathrm{m}
$$

Ou seja, extremamente curto.

Pensando em um átomo de cobalto isolado, a perda em energia cinética sofrida em uma colisão com um átomo de Ar é muito alta uma vez que a massa atômica do Ar corresponde a mais de $2 / 3$ da massa atômica do Co. Supondo que a energia com que um átomo de Co é removido do alvo é $10 \mathrm{eV}$ [41] então classicamente, isso pode ser traduzido em uma velocidade de aproximadamente $5800 \mathrm{~m} / \mathrm{s}$. A velocidade térmica do Ar, por outro lado, é da ordem de $300 \mathrm{~m} / \mathrm{s}$ (a temperatura ambiente). Apesar dessa diferença parecer marcante, é possível mostrar classicamente que como a energia perdida pelo cobalto a cada colisão é muito alta, após apenas 7 colisões a sua velocidade já seria comparável a velocidade térmica do Ar.

Isto, somado com o lcm curto, nos induz a pensar que o vapor de cobalto deve termalizar muito rapidamente seguindo então seu trajeto ao longo do copo na velocidade de escoamento do argônio. Mas, é muito importante notar que isso só é válido quando o número de átomos de Ar é muito maior que o número de átomos de Co pois, caso contrário, o gás seria incapaz de escoar a energia do vapor atômico. 
Com isso, duas grandezas tem de ser ponderadas: o fluxo, responsável por determinar a quantidade de átomos de Ar adentrando ao copo por segundo e a potência, relacionada com a quantidade de átomos de Co sendo removidos do alvo por segundo.

Em um sistema de "sputtering" usual, o fluxo de gás também influencia de forma intensa na quantidade de átomos removidos do alvo pois influencia na quantidade de íons de Ar. No nosso sistema, no entanto, isso não acontece. A razão para isso é pois como a pressão já é extremamente elevada (mesmo para valores baixos de fluxo), ocorre uma saturação da quantidade de íons de Ar. Assim, para este sistema em particular, é uma boa aproximação afirmar que o fluxo de gás determina apenas a quantidade de Ar no copo e a potência apenas a quantidade de Co.

É então de interesse comparar estes valores. Em termos de fluxos de Ar, os números fornecidos pelo aparelho em sccm podem ser convertidos para átomos/segundo levando em consideração a densidade atômica de Ar na câmara (conhecida pois a pressão é conhecida). Átomos por segundo é uma unidade interessante por ser absoluta. $\mathrm{O}$ gráfico da Fig. 2.10 denota a dependência linear entre as duas grandezas.

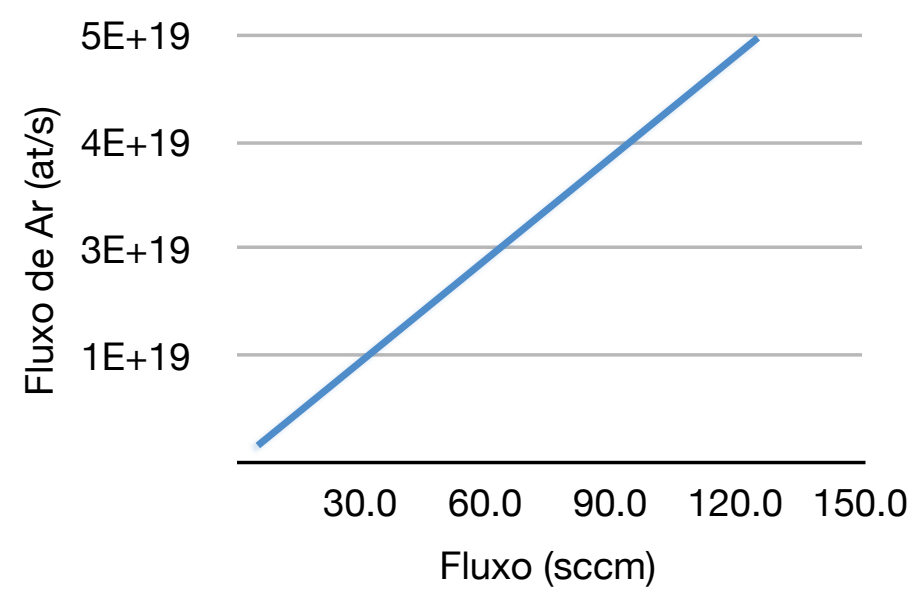

Fig. 2.10: dependência do número de átomos de Ar entrando no copo por segundo com o fluxo de gás medido com o controlador de fluxo.

A potência aplicada ao alvo influencia de forma linear na corrente iônica. Sabendo o "sputtering yield" (número de átomos removidos do alvo para cada íon incidente aproximadamente 1 at/íon para o Co) e assumindo que a razão entre elétrons e íons é 
1:1, é possível traduzir esta corrente iônica em fluxo de Co sendo removido do alvo. A figura 2.11 ilustra a dependência deste fluxo com a potência.

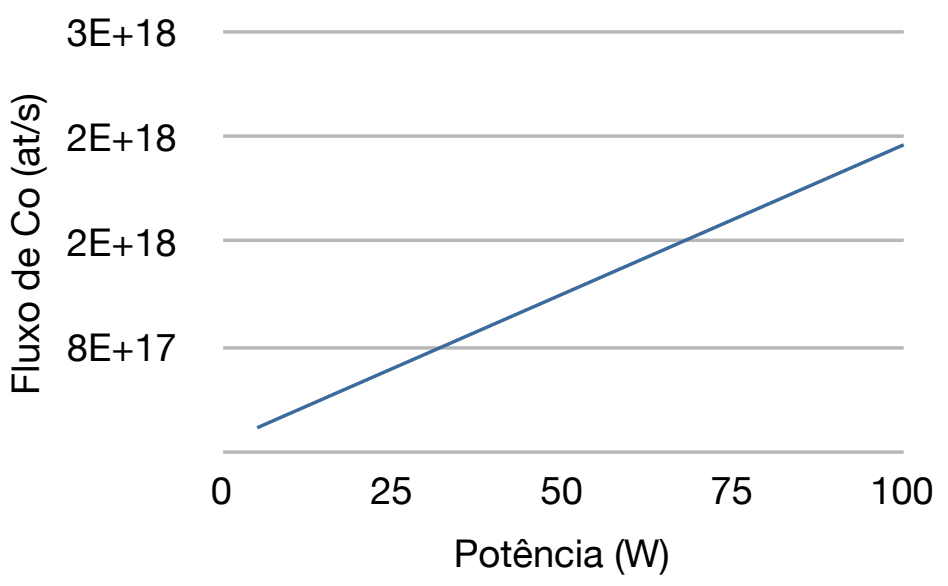

Fig. 2.11: relação entre o fluxo de átomos de Co sendo removido do alvo com a potência DC aplicada.

A tabela 2.2 ilustra as quantidades relativas de Co para 4 situações distintas que serão posteriormente estudadas (seção 3.2). Nesta, é possível notar que para um fluxo de 85 sccm, onde sabemos que a colimação de material é bastante eficiente, a quantidade relativa de Co não varia significativamente, mesmo para potências altas. Por outro lado, quando o fluxo é mais baixo, a diferença na concentração é mais evidente.

\begin{tabular}{|c|c|c|}
\cline { 2 - 3 } \multicolumn{1}{c|}{} & $30 \mathrm{~W}$ & $75 \mathrm{~W}$ \\
\hline $30 \mathrm{sccm}$ & $6 \%$ & $12 \%$ \\
\hline $85 \mathrm{sccm}$ & $2 \%$ & $4 \%$ \\
\hline
\end{tabular}

Tabela 2.2: quantidades relativas de Co para diferentes condições de operação.

Como todos os processos ocorrem em uma mesma região, é razoável afirmar que o processo de condensação ocorre simultaneamente com o processo de colimação. Assim, é interessante que ambos sejam estudados em paralelo. Este estudo pode ser separado em duas regiões distintas: uma região onde a quantidade de Ar é predominante (85 sccm se aproxima disso) e os processos ocorrem de formas semelhantes, independentemente da potência aplicada e uma outra situação, que corresponde a quando o Ar deixa de ser o gás predominante e a influência de cada variável tem de ser ponderada e avaliada. 
Como a potência determina a quantidade de átomos de Co sendo injetados na câmara, ela deve influenciar diretamente no tamanho das partículas. Além disso, o diâmetro médio dos objetos é proporcional ao seu número de átomos elevado a 1/3 (o número de átomos de uma nanopartícula é proporcional ao volume que é proporcional ao diâmetro ao cubo). Assim, podemos concluir que o diâmetro médio das partículas, na condição de alto fluxo, deva ser proporcional a raiz cúbica da potência. Ou seja:

$$
\mathrm{d} \propto \mathrm{P}^{1 / 3}
$$

Esta influência é sutil. Um aumento por um fator 2.5 na potência (de 30 W para 75 W, como na Tab. 2.2) corresponde a apenas 1,4 no diâmetro.

No outro regime, quando o fluxo de Ar não é dominante, é provável que a potência também influencie no tamanho. Mas, não necessariamente haverá gás suficiente para remover os objetos maiores. Assim, é possível que apenas os objetos menores sejam removidos do copo e os maiores fiquem dentro dele.

Esta influência do tamanho na eficiência da colimação também tem um papel importante no inicio do processo de condensação, próximo do alvo. Como havíamos mencionado, o Ar deve termalizar rapidamente um átomo de Co. Mas a eficiência dessa termalização diminui abruptamente caso um átomo se aglomere com um vizinho, formando uma nanopartícula de 2 átomos. Para aglomerações posteriores, esta perda de eficiência se intensifica exponencialmente.

Assim, deve haver uma competição entre velocidade de aglomeração e velocidade de termalização de tal forma que só haverá uma colimação eficiente se a termalização ocorrer mais rapidamente que a aglomeração. Estas hipóteses foram investigadas na seção 3.2.

\subsection{Técnicas de análise}

Nesta seção encontram-se relacionadas todas as técnicas de análise envolvidas no trabalho juntamente com os substratos utilizados em cada uma. Em suma, as técnicas utilizadas foram: 

I. Microscopia eletrônica de transmissão (TEM) e varredura (SEM)
II. Retro-espalhamento Rutherford (RBS);
III. Difração de raios X;
IV. Magnetômetro de amostra vibrante (VSM);

\subsubsection{Microscopia eletrônica}

Microscopia eletrônica de transmissão (TEM) e microscopia eletrônica de varredura (SEM) foram utilizadas em conjunto para a caracterização morfológica dos objetos.

O TEM utilizado neste trabalho foi um Jeol JEM-2100 situado no Centro de Ciência e Tecnologia dos Materiais (CCTM) do Instituto de Pesquisas Energéticas e Nucleares (IPEN). Todas as medidas foram realizadas por Nildemar Aparecido Messias Ferreira, técnico do laboratório. Os substratos utilizados foram grades de $\mathrm{Cu}$ próprias para TEM e a tensão aceleradora utilizada foi de $200 \mathrm{kV}$.

As análises com um SEM foram feitas em um Nova NanoSEM da Fei Company que se encontra no Laboratório de Sistemas Integráveis (LSI) da Escola Politécnica da Universidade de São Paulo (EPUSP). O operador foi Adir José Moreira, técnico do laboratório. Os substratos utilizados foram Si ou C e as tensões aceleradoras sempre da ordem de $20 \mathrm{kV}$.

Algumas dificuldades foram encontradas com o SEM pois a alta porosidade das amostras somadas com a oxidação das partículas dificultava o escoamento de cargas. Isto tinha dois efeitos: impedia focalizações em magnificações mais altas e aquecia a amostra "soldando" as nanopartículas. Foi por tal razão que os substratos de carbono foram os mais utilizados, uma vez que são condutores. Apesar de ajudarem, eles não eram capazes de resolver completamente o problema, que permaneceu durante todo o trabalho.

\subsubsection{Retro-espalhamento Rutherford}


Com o intuito de obter informações sobre a espessura das amostras produzidas, medidas de retro-espalhamento Rutherford (RBS) foram realizadas. Em suma, esta técnica consiste em incidir sobre a amostra um feixe de prótons ou partículas $\alpha$, coletando as que são retro-espalhadas. A partir da energia do feixe coletado é possível inferir informações sobre a composição e a espessura da amostra.

Ao contrário de filmes finos, cuja espessura é aproximadamente constante ao longo da superfície depositada, a quantidade de material sobre as amostras produzidas com o gerador de nanopartículas varia fortemente ao longo dela. Portanto, utilizamos o RBS para determinar a distribuição de espessuras sobre a amostra.

Esta técnica é muito comumente utilizada na determinação da espessura de filmes finos. No entanto, havia uma dificuldade intrínseca no nosso caso para analisar as amostras que continham as nanopartículas uma vez que elas correspondem ao empilhamento de nanoobjetos (porosas). Isto pôde ser contornado incluindo a rugosidade do material no ajuste dos dados experimentais durante a análise.

Todas as medidas de RBS foram realizadas no Laboratório de Análise de Materiais por Feixes Iônicos (LAMFI) localizado no próprio IFUSP. O equipamento foi operado por Marco Antonio Rodrigues e Marcel Dupret Lopes Barbosa, técnicos do laboratório. Os substratos utilizados foram silício e carbono.

\subsubsection{Difração de raios $X$}

Para obter informações sobre a estrutura cristalina das nanopartículas, medidas de difração de raios $\mathrm{X}$ foram realizadas. $\mathrm{O}$ instrumento utilizado neste trabalho foi um Rigaku X Ray Diffractometer que pertence ao Laboratório de Cristalografia do IFUSP. As medidas foram realizadas por mim com o auxílio da Profa. Dr. Marcia Carvalho de Abreu Fantini e o técnico Antonio Carlos Franco da Silveira. O feixe de raios X utilizado correspondia ao $\mathrm{Cu} \mathrm{k} \alpha(\lambda=1,540 \AA)$ e o substrato foi o vidro pois não apresenta picos de difração, mas apenas uma banda em baixos ângulos. 


\subsubsection{Magnetômetro de amostra vibrante}

Um magnetômetro de amostra vibrante (VSM) tem como princípio de operação a lei da indução de Faraday. A amostra magnética de interesse é colocada em uma região com campo magnético ajustável que faz com ela se magnetize. A peça onde a amostra é fixada é posta para vibrar em uma frequência conhecida fazendo com que o seu campo magnético varie em função do tempo. Tal variação do campo acarreta em uma variação no fluxo magnético que por sua vez gera uma diferença de potencial induzindo correntes em bobinas colocadas próximas da amostra. É possível assim traduzir estas correntes em informações sobre sua magnetização. Com isso, variando o campo magnético é possível medir as curvas de histerese. Além disso, é possível variar o ângulo entre a amostra e o campo magnético afim de verificar a existência de eixos preferenciais de magnetização.

O VSM utilizado neste trabalho pertence ao Laboratório de Materiais Magnéticos (LMM) do IFUSP. O campo magnético é produzido por um eletroimã e atinge valores máximos de $2 \mathrm{~T}$ o que, para nossas amostras, foi suficiente para atingir a saturação. $\mathrm{O}$ tipo de substrato utilizado não era muito importante pois o seu comportamento diamagnético ou paramagnético pode ser subtraído dos dados através de uma amostra de controle.

\subsubsection{Preparação e limpeza dos substratos}

Substratos de vidro, silício, óxido de silício e carbono são limpados com um processo de "limpeza piranha" próprio para este tipo de material. Este consiste em primeiramente limpá-los com água deionizada e em seguida inseri-los em uma solução de 2 partes $\mathrm{H}_{2} \mathrm{O}, 1$ parte $\mathrm{NH}_{4}$ e 1 parte $\mathrm{H}_{2} \mathrm{O}_{2}$ aquecida a $80^{\circ} \mathrm{C}$ por 20 minutos. Após esta etapa, lava-se novamente os substratos com água deionizada e seca-os com um jato de $\mathrm{N}_{2}$ super seco.

Grades de Cu são utilizadas em TEM para possibilitar que o feixe de elétrons seja transmitido através da amostra. Estas são preparadas em duas etapas. Primeiramente, 
um filme fino polimérico* é colocado sobre a grade para garantir sustentação mecânica a amostra. Em seguida, um filme de carbono é depositado sobre ela por evaporação térmica com o intuito de garantir condutividade elétrica evitando o acúmulo de cargas superficiais.

* Collodion ( Parlodion ) $2 \%$ em Amylacetato. 


\section{Resultados experimentais e análise dos dados}

Neste capítulo encontram-se os resultados experimentais relativo às NPs de cobalto produzidas pelo gerador de nanopartículas. Estes resultados estão intimamente vinculados com o desenvolvimento do sistema como um todo.

Determinamos, a partir destas análises, o tamanho dos objetos, as taxas de deposição e as suas propriedades estruturais e magnéticas. Além disso, informações sobre a variação destes parâmetros com relação as variáveis do sistema também foram investigadas.

\subsection{Introdução}

Durante os estágios iniciais do desenvolvimento do sistema houve uma certa ignorância natural com relação ao estado geral das amostras que produzíamos. Com o tempo, esta foi em grande parte esclarecida. Como será mostrado neste capítulo, para o cobalto, o gerador de nanopartículas é capaz de produzir amostras colimadas, com NPs de aproximadamente $10 \mathrm{~nm}, 13 \%$ de dispersão, nanocristalinas e ferromagnéticas.

Seria possível - e inclusive plausível - que além da formação das NPs houvesse também a formação de um filme fino proveniente de uma parcela do vapor atômico não condensado. O que observamos, no entanto, é que isso não ocorre e que todo, ou praticamente todo o material é nanoparticulado.

Iniciamos a exposição dos resultados com um estudo da morfologia dos objetos. Para isso, as principais técnicas utilizadas foram TEM e SEM. Além disso, uma investi- 
gação sobre o efeito das variáveis do sistema (fluxo e potência) no tamanho das nanopartículas foi realizada. Todos estes resultados estão descritos na seção 3.2.

Em seguida, procedemos com uma análise da quantidade de material depositado no substrato (seção 3.3). Para isso, utilizamos basicamente RBS e SEM e analisamos os casos do porta-substrato parado (maior concentração) e girando (menor concentração).

Através de medidas de XRD, obtivemos informações sobre a estrutura cristalina das nanopartículas e, através de medidas com um VSM, informações de suas propriedades magnéticas. Ambas estas análises estão sucintamente discutidas nas seções 3.4 e 3.5 respectivamente.

Por fim, após algumas considerações sobre o regime de colimação (seção 3.6), encontram-se expostos também alguns resultados preliminares com NPs de Cu e SmCo (seção 3.7).

\subsection{Morfologia dos objetos}

Esta seção é destinada ao estudo da distribuição de tamanhos das nanopartículas e como estes variam com as variáveis de controle do sistema. As principais técnicas utilizadas foram microscopia eletrônica de transmissão (TEM) e varredura (SEM). Houveram também, tentativas não conclusivas com microscopia de força atômica e espalhamento de raios $\mathrm{X}$ a baixos ângulos mas estes resultados não serão mostrados.

Como será visto, um ajuste de como a morfologia dos objetos varia em função das variáveis do sistema não pôde ser alcançado. Mas, mesmo assim, diversas conclusões puderam ser obtidas.

A forma como os dados estão expostos nesta seção tem por intuito ilustrar o processo de convergência dos parâmetros experimentais até as condições padrões de operação (vide seção 2.3.2, tabela 2.1). 


\subsubsection{Influência do fluxo de gás sobre o tamanho dos aglomerados}

\section{ANÁLISE POR MICROSCOPIA ELETRÔNICA DE VARREDURA (SEM)}

Primeiramente, um estudo de como a morfologia das nanopartículas varia em função do fluxo de gás injetado no copo de condensação foi realizado utilizando um microscópio eletrônico de varredura (SEM).

Fixando a potência da fonte DC em 75 W, 4 amostras foram produzidas, cada uma com um valor diferente de fluxo: 85, 75, 60 e 20 sccm. O substrato utilizado foi vidro e o tempo de deposição razoavelmente curto, apenas 30 segundos, uma vez que com a potência a $75 \mathrm{~W}$ e o substrato parado, a taxa de deposição era expressivamente alta. Na ficha 1 encontram-se todas as informações sobre estas amostras.

\section{FICHA 1}

\begin{tabular}{|lll|}
\hline INFORMAÇÕES GERAIS & CONDIÇÕES DO ALVO & CONDIÇÕES DA DEPOSIÇÃo \\
Material: Cobalto & Potência: $75 \mathrm{~W}$ & Tempo: 30 seg \\
& Corrente: $\sim 250 \mathrm{~mA}$ & Substrato: vidro coberto com um \\
Objetivos: estudar a variação & Voltagem: $\sim 289 \mathrm{~V}$ & filme de cobre \\
morfológica das NPs em função & & Porta-substrato: parado \\
do fluxo de gás. & & Distância PS - Copo: $3 \mathrm{~cm}$ \\
& & \\
& & \\
\hline
\end{tabular}

\begin{tabular}{|c|c|c|c|}
\hline \multicolumn{5}{|c}{ AMOSTRAS PRODUZIDAS } \\
\hline Amostra & $\begin{array}{c}\text { Fluxo } \\
(\mathbf{s c c m})\end{array}$ & $\begin{array}{c}\mathbf{P}_{\text {copo }} \\
(\mathbf{m T o r})\end{array}$ & $\begin{array}{c}\mathbf{P}_{\text {cam }} \\
(\mathbf{m T o r})\end{array}$ \\
\hline A & 85 & 1000 & 4.8 \\
\hline B & 75 & 910 & 4.3 \\
\hline C & 60 & 760 & 3.5 \\
\hline D & 20 & 290 & 1.3 \\
\hline
\end{tabular}

A figura 3.1 ilustra as imagens obtidas dos aglomerados. Na obtenção destas foi levado em consideração que a concentração de material varia de forma acentuada nas diferentes regiões do substrato (assunto da próxima seção, 3.3) e portanto, tomamos o cuidado de obter todas as imagens em regiões análogas que correspondiam ao centro da mancha de material (figura 2.7). 


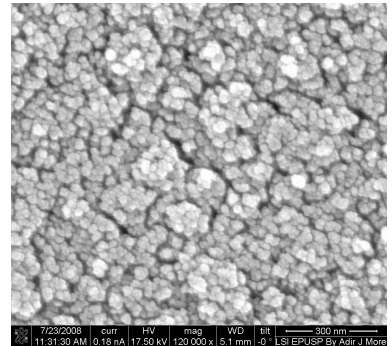

(a)

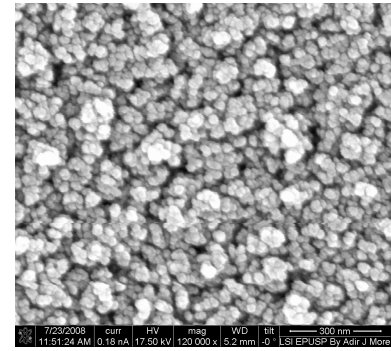

(b)

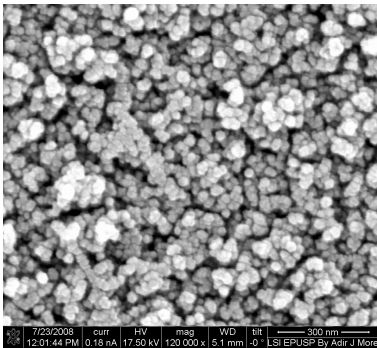

(c)

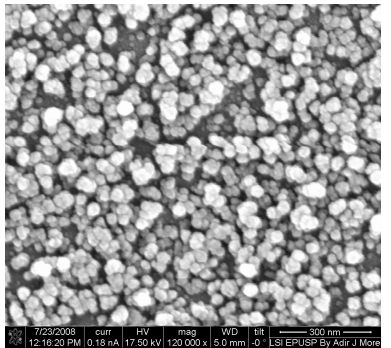

(d)

Fig. 3.1: imagens SEM das amostras 1 produzidas com $75 \mathrm{~W}$ e diferentes fluxos de argônio: (a) 85 sccm, (b) $75 \mathrm{sccm}$, (c) $60 \mathrm{sccm}$ e (d) $20 \mathrm{sccm}$.

Analisando as imagens da figura 3.1, pode-se notar que não há como discernir se há de fato variações no tamanho dos aglomerados. É nítido, no entanto, que há uma diferença na concentração de material e na forma geral de como ele está disposto. Como era esperado, a imagem com menor fluxo tem uma quantidade menor de material. As diferenças no empacotamento também são observáveis.

Obter valores para o tamanho das nanopartículas não é trivial de ser feito utilizando o SEM. A razão para isso, já mencionada no capítulo 2.5.1, é que ao chegar em magnificações muito grandes há uma dificuldade intrínseca do equipamento em focalizar a imagem. Quando desfocalizada, todos os objetos são interpretados como esferas com tamanhos diferentes dos reais. Portanto, para analisar com maior eficiência a morfologia das nanopartículas, um microscópio eletrônico de transmissão (TEM) foi utilizado.

\section{ANÁLISE POR MICROSCOPIA ELETRÔNICA DE TRANSMISSÃo (TEM)}

Fixando condições análogas a anterior, duas amostras foram preparadas sobre grades de cobre recobertas com um filme polimérico e um filme de carbono (ficha 2). A potência utilizada se manteve em $75 \mathrm{~W}$ e os fluxos foram de $30 \mathrm{sccm}$ (A) e $85 \mathrm{sccm}$ (B). O tempo de deposição também foi curto, apenas 30 segundos. 


\section{FICHA 2}

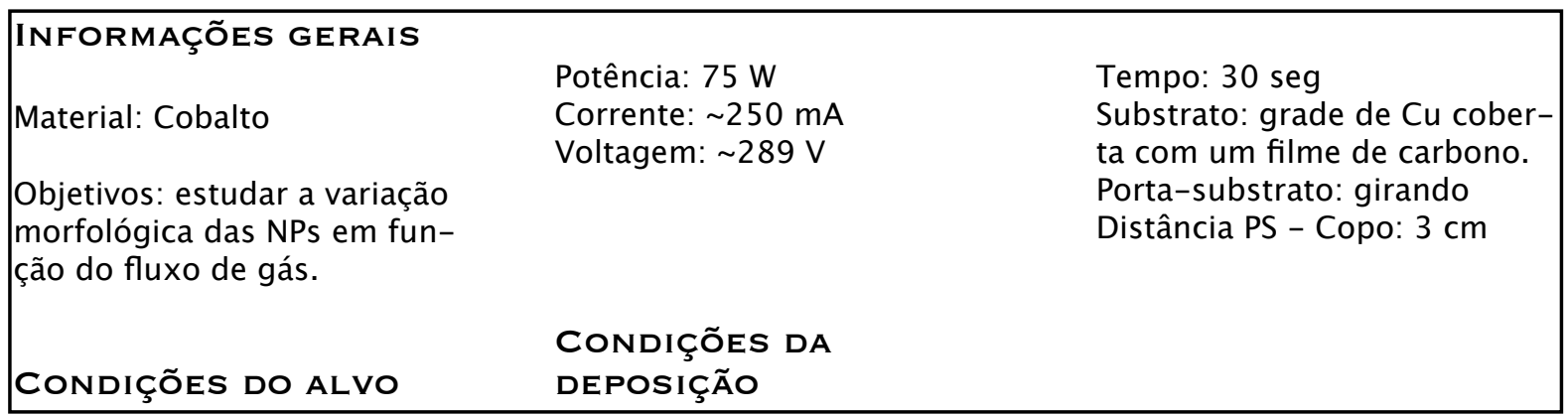

\begin{tabular}{|c|c|c|c|}
\hline \multicolumn{5}{|c}{ AMOSTRAS PRODUZIDAS } \\
\hline Amostra & $\begin{array}{c}\text { Fluxo } \\
\text { (sccm) }\end{array}$ & $\begin{array}{c}\mathbf{P}_{\text {copo }} \\
\text { (mTorr) }\end{array}$ & $\begin{array}{c}\mathbf{P}_{\text {cam }} \\
\text { (mTorr) }\end{array}$ \\
\hline $\mathrm{A}$ & 30 & 400 & 1.6 \\
\hline $\mathrm{B}$ & 85 & 1000 & 4.8 \\
\hline
\end{tabular}

Uma sequência de mais de 8 imagens foi obtida para cada amostra. A figura 3.2 ilustra algumas delas correspondentes a amostra com $30 \mathrm{sccm}$ (2 (A)). Começamos com esta amostra pois, por ter um valor mais baixo de fluxo, resultou em NPs razoavelmente dispersas. Com isso, foi possível realizar uma análise estatística do tamanho dos objetos (figura 3.3). O universo de partículas utilizadas foi da ordem de 100.

Desta análise conclui-se que o tamanho médio das NPs é de $(9,9 \pm 1,7) \mathrm{nm}$. Isto corresponde a um desvio padrão de 17\%, mostrando que a distribuição está próxima de ser monodispersa*.

Algumas imagens correspondentes a amostra com 85 sccm (ficha 2 (B)) estão apresentadas na figura 3.4. Nelas, nota-se claramente as aglomerações entre NPs formando um estrutura rugosa e desordenada (semelhante em partes as imagens de SEM mostradas na figura 3.1). Por tal razão, foi inviável obter uma distribuição de tamanhos a partir destas imagens. Mas, mesmo assim, é possível observar que o tamanho médio das partículas aparenta ser maior. É natural também, esperar uma dispersão mais acentuada.

* Normalmente adota-se como monodisperso desvios de até ıo \%. 

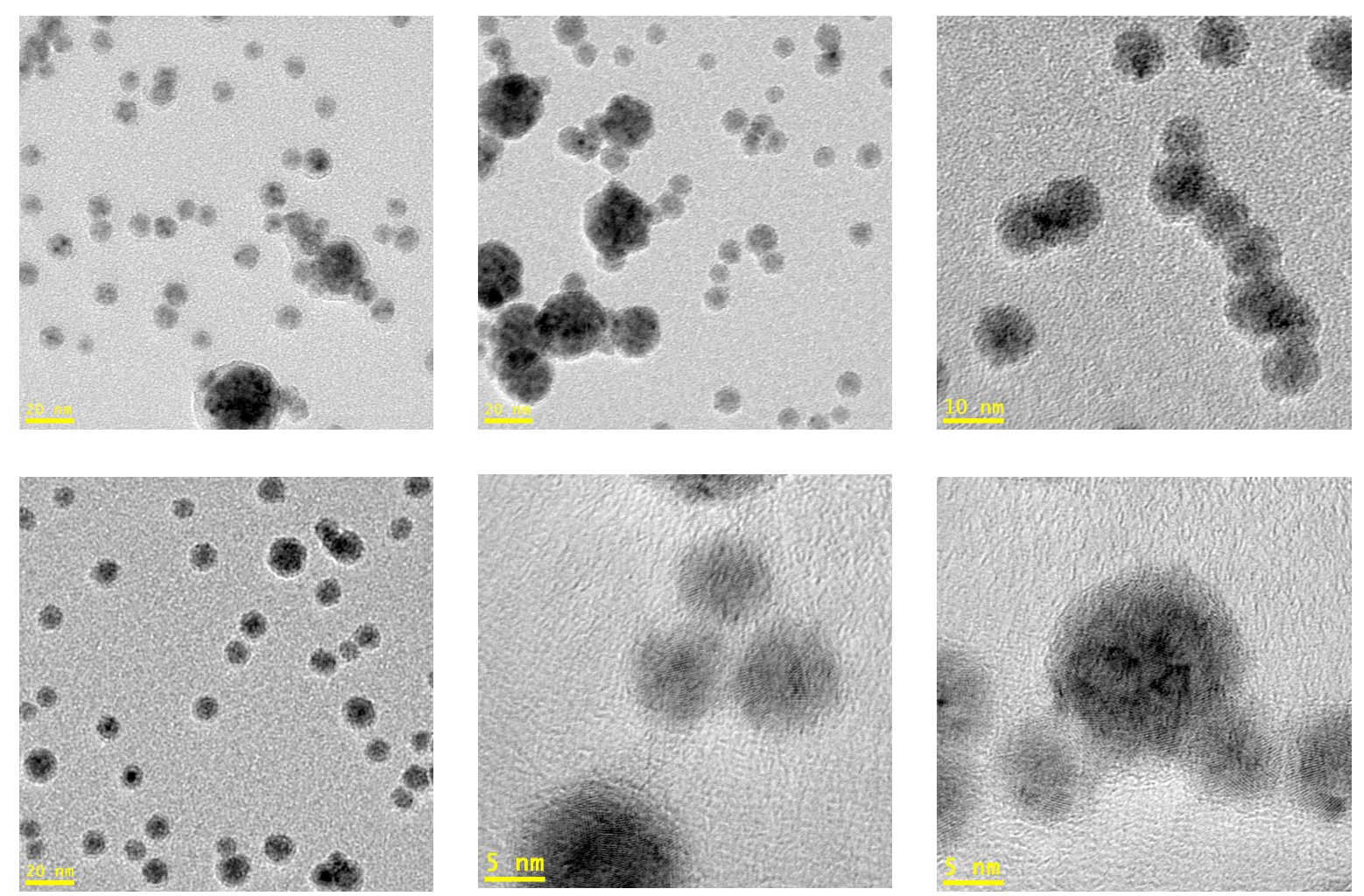

Fig. 3.2: imagens TEM da amostra 2 (A) (75 W e 30 sccm).

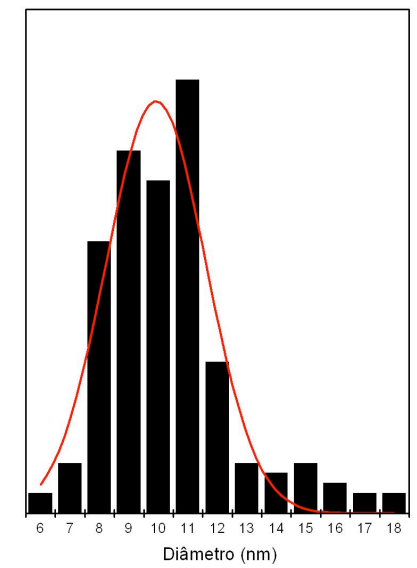

Fig. 3.3: distribuição de tamanhos da amostra 2 (A) (75 W e 30 sccm). Valor médio: $(9,9+/-1,7) \mathrm{nm}$. 

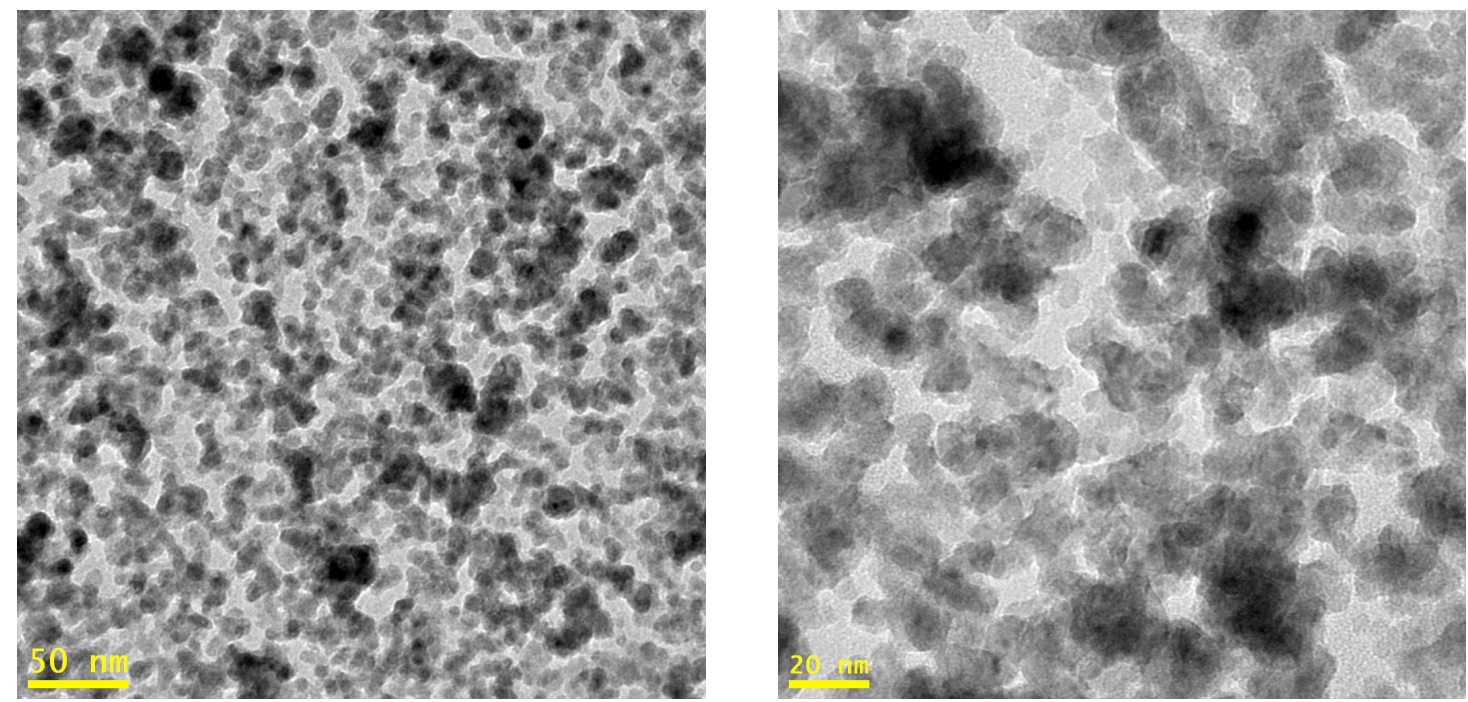

Fig. 3.4: imagens TEM da amostra 2 (B) (75 W e 85 sccm).

\subsubsection{Influência da potência aplicada sobre o tamanho dos aglomerados}

Como já discutido, acreditamos que a potência influencie diretamente no tamanho dos objetos. Para verificar tal dependência, uma amostra para TEM foi produzida com $85 \mathrm{sccm}$ e $30 \mathrm{~W}$ (ficha 3). O nosso intuito era compará-la com a amostra relativa a ficha 2 (B) que foi preparada também com 85 sccm mas com 75 W. O substrato utilizado foi o mesmo desta última: uma grade de cobre recoberta com um filme polimérico e um filme de carbono.

Ao contrário da amostra 2 (B), no entanto, esta foi preparada com o substrato girando* e para compensar este fator e a potência mais baixa, o tempo de deposição foi mais longo: 5 minutos. Finalmente, é importante notar também que esta amostra corresponde as condições padrões de operação descritas na seção 2.3.2 (tabela 2.1).

\footnotetext{
* Foi uma tentativa de quantificar o quanto de material era depositado "em cada passada". Mas, infelizmente, isso não foi possível devido ao tempo limitado de utilização do TEM.
} 
FICHA 3

\begin{tabular}{|c|c|c|c|}
\hline $\begin{array}{l}\text { INFORMAÇÕES GE- } \\
\text { RAIS }\end{array}$ & $\begin{array}{l}\text { GRANDEZAS DO } \\
\text { SISTEMA }\end{array}$ & $\begin{array}{l}\text { CONDIÇÕES DO } \\
\text { ALVO }\end{array}$ & $\begin{array}{l}\text { CONDIÇÕES DA } \\
\text { DEPOSIÇÃO }\end{array}$ \\
\hline $\begin{array}{l}\text { Material: Cobalto } \\
\text { Objetivos: estudar as } \\
\text { variações morfológicas } \\
\text { das NPs em função da } \\
\text { potência aplicada }\end{array}$ & $\begin{array}{l}\text { Fluxo: } 85 \text { sccm } \\
\text { Pressão no copo: } \\
\text { Torr } \\
\text { Pressão na câmara: } 4.8 \\
\text { mTorr }\end{array}$ & $\begin{array}{l}\text { Potência: } 30 \mathrm{~W} \\
\text { Corrente: } 105 \mathrm{~mA} \\
\text { Voltagem: } 270 \mathrm{~V}\end{array}$ & $\begin{array}{l}\text { Tempo: } 5 \text { min } \\
\text { Substrato: grade de } \mathrm{Cu} \\
\text { coberta com um filme de } \\
\text { carbono. } \\
\text { Porta-substrato: rodan- } \\
\text { do } \\
\text { Distância PS - Copo: } 3 \\
\text { cm }\end{array}$ \\
\hline
\end{tabular}

Na figura 3.5 encontram-se duas imagens correspondentes a esta amostra. Nelas, uma série de observações podem ser feitas. Primeiramente, é nítido que ainda ocorre a aglomeração NP-NP observada na amostra 2 (A) (Fig. 3.4). Mas, nota-se também que ela ocorre de uma forma mais sutil. Pode-se argumentar que isso seja devido à menor quantidade de material com que a amostra foi produzida já que a potência era menor.
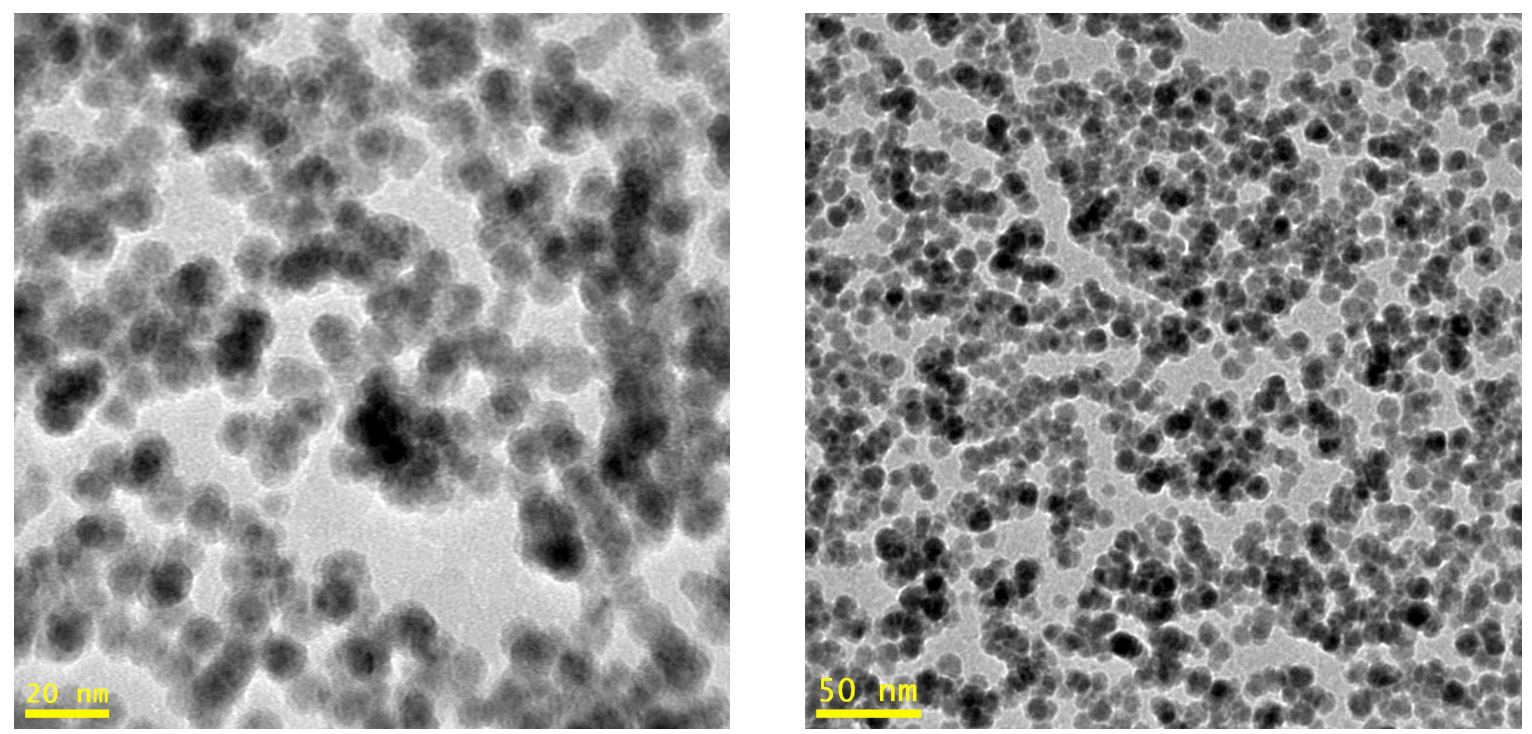

Fig. 3.5: imagens TEM da amostra 3 produzidas com $30 \mathrm{~W}$ e $85 \mathrm{sccm}$.

Em segundo lugar, devido a maior homogeneidade, foi possível realizar uma análise estatística da distribuição de tamanhos. A figura 3.6 ilustra um histograma de tamanhos relativo a 6 imagens em regiões próximas do centro da amostra. Além disso, um ajuste dos dados experimentais através de uma curva Gaussiana foi realizado. Os 
valores obtidos deste ajuste são $(9,9 \pm \mathbf{1}, \mathbf{4}) \mathbf{n m}$. Isso corresponde a um desvio padrão de aproximadamente $14 \%$, próximo dos $17 \%$ obtidos no ajuste da figura 3.2.

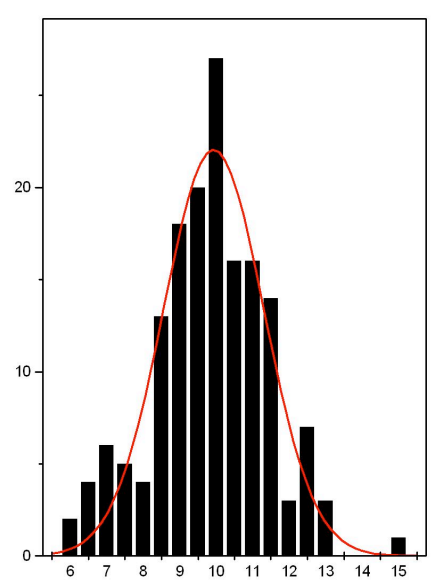

Fig. 3.6: histograma de distribuição de tamanhos da amostra 3 (30 W e 85 sccm) e ajuste Gaussiano dos dados. Valor médio $(9,9 \pm 1,4) \mathrm{nm}$.

\subsubsection{Algumas considerações sobre as amostras produzidas}

Em primeiro lugar, é importante esclarecer porque a condição de $30 \mathrm{sccm}$ e $30 \mathrm{~W}$ não foi estudada. A razão para isso é que tais parâmetros resultam em taxas de deposição significativamente mais baixas saindo do que costumamos chamar de regime de colimação. Ou seja, das situações onde as taxas de deposição aumentam exponencialmente.

Além de expor e analisar os dados obtidos, esta seção teve também o intuito de ilustrar o processo de convergência dos parâmetros experimentais com o intuito de encontrar soluções estáveis de trabalho. Acreditamos que condições padrões de operação sejam fundamentais para produzir amostras com reprodutibilidade garantida, minimizando a degradação do sistema.

\subsubsection{Variações no tamanho das nanopartículas}

Por TEM, as três condições investigadas foram:

(1) $30 \mathrm{~W}$ e $85 \mathrm{sccm}$;

(2) $75 \mathrm{~W}$ e 85 sccm; 
(3) $75 \mathrm{~W}$ e $30 \mathrm{sccm}$.

Como discutido no capítulo 2.4, esperaríamos um aumento no diâmetro médio das partículas de $40 \%$ entre as condições (1) e (2) pois o aumento na potência foi de um fator 2,5. Apesar de realmente aparentarem maiores, não foi possível obter uma análise estatística de tamanhos para a condição (2) (Amostra 2 (B), Figs. 3.4). Assim, infelizmente, não foi possível concluir de forma precisa a influência do tamanho nas partículas.

Por outro lado, a semelhança no diâmetro médio entre as condições (1) e (3) está condizente com a hipótese, também proposta na seção 2.4, de que com $75 \mathrm{~W}$, mesmo que haja a formação de objetos maiores, não há fluxo suficiente de Ar para removê-los do copo. Assim, sairão deste apenas objetos menores.

Finalmente, é importante quantificar os tamanhos de partícula obtidos em termos de números de átomos o que ajuda a entender como a dependência do diâmetro com a potência é sutil.

As NPs produzidas nas condições padrões de operação (30 W e 85 sccm) tem diâmetros médios de $(9,9 \pm 1,4)$ nm o que significa que mais de $60 \%$ das NPs tem seus

diâmetros entre 8,5 nm e 11,3 nm. É possível também derivar uma expressão aproximada para o relacionar o diâmetro das partículas com o seu número de átomos. Para diâmetros pequenos, temos da literatura $[42,43]$ que $d \approx 0,24 n^{1 / 3}$.

Assim, 9,9 $\mathrm{nm}$ corresponde a aproximadamente 70.000 átomos e 8,5 nm e 11,3 nm a 45.000 e 120.000 respectivamente. Isso significa que, devido a dependência cúbica entre o diâmetro e o número de átomos, apesar do primeiro não variar significativamente o último varia, chegando até a quase triplicar de valor dentro de apenas uma dispersão!

\subsubsection{Variações nas taxas de deposição}

Referente as taxas de deposição, analisando as amostras 2 (A) e (B), fica nítida a influência do fluxo (figuras 3.2 e 3.4 respectivamente). Ambas foram preparadas no mesmo tempo e potência e a amostra (B), cujo fluxo era de $85 \mathrm{sccm}$, apresentou uma 
quantidade drasticamente maior de material do que a (A), de $30 \mathrm{sccm}$. Estes resultados, como discutido no capítulo 2.4.3, eram esperados. As imagens 3.1, referentes a ficha 1, também denotam claramente esta dependência.

A influência linear que a potência tem na quantidade de material dentro do copo se traduz em uma quantidade maior de partículas sendo removidas dele. Ou seja, é natural de se esperar uma influência da potência também nas taxas de deposição. Por outro lado, não é trivial de concluir se há efeitos não lineares desta dependência e quais as razões físicas para estes.

\subsection{Distribuição de material no substrato}

\subsubsection{Porta-substrato parado}

\section{MedidAs DE RBS}

Com a finalidade de estudar como é a distribuição do material sobre o substrato, uma amostra com nanopartículas de cobalto foi preparada com o intuito de ser analisada por RBS (ficha 4). As condições foram as padrões de utilização, que correspondem a $30 \mathrm{~W}$ de potência e $85 \mathrm{sccm}$ de fluxo. O tempo total de deposição foi de 10 minutos e o substrato utilizado foi o silício. Para maximizar a quantidade de material, utilizamos o porta-substrato parado.

No total, 22 irradiações foram realizadas utilizando um feixe de prótons de 0,3 mm de largura. Estas cobriram a trajetória descrita pela linha pontilhada na imagem 3.7. A energia do feixe foi de $1.4 \mathrm{keV}$ e o ângulo de detecção de $170^{\circ}$. 
FICHA 4

\begin{tabular}{|c|c|c|c|}
\hline $\begin{array}{l}\text { INFORMAÇÕES GE- } \\
\text { RAIS }\end{array}$ & $\begin{array}{l}\text { GRANDEZAS DO } \\
\text { SISTEMA }\end{array}$ & $\begin{array}{l}\text { CONDIÇÕES DO } \\
\text { ALVO }\end{array}$ & $\begin{array}{l}\text { CONDIÇÕES DA } \\
\text { DEPOSIÇÃO }\end{array}$ \\
\hline $\begin{array}{l}\text { Material: Cobalto } \\
\text { Objetivos: medir a dis- } \\
\text { tribuição da concentra- } \\
\text { ção de material sobre o } \\
\text { substrato }\end{array}$ & $\begin{array}{l}\text { Fluxo: } 85 \text { sccm } \\
\text { Pressão no copo: } \\
1 \text { Torr } \\
\text { Pressão na câmara: } 4.6 \\
\text { mTorr }\end{array}$ & $\begin{array}{l}\text { Potência: } 30 \mathrm{~W} \\
\text { Corrente: } 103 \mathrm{~mA} \\
\text { Voltagem: } 286 \mathrm{~V}\end{array}$ & $\begin{array}{l}\text { Tempo: } 10 \text { min } \\
\text { Substrato: Silício } \\
\text { Porta-substrato: } \\
\text { parado } \\
\text { Distância PS - Copo: } 3 \\
\text { cm }\end{array}$ \\
\hline
\end{tabular}

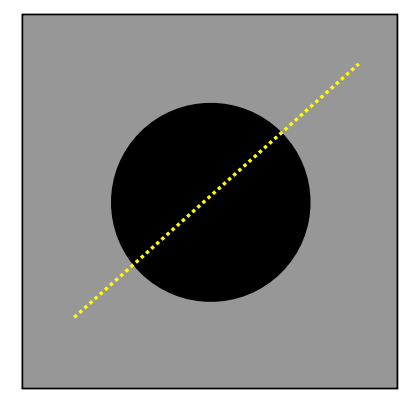

Fig. 3.7: direção pela qual a análise de RBS da amostra 4 foi realizada. A parte cinza denota o substrato, a mancha preta a área depositada e a linha pontilhada o caminho por onde as medidas foram realizadas.

A figura 3.8 exemplifica dois espectros de RBS completos, obtidos em regiões diferentes, com pouco e muito material. $\mathrm{O}$ intuito desta figura é ilustrar o espectro como um todo onde destacam-se duas regiões: a região plana em baixas energias que corresponde ao substrato de silício e os picos em altas energias que correspondem as nanopartículas.

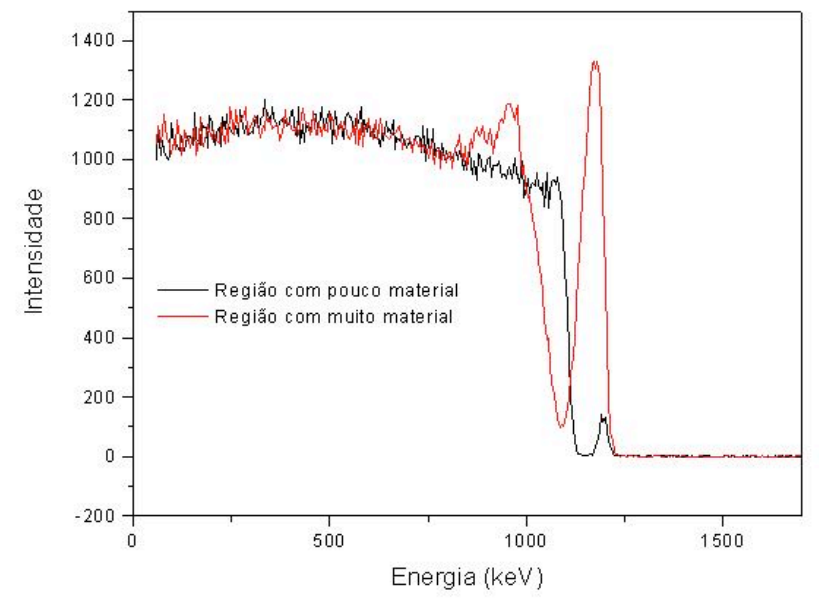

Fig. 3.8: dois espectros de $R B S$ da amostra 4 em regiões com pouco e muito material. O intuito desta imagem é mostrar a região plana, correspondente ao substrato e os picos correspondentes as nanopartículas. 
No espectro relativo a região com muito material, nota-se um pequeno pico próximo de $900 \mathrm{keV}$, sobreposto com a banda plana do Si. Este corresponde ao oxigênio presente nas NPs, já que nenhum tipo de proteção foi utilizada.

Na figura 3.9 estão expostos, apenas para fins ilustrativos, todos os espectros com uma magnificação na região de interesse (compare a escala horizontal com o gráfico da figura 3.8). Nenhuma legenda foi utilizada para distinguir entre os espectros com a finalidade de não poluir a imagem. Neste, nota-se claramente que o pico referente ao oxigênio muda em fase com o pico do cobalto.

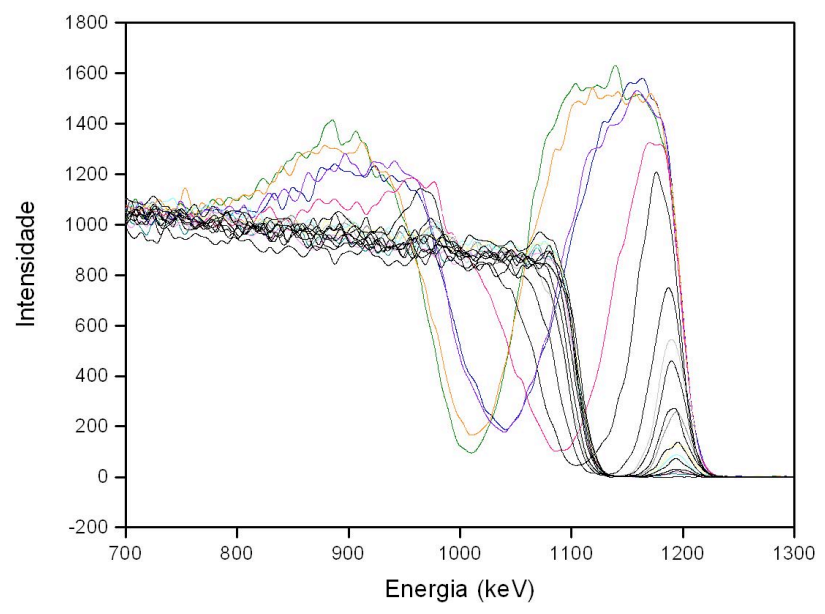

Fig. 3.9: todos os espectros de RBS da amostra 4 com uma magnificação na região de interesse.

Em cada um dos espectros obtidos, uma simulação da densidade de átomos de cobalto foi realizada. O programa utilizado foi o SIMRA, próprio para simulações de espectros irradiados com feixes de prótons.

Tivemos que incluir, na simulação computacional, que a amostra era composta de um filme fino somado com uma certa rugosidade que variava de forma aproximadamente linear com a espessura. Esta rugosidade diz respeito a rugosidade em filmes finos o que não é o nosso caso pois nossa amostra corresponde ao empilhamento de nanoobjetos, sendo significativamente porosa. Mas, infelizmente, esta foi a única forma de simularmos os dados experimentais.

Devido a esta porosidade, a espessura equivalente em número de átomos e a espessura física da amostra são diferentes. 
A figura 3.10 ilustra, tanto a curva experimental quanto a curva simulada, para o espectro da figura 3.8 correspondente a região com muito material. Foi necessário, nesta simulação, considerar o óxido de cobalto (na forma de $\mathrm{Co}_{2} \mathrm{O}_{3}$ ) e também, para reproduzir o formato do pico, acrescentou-se uma rugosidade comparável a própria espessura da camada.

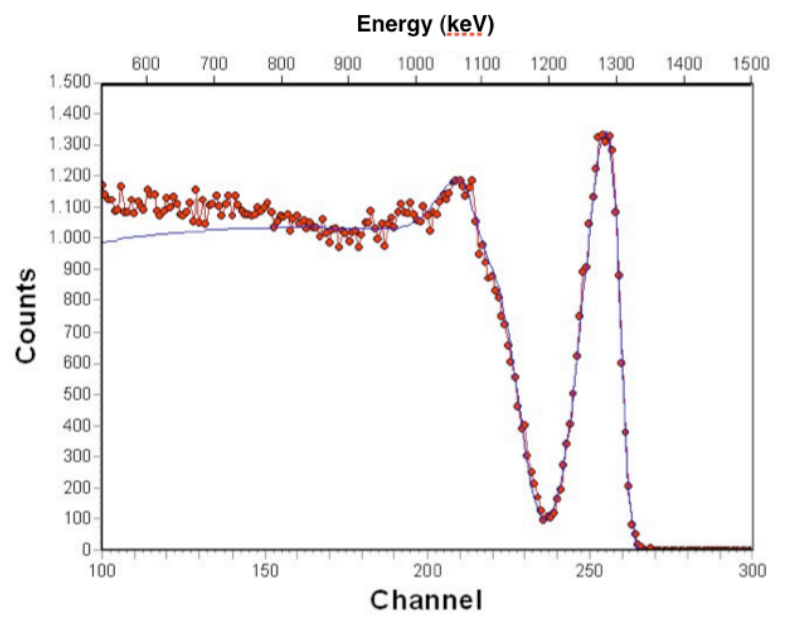

Fig. 3.10: dados experimentais e curva simulada para um espectro de RBS da amostra 4.

Após tal simulação ter sido feita para todos os pontos, um gráfico da densidade atômica em função da posição foi confeccionado (figura 3.11).

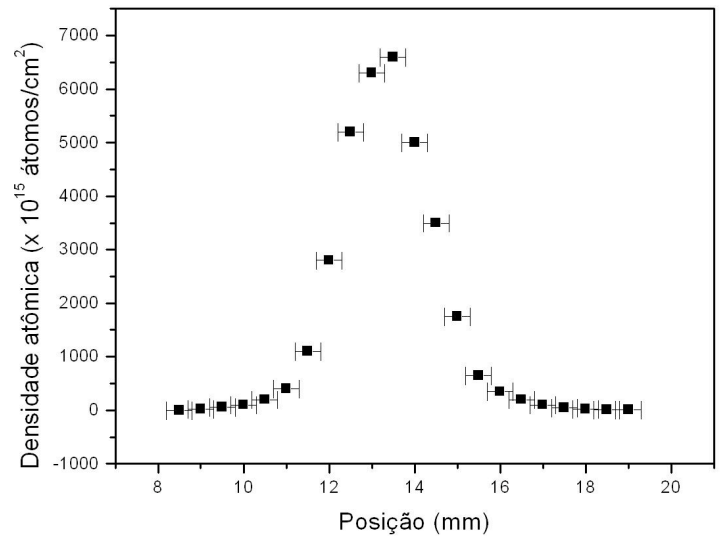

Fig. 3.11: densidade atômica em função da espessura para a amostra 4.

Em seguida, os resultados foram transformados em espessura equivalente em número de átomos admitindo que a densidade das NPs de cobalto é a mesma que a do "bullk". Esta aproximação é razoável tendo em vista que o diâmetro médio das NPs é da ordem de $10 \mathrm{~nm}$, de tal forma que a estrutura cristalina já se aproxima da deste úl- 
timo. O fator de conversão utilizado foi 1 x $10^{15}$ at $/ \mathrm{cm}^{2}=0,1112 \mathrm{~nm}$. Tais resultados estão denotados na figura 3.12. O valor utilizado como incerteza na posição de medida (eixo $\mathrm{x}$ ) foi de $0,3 \mathrm{~mm}$, que corresponde a própria largura do feixe.

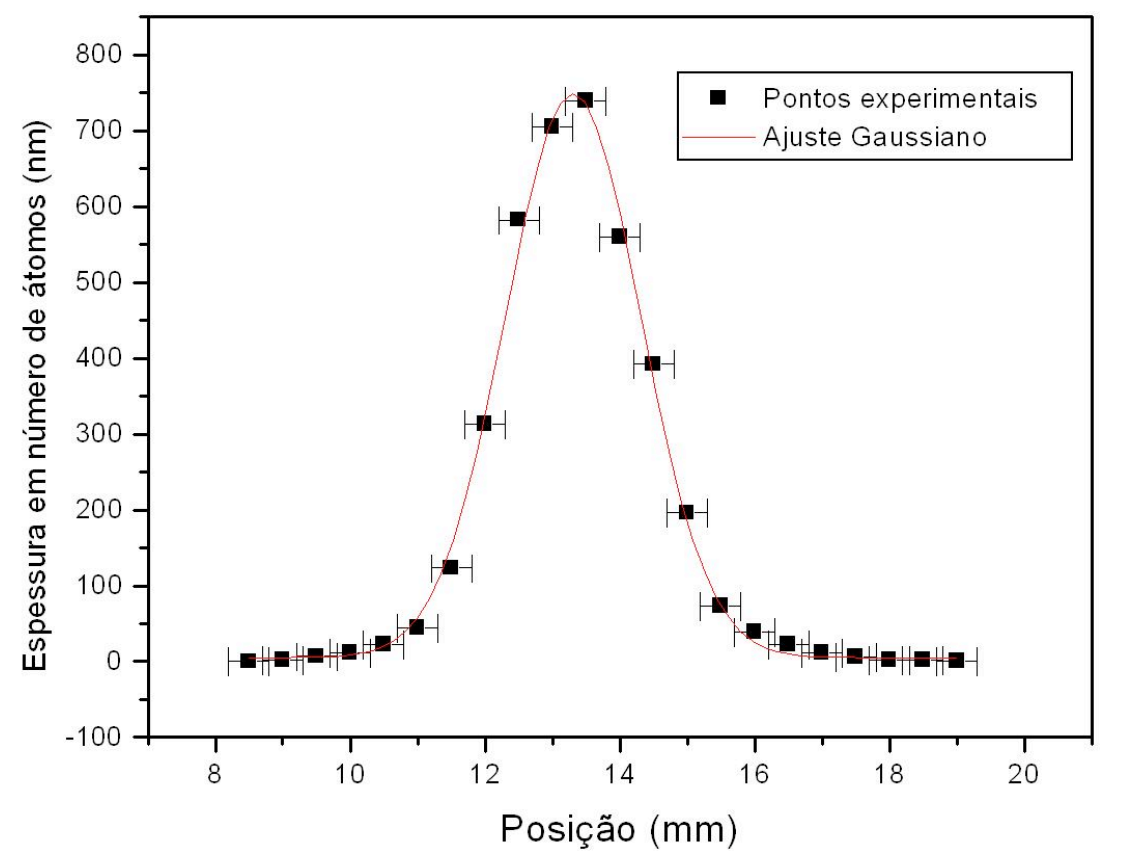

\begin{tabular}{|c|c|c|c|}
\hline Centro & Altura & $\begin{array}{c}\text { Largura a meia } \\
\text { altura }\end{array}$ & Área \\
\hline $13,307 \mathrm{~mm}$ & $743,99 \mathrm{~nm}$ & $2,00 \mathrm{~mm}$ & 18723 \\
\hline
\end{tabular}

Fig. 3.12: espessura equivalente em número de átomos da amostra 4. Cada ponto corresponde a um espectro de RBS obtido em uma região diferente do substrato (figura 3.9), cuja separação está denotada na escala horizontal. A tabela acima denota os valores obtidos através de um ajuste Gaussiano nos dados experimentais.

Também mostrado na figura 3.12 está um ajuste Gaussiano feito para os pontos em questão (cujos resultados numéricos estão apresentados na tabela logo abaixo da imagem). Este tem uma compatibilidade impressionante com os dados experimentais e confirma a nossa expectativa de que a deposição é mais intensa no centro da amostra decaindo de forma exponencial, simetricamente, em todas as direções.

No centro da amostra a espessura total obtida foi de aproximadamente $750 \mathrm{~nm}$. Como o tempo de deposição foi 10 minutos, é possível inferir que a taxa de deposição 
no centro vale $1.25 \mathrm{~nm} / \mathrm{s}(75 \mathrm{~nm} / \mathrm{min})^{*}$. Sem o gerador, na mesma potência, a taxa de deposição do cobalto seria de aproximadamente $0,03 \mathrm{~nm} / \mathrm{s}(1,8 \mathrm{~nm} / \mathrm{min})$. Ou seja, há um aumento de mais de 40 vezes na quantidade de material, o que ajuda a quantificar a capacidade de colimação do sistema. Como o tamanho médio das NPs é da ordem de $10 \mathrm{~nm}$, o centro da deposição corresponde a quase 80 camadas de nanopartículas.

Como a rugosidade é da mesma ordem de grandeza que a espessura atômica, a espessura física da amostra seria aproximadamente o dobro desta última. Mas, como o programa não é próprio para este tipo de análise, este valor pode ser bastante impreciso.

\section{MedidAS DE SEM}

Ainda para a mesma amostra (ficha 4), imagens de SEM foram obtidas em regiões com diferentes concentrações (figura 3.13). A intenção desta análise não foi distinguir entre os tamanhos dos objetos, mas apenas obter imagens que mostrassem o caráter geral das diferentes regiões. É bastante nítida a forma como a concentração de material varia ao longo delas.

Um fato bastante interessante são as imagens obtidas nas bordas, em $8 \mathrm{~mm}$ e 19 mm (na escala horizontal). Nestas, de acordo com os dados do RBS, a quantidade de material deveria ser praticamente nula. Nota-se, no entanto, que há material nanoparticulado nessa região - em pouca quantidade - mas nitidamente visível. Isso significa que deve haver uma espessura mínima (principalmente considerando o fato de que não estamos tratando de um filme fino) para que as medidas sejam capazes de detectar a presença de NPs. De acordo com o RBS, o diâmetro da área depositada vale aproximadamente $6 \mathrm{~mm}$. Mas, de acordo com as imagens de SEM, esta seria de aproximadamente $10 \mathrm{~mm}$, quase duas vezes maior.

\footnotetext{
* É importante enfatizar que as condiçôes com que esta amostra foi preparada correspondem às condições padrões de utilização descritas na tabela 2.I no capítulo 2.3.2.
} 
Considerando que a análise do RBS pressupõe um filme fino, é possível que a razão pela qual as medidas nestas regiões forneceram tais resultados seja devido a baixa área preenchida por NPs e não relativo a quantidade de "camadas" de objetos.

Já nas regiões muito mais afastadas, observa-se que não há material, o que serve para mostrar que o substrato foi propriamente limpo.

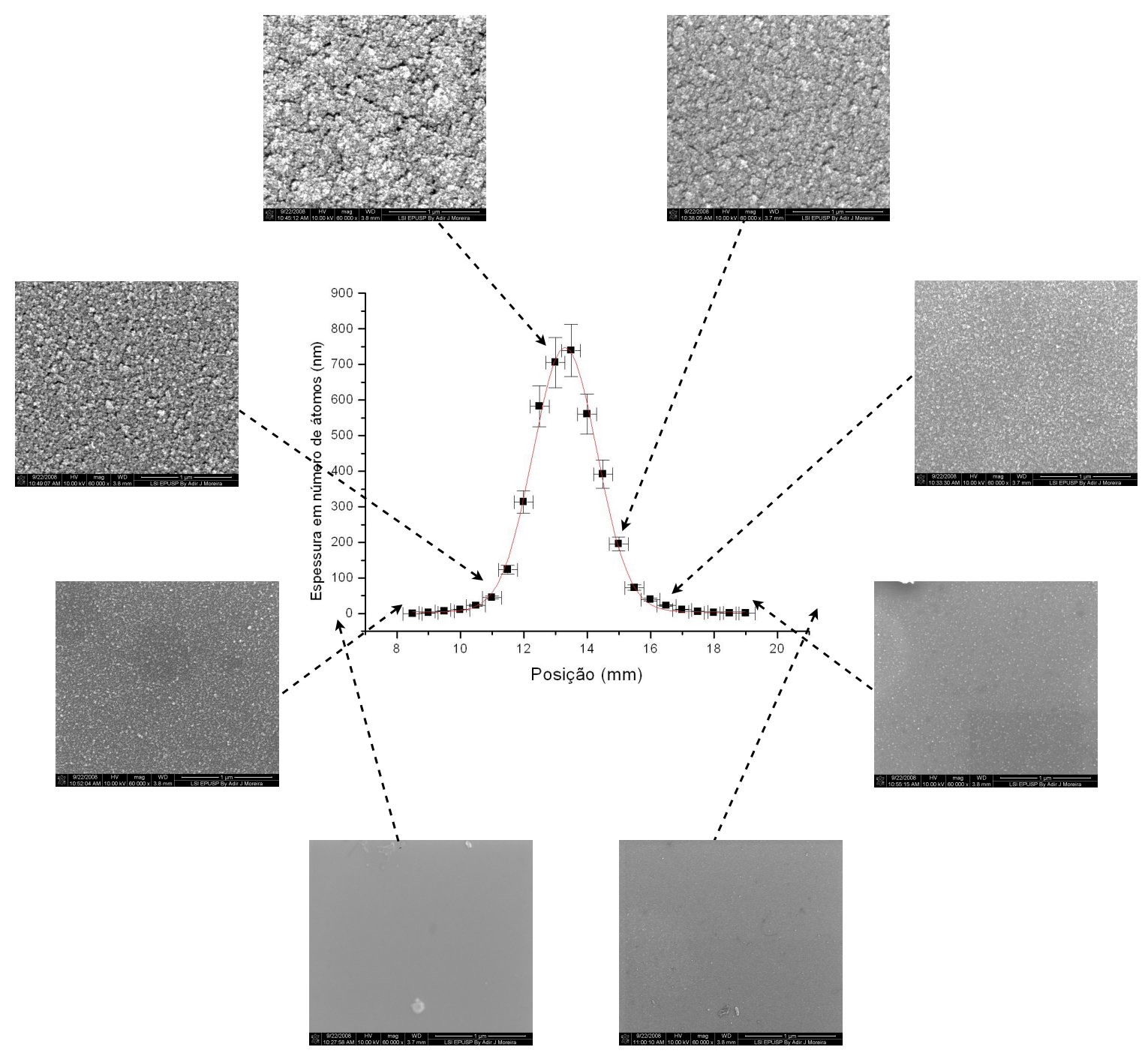

Fig. 3.13: análise topográfica da amostra 4 em diferentes regiões evidenciando as mudanças significativas no empacotamento do material (vide figura 3.12 para mais informações sobre a confecção do gráfico em si). As imagens inferiores foram obtidas em regiões afastadas onde medidas de RBS não foram realizadas. 


\subsubsection{Porta-substrato girando}

Um procedimento análogo ao da seção anterior foi realizado para medir a concentração de material em uma amostra produzida com o porta-substrato girando. Os detalhes da amostra preparada estão descritos na ficha 5. As condições de deposição foram exatamente as mesmas (30 W, $85 \mathrm{sccm})$. As diferenças, se comparada com a amostra da ficha 4 (da seção anterior), são basicamente o tempo de deposição (20 minutos, o dobro) e o substrato (carbono ao invés de silício). A imagem 3.14 ilustra como a varredura do RBS foi realizada (vide a figura 2.8 para eventuais esclarecimentos).

\section{FICHA 5}

\begin{tabular}{|c|c|c|c|}
\hline $\begin{array}{l}\text { INFORMAÇÕES } \\
\text { GERAIS }\end{array}$ & $\begin{array}{l}\text { GRANDEZAS DO } \\
\text { SISTEMA }\end{array}$ & $\begin{array}{l}\text { CONDIÇÕES DO } \\
\text { ALVO }\end{array}$ & $\begin{array}{l}\text { CONDIÇÕES DA } \\
\text { DEPOSIÇÃO }\end{array}$ \\
\hline $\begin{array}{l}\text { Material: Cobalto } \\
\text { Objetivos: medir a } \\
\text { distribuição da con- } \\
\text { centração de material } \\
\text { sobre o substrato } \\
\text { com ele girando. }\end{array}$ & $\begin{array}{l}\text { Fluxo: } 85 \text { sccm } \\
\text { Pressão no copo: } \\
1 \text { Torr } \\
\text { Pressão na câmara: } \\
4.6 \text { mTorr }\end{array}$ & $\begin{array}{l}\text { Potência: } 30 \mathrm{~W} \\
\text { Corrente: } 105 \mathrm{~mA} \\
\text { Voltagem: } \sim 286 \mathrm{~V}\end{array}$ & $\begin{array}{l}\text { Tempo: } 20 \text { min } \\
\text { Substrato: Carbono } \\
\text { Porta-substrato: } \\
\text { girando } \\
\text { Distância PS - Copo: } \\
3 \mathrm{~cm}\end{array}$ \\
\hline
\end{tabular}

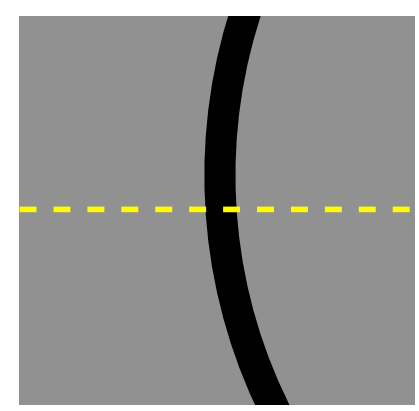

Fig. 3.14: esquema de como foi realizada a varredura do RBS para a amostra 5. O quadrado cinza representa o substrato, a mancha preta o material depositado e a linha pontilhada o caminho por onde a medida foi realizada.

A figura 3.15 ilustra todos os 8 espectros obtidos. A diminuição no número de espectros se deve a diminuição na área depositada dificultando as medidas experimentais*. Uma informação importante é que esta análise foi feita com um feixe de partículas $\alpha$ em contrapartida com o feixe de prótons utilizado na seção anterior. Por tal razão, o

\footnotetext{
* Mais informações sobre isso adiante.
} 
programa de análise foi o RUMP, próprio para este tipo de irradiação. A energia do feixe foi era 2,2 MeV e a o ângulo de incidência se manteve em $170^{\circ}$.

Uma característica que pode ser notada na figura 3.15 é a presença de pequenos picos na região de $600 \mathrm{keV}^{*}$. Estes, assim como o pico na figura 3.8, dizem respeito ao oxigênio correspondente a oxidação das nanopartículas (pois, novamente, nenhum tipo de proteção foi utilizada). A razão pela qual, neste caso, o pico está isolado da banda do substrato é porque a energia das partículas retro-espalhadas esta relacionada com a massa atômica do elemento espalhador. Assim, na amostra 4, o substrato de silício (massa atômica 28) sobrepunha-se com o oxigênio (massa atômica 16), o que não ocorre neste caso já que o substrato utilizado foi carbono (massa atômica 12).

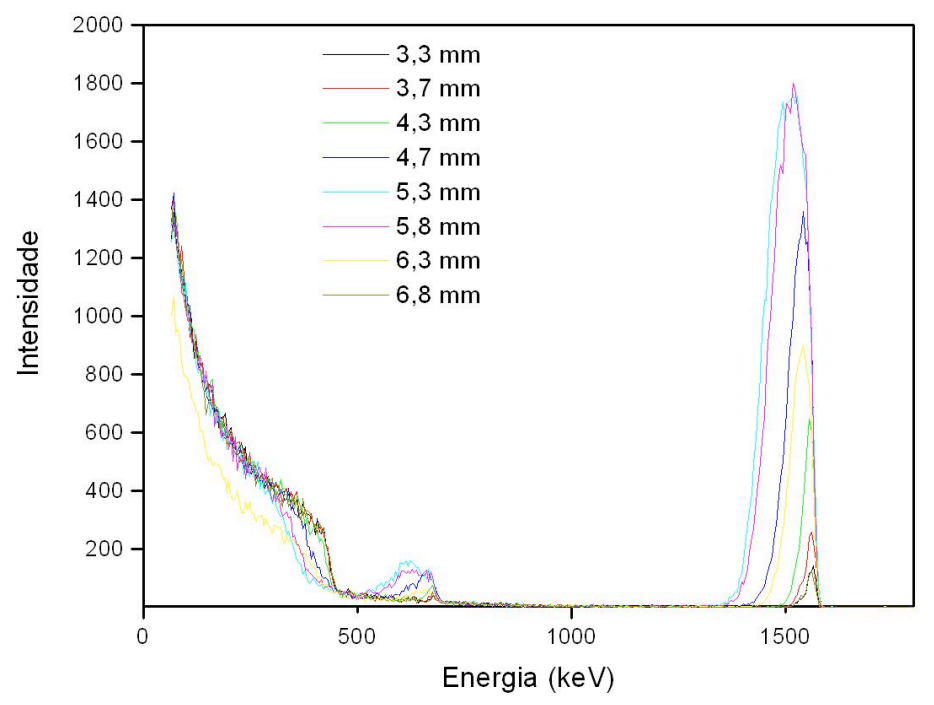

Fig. 3.15: espectros de RBS obtidos para a amostra 5. O feixe utilizado neste caso foi de partículas $\alpha$.

Estes espectros foram analisados de forma análoga à descrita na seção 3.3.1. Na figura 3.16 encontram-se os dados experimentais de um dos espectros juntamente com a simulação computacional.

\footnotetext{
* A diferença no substrato entre as duas análises pode ser vista na forma como os espectros se comportam em baixas energias, (imagens 3.8 e 3.15). A diferença na partícula usada na irradiação tem que ser considerada.
} 


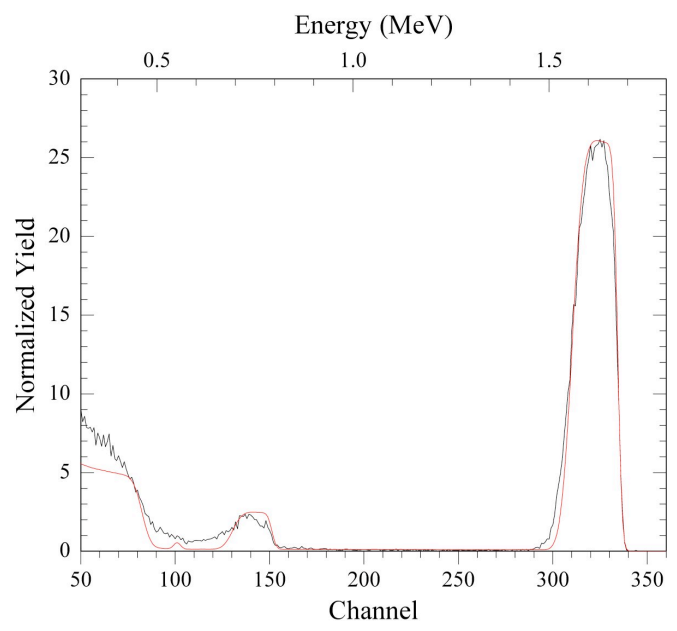

Fig. 3.16: dados experimentais e curvas simuladas para um espectro relativo a amostra 5.

Assim como na seção anterior, um gráfico da distribuição da espessura ao longo da amostra foi confeccionado (figura 3.17) e sobre este, um ajuste Gaussiano foi realizado.

Desta figura é possível notar a clara diminuição na taxa de deposição, principalmente considerando que a amostra foi preparada com o dobro do tempo. No pico, a espessura máxima vale aproximadamente $75 \mathrm{~nm}$. Considerando o tempo de deposição de 20 minutos, isso corresponde a aproximadamente $0.06 \mathrm{~nm} / \mathrm{s}(3,6 \mathrm{~nm} / \mathrm{min})$. Ou seja, um fator $\mathbf{2 0}$ de diminuição com relação ao substrato parado mas ainda um fator $\mathbf{2}$ de aumento com relação a deposição usual do "sputtering".

Uma diminuição na largura a meia altura também pode ser observada. Com o processo de deposição em mente, isto não parece intuitivo. A diminuição na quantidade material deveria ser evidente mas a largura do espalhamento dos objetos não. A explicação para este problema pode ser dada tendo a figura 3.13 em mente onde, como já discutido, as imagens de SEM mostram que há nanopartículas em regiões onde os dados do RBS dizem o contrário.

Apesar destas diferenças, a distribuição Gaussiana da espessura se manteve, mostrando a reprodutibilidade do experimento. 


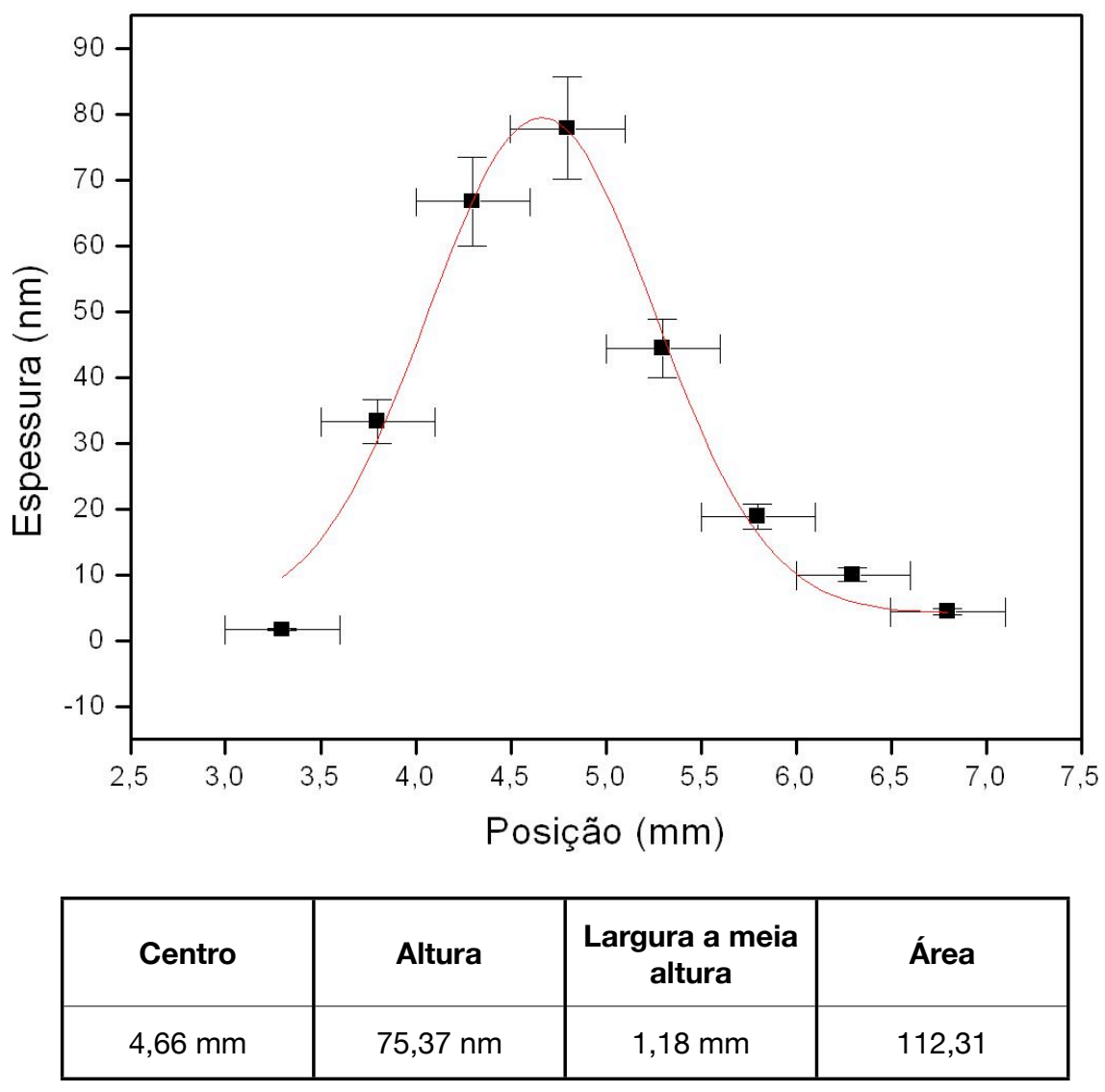

Fig. 3.17: distribuição de espessura de uma amostra produzida com o substrato girando (ficha 5). Tabela com os valores do ajuste Gaussiano dos dados experimentais.

\subsubsection{Discussões referentes a distribuição do material e as taxas de deposição}

Um diferencial deste trabalho é, sem dúvida, a velocidade com que as amostras podem ser produzidas uma vez que a deposição se dá de forma concentrada aumentando significativamente a taxa de deposição das NPs.

Ao sair do copo de condensação, devido a diferença de pressão entre ele e a câmara principal, o material se expande conicamente. O gás, por ser mais leve, deve sofrer esta expansão mais intensa. Já as NPs, por serem muito mais pesadas (da ordem de 60.000 átomos), não tanto. Este efeito pode ser notado, visualmente, nas figuras 2.6 e 2.7 do capítulo 2.3.3.

A largura a meia altura da Gaussiana está intimamente relacionada com a distância substrato-copo e a expansão aerodinâmica que o feixe de nanopartículas sofre ao sair da região de condensação (vide seção 2.3.3). O efeito de variar a distância entre o 
copo e o porta-substrato é mudar a forma da distribuição mantendo igual a área sobre o ajuste (que está relacionada com a quantidade total de material depositado). Para que isso pudesse ser comprovado, seriam necessárias amostras produzidas nas mesmas condições mudando apenas a distância substrato-copo. Tal análise não foi feita pois acreditamos que estas variações seriam pequenas demais estando dentro da incerteza das medidas experimentais (na figura 2.7 nota-se que a área não varia significativamente, apesar de nitidamente variar).

Como a expansão aerodinâmica do feixe de partículas está vinculada com a massa dos aglomerados, poderia-se esperar que houvessem variações no tamanho das nanopartículas ao longo da amostra. Isto foi investigado por TEM e SEM mas nada notável foi observado.

Finalmente, um comentário sobre a aderência das NPs no substrato é importante de ser feito. Durante a deposição de um filme fino, o vapor atômico colide com o substrato com uma energia próxima da energia que é removido do alvo; em torno de algumas dezenas de eV. Essa energia é suficientemente alta para que ele "solde" com os átomos vizinhos fixando-se no substrato (principalmente levando em consideração a massa reduzida).

No nosso caso, no entanto, as NPs chegam no substrato com uma energia muito menor, que corresponde a energia de escoamento do fluxo de gás. Assim, a aderência delas no substrato é significativamente menor e este acaba servindo apenas como um "apoio" para os aglomerados.

Isto foi observado de duas formas. Primeiro, através do cristal oscilador utilizado para medir a taxa de deposição. Nota-se que quando começamos a deposição, a taxa fica alta rapidamente. Mas, alguns segundos depois, ela passa a marcar valores negativos indicando que a quantidade de material total no cristal está diminuindo. Isto ocorre pois o cristal está vibrando em uma frequência altíssima (da ordem de alguns kHz).

Uma outra forma de verificar isso é raspando a amostra com uma pinça. Nota-se que ela não se comporta como um filme fino mas sim como um pó que pode ser facilmente removido do material com algumas raspadas. 


\subsubsection{Alguns comentários sobre codeposições}

Como será descrito no capítulo 4, este trabalho rendeu diversas colaborações, todas envolvendo NPs emberçadas em matrizes diversas. Para codeposições, podemos comparar a taxa de deposição no centro da amostra de 3,6 nm/ min (seção 3.3.2, relativo ao porta-substrato girando) com alguns materiais.

Para o Cu por exemplo, a taxa de deposição a $100 \mathrm{~W}$ é de aproximadamente 3,4 $\mathrm{nm} /$ min (medida também por RBS). Como um exemplo, para que o pico da deposição de NPs represente $30 \%$ da quantidade de material, utiliza-se $300 \mathrm{~W}$. Neste caso isso não é de fato um problema pois como o Cu não está dentro da câmara de condensação, e sim em um dos outros canhões, sua pressão corresponde a pressão da câmara que é da ordem de 5 mTorr. Isso significa que não há problemas em aumentar a potência.

Para metais nobres como Au e a Ag, cujas taxa de deposição são significativamente mais altas, potências da ordem de $100 \mathrm{~W}$ já são suficientes para alcançar tal estequiometria.

Outro material extensivamente utilizado foi o $\mathrm{Si}_{3} \mathrm{~N}_{4}$, principalmente para recobrir as amostras evitando a oxidação. A taxa de deposição deste material é significativamente baixa; da ordem de 0,36 nm/min para $100 \mathrm{~W}$ RF (pois ele é isolante). Isso corresponde a aproximadamente $10 \%$ da taxa do Co (a $30 \mathrm{~W}$ e $85 \mathrm{sccm}$ ).

Para o recobrimento, usamos normalmente 30 minutos de $\mathrm{Si}_{3} \mathrm{~N}_{4}$ o que corresponde a aproximadamente $12 \mathrm{~nm}$, o suficiente para evitar a oxidação.

Por outro lado, quando desejamos codepositar o $\mathrm{Si}_{3} \mathrm{~N}_{4}$ com as NPs, o problema fica mais complicado. A solução é alternar entre a codeposição de ambos os materiais e a deposição apenas do $\mathrm{Si}_{3} \mathrm{~N}_{4}$. Ou seja, codeposita-se por alguns minutos e depois deixa um tempo longo apenas com o $\mathrm{Si}_{3} \mathrm{~N}_{4}$, repetindo este processo diversas vezes.

\subsection{Estrutura cristalina}


Para estudar a estrutura cristalina das nanopartículas preparamos uma amostra sobre um substrato de vidro*. As condições com que esta amostra foi preparada foram as padrões, $30 \mathrm{~W}$ e 85 sccm e o tempo, longo, 30 minutos (ficha 6). Após a deposição, um filme de aproximadamente $12 \mathrm{~nm}$ de $\mathrm{Si}_{3} \mathrm{~N}_{4}$ foi depositado com o intuito de evitar a oxidação das nanopartículas (sabemos da literatura que as fases cristalinas do óxido de cobalto são drasticamente diferentes das do cobalto [44]]).

\section{FICHA 6}

\begin{tabular}{|llll|}
\hline INFORMAÇÕES & GRANDEZAS DO & CONDIÇÕES DO & CONDIÇÕES DA \\
GERAIS & SISTEMA & ALVo & DEPOSIÇÃo \\
Material: Cobalto & Fluxo: $85 \mathrm{sccm}$ & Potência: $30 \mathrm{~W}$ & Tempo: $30 \mathrm{~min}$ \\
& Pressão no copo: & Corrente: $\sim 105 \mathrm{~mA}$ & Substrato: vidro \\
Objetivos: estudar a & 1 Torr & Voltagem: $\sim 270 \mathrm{~V}$ & Porta-substrato: pa- \\
estrutura cristalina & Pressão na câmara: & & rado \\
das NPs & 4.8 mTorr & & Distância PS - Copo: \\
& & & 3 cm \\
& & & \\
& & & \\
\hline
\end{tabular}

Como discutido na seção 2.4.2, acreditamos que a energia com que as nanopartículas chegam no substrato seja muito baixa, correspondendo basicamente a energia de escoamento do fluxo de gás. Este sendo o fato, é então razoável de se esperar que o contato entre as nanopartículas não seja, de forma alguma, energético o suficiente para alterar suas estruturas cristalinas.

Isto está sendo dito para justificar o fato da amostra ter sido preparada sem que as NPs fossem isoladas umas das outras por meio de uma matriz. Além disso, caso esta fosse utilizada, sua estrutura cristalina poderia influenciar nos resultados.

As medidas foram realizadas de $10^{\circ}$ a $100^{\circ}$, a cada $0,02^{\circ}$, medindo 20 segundos por ponto (uma medida longa foi feita para garantir um bom sinal). A tensão aceleradora era $40 \mathrm{kV}$ e a corrente do feixe $30 \mathrm{~mA}$.

A figura 3.18 ilustra o espectro de difração relativo a duas amostras: a amostra XRD propriamente dita e uma amostra de controle, preparada junto com esta última, no mesmo substrato mas contendo apenas a proteção de $\mathrm{Si}_{3} \mathrm{~N}_{4}$. Desta figura, nota-se

* Vidro é uma boa opção para XRD pois não possui picos de difração, apenas uma banda em baixos ângulos. 
claramente que não há diferença alguma entre as duas curvas. Em outras palavras, isso significa que nenhuma propriedade cristalina pode ser observada nas nanopartículas. A banda, presente de forma idêntica em ambas, corresponde claramente ao substrato de vidro.

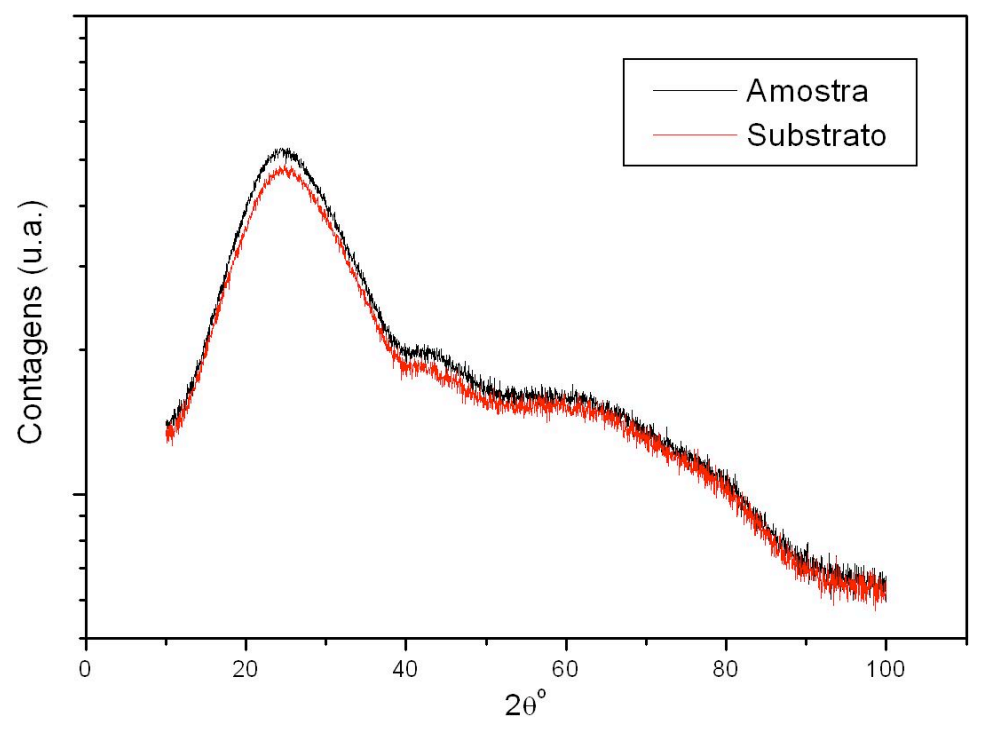

Fig. 3.18: difratograma da amostra 6 e do substrato de vidro.

Isso ocorre devido a forma como ocorre o processo de condensação: a partir da aglomeração de objetos menores. Para melhor compor este quadro, a figura 3.19 ilustra uma alta magnificação de uma nanopartícula referente a amostra 2 (A). Nesta, nota-se claramente que a nanopartícula é formada de outras nanopartículas com planos cristalinos orientados em direções diferentes.

Ambos o difratograma (figura 3.18) e a imagem de TEM (figura 3.19) corroboram a hipótese de que a aglomeração ocorre entre objetos menores.

Observamos diversas imagens onde há um alto nível de aglomeração entre as NPs de $10 \mathrm{~nm}$ (3.4 ou 3.5, por exemplo). Como a resolução de um TEM já é bastante boa para esta escala, então é possível distinguir entre estes objetos. Talvez, se o TEM fosse capaz de ir a uma magnificação ainda maior, ficaria ainda mais evidente a presença das nanopartículas menores aglomeradas entre si, formando os objeto de $10 \mathrm{~nm}$.

Por outro lado, se o TEM tivesse uma resolução pior ou se, por exemplo, tivéssemos utilizado apenas o SEM para as análises, seria provável que os objetos observados 
fossem maiores já que não seríamos capazes de distinguir entre NPs de 10 nm (figura 3.1, por exemplo).

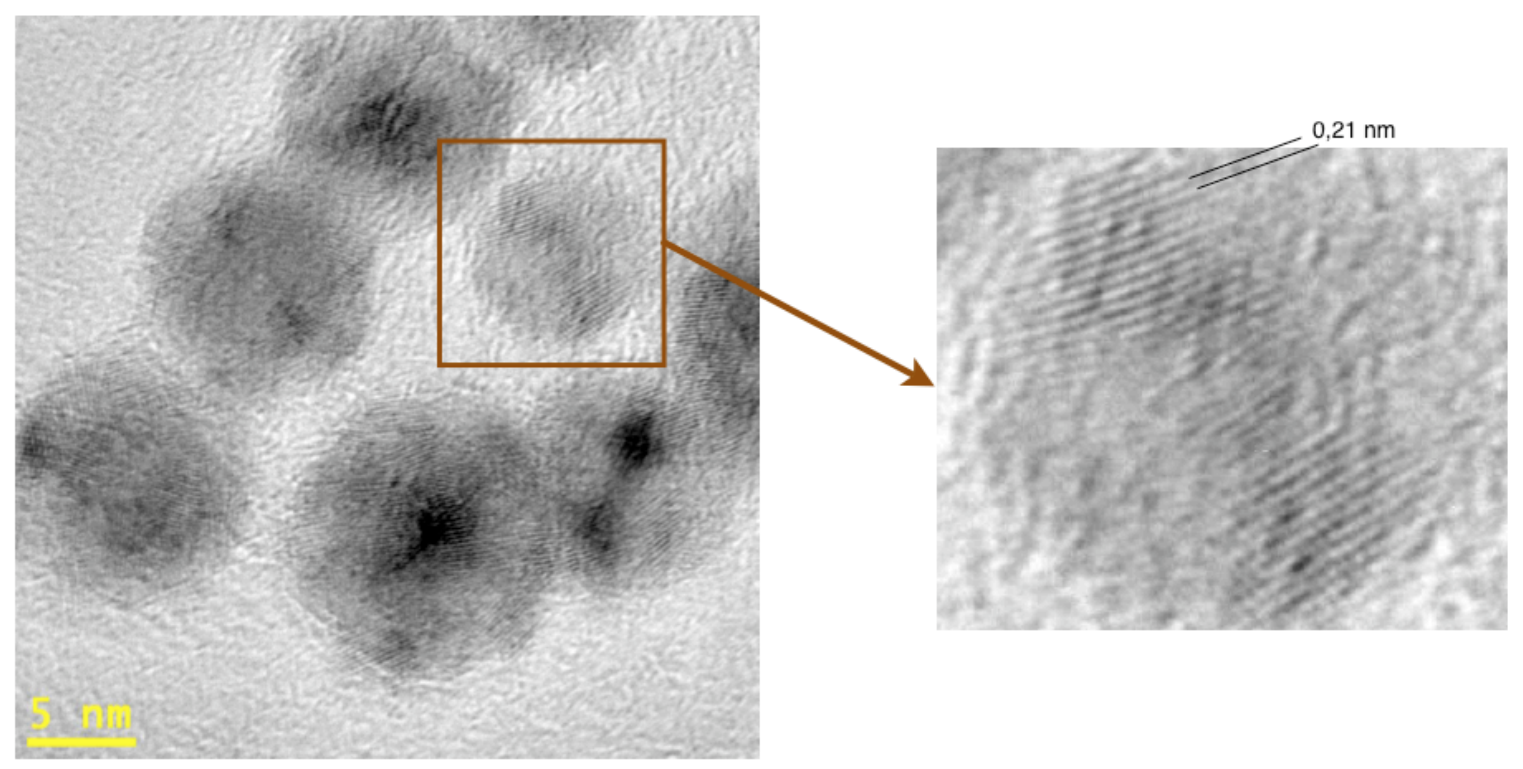

Fig. 3.19: imagem de TEM em alta magnificação relativo a amostra 2 (A) onde nota-se claramente que a nanopartícula é composta de mais de um objeto.

\subsection{Propriedades magnéticas}

Não esperávamos nenhum resultado surpreendente de uma análise magnética das NPs. Mas mesmo assim, esta era importante de ser realizada e foi feita com um VSM.

Era de interesse preservar o caráter nanoparticulado da amostra. Para isso, uma amostra foi preparada onde emberçamos as NPs em uma matriz de cobre diluindo-as significativamente.

As condições do cobalto foram as padrões, $30 \mathrm{~W}$ e $85 \mathrm{sccm}$. Como a montagem na qual esta amostra foi preparada foi a mesma da amostra relativa a análise de espessura da seção 3.3.2, a taxa de deposição das NPs já era conhecida. Para o cobre, utilizamos $100 \mathrm{~W}$ e determinamos a taxa de deposição por RBS.

No centro da trilha de NPs, a taxa de deposição do cobalto era da ordem de 3,6 $\mathrm{nm} /$ min e para o cobre, da ordem de 3,4 nm/min. Assim, para garantir um espaçamen- 
to significativo entre as nanopartículas, a amostra foi feita de forma alternada, primeiramente depositando $\mathrm{Cu}$ por 5 minutos e depois $\mathrm{Co}+\mathrm{Cu}$ por 2 minutos, repetindo este processo 10 vezes (para garantir uma espessura grande o suficiente para que o sinal no VSM fosse bom). Em seguida foram depositadas uma última camada de 5 minutos de cobre e um recobrimento com aproximadamente $12 \mathrm{~nm}$ de $\mathrm{Si}_{3} \mathrm{~N}_{4}$. Os detalhes da produção desta amostra estão descritos na ficha 7.

\section{FICHA 7}

\begin{tabular}{|c|c|c|}
\hline $\begin{array}{l}\text { INFORMAÇÕES GERAIS } \\
\text { Material: Cobalto } \\
\text { Objetivos: estudar as proprie- } \\
\text { dades magnéticas das NPs }\end{array}$ & $\begin{array}{l}\text { GRANDEZAS DO SISTEMA } \\
\text { Fluxo: } 85 \text { sccm } \\
\text { Pressão no copo: } 1 \text { Torr } \\
\text { Pressão na câmara: } 4.8 \text { mTorr }\end{array}$ & $\begin{array}{l}\text { CONDIÇÕES DA } \\
\text { DEPOSIÇÃO } \\
\text { Tempo total: } 105 \mathrm{~min} \\
\text { Substrato: Si } \\
\text { Porta-substrato: girando } \\
\text { Distância PS - Copo: } 3 \mathrm{~cm}\end{array}$ \\
\hline ALVO DE CO & ALVO DE CU & ALVO DE $\mathrm{SI}_{3} \mathbf{N}_{4}$ \\
\hline $\begin{array}{l}\text { Potência: } 30 \mathrm{~W} \\
\text { Corrente: } 105 \mathrm{~mA} \\
\text { Voltagem: } 270 \mathrm{~V} \\
\text { Taxa de deposição: } \\
\text { 3,6 nm/min (topo) }\end{array}$ & $\begin{array}{l}\text { Potência: } 100 \mathrm{~W} \\
\text { Corrente: } 270 \mathrm{~mA} \\
\text { Voltagem: } 320 \mathrm{~V} \\
\text { Taxa de deposição: } \\
3,4 \mathrm{~nm} / \mathrm{min}\end{array}$ & $\begin{array}{l}\text { Potência: } 100 \text { W RF } \\
\text { Taxa de deposição: } \\
0,4 \mathrm{~nm} / \mathrm{min}\end{array}$ \\
\hline
\end{tabular}

CALIBRAÇão: Todas as taxas de deposição foram obtidas através de análises de RBS. Em particular, a taxa de deposição das NPs de cobalto foi estimada a partir da análise da seção 3.3 .2 relativa a amostra 5 .

\begin{tabular}{|c|c|}
\hline $\begin{array}{l}\text { DEPOSIÇÃO } \\
\begin{array}{l}5 \text { min de } \mathrm{Cu}-17 \mathrm{~nm} \\
2 \min \text { de } \mathrm{Cu}+\mathrm{Co}-(7,2 \mathrm{~nm}+8 \mathrm{~nm}) \\
\mathbf{x} 10\end{array}\end{array}$ & $\begin{array}{l}\text { Total: } \\
\cdot 267 \mathrm{~nm} \text { de } \mathrm{Cu} \\
\cdot 72 \mathrm{~nm} \text { de } \mathrm{NPs} \text { de Co } \\
\cdot 12 \mathrm{~nm} \text { de } \mathrm{Si}_{3} \mathrm{~N}_{4} .\end{array}$ \\
\hline $\begin{array}{l}5 \mathrm{~min} \text { de } \mathrm{Cu}-17 \mathrm{~nm} \\
30 \mathrm{~min} \text { de } \mathrm{Si}_{3} \mathrm{~N}_{4}-12 \mathrm{~nm}\end{array}$ & \\
\hline
\end{tabular}

Na figura 3.20 encontram-se curvas de histerese para a amostra, obtida realizando medidas de 20 em 20 Oe, com 10 segundos por ponto e com um campo máximo de 5 kOe. Duas curvas distintas foram obtidas para o campo magnético orientado no plano e fora dele e em seguida, normalizadas.

Curvas de histerese foram também medidas para uma amostra de controle que novamente, continha tudo (substrato, $\mathrm{Cu}$ e $\mathrm{Si}$ ) menos as nanopartículas. Com estas, o efeito diamagnético do substrato foi subtraído da curva original. 
A partir desta imagem, poucas conclusões podem ser obtidas. Entre elas, a mais notável é a ausência de eixos preferenciais de magnetização uma vez que ambas as curvas apresentam campos coercivos próximos. Isso já era esperado devido a forma aproximadamente esférica das NPs. Além disso, o valor obtido para o campo coercivo é da ordem de 100 Oe, um valor usualmente encontrado em filmes finos de cobalto.

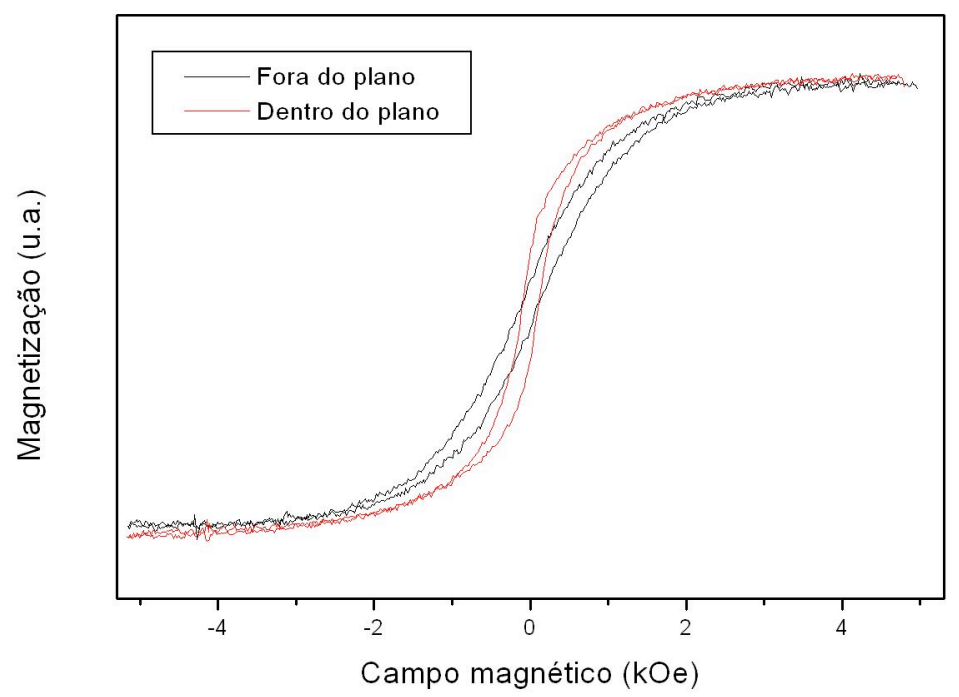

Fig. 3.20: curva de histerese dentro e fora do plano para a amostra relativa a ficha 7.

Um último argumento de interesse é a investigação de fases superparamagnéticas em nanopartículas de Co, o que pode ocorrer dependendo do tamanho do objeto. Da literatura, sabe-se que o superparamagnetismo em NPs de Co começa a existir para diâmetros menores que $6 \mathrm{~nm}$ [24]. Estamos acima deste valor ( 10 nm) e portanto, esperávamos um comportamento ferromagnético, o que foi de fato observado na curva da figura 3.20.

\subsection{Considerações sobre o regime de colimação}

Durante o trabalho, determinamos condições padrões de utilização do sistema. Estas podem ser entendidas como condições estáveis que fornecem resultados reprodutíveis e razoáveis minimizando também a degradação das peças. Tais valores corres- 
pondem a $30 \mathrm{~W}$ de potência e $85 \mathrm{sccm}$ de fluxo de gás (descritos em maior detalhe na seção 2.3.2).

Tais condições dizem respeito também ao que costumamos chamar de regime de colimação que corresponde a uma "região" dos parâmetros potência e fluxo para os quais a quantidade de material removido do copo é expressivamente alta.

A razão pela qual este regime é de interesse é que, estando nele, somos capazes de ter certeza que estamos produzindo material. Em uma situação ideal onde técnicas de análise pudessem ser utilizadas com facilidade, isto não seria um problema. Mas, como este não é o caso e como a grande maioria das técnicas que necessitamos são sofisticadas e complexas, ter confiança nas amostras produzidas é fundamental para garantir que o trabalho se desenvolva no tempo certo.

Além disso, um termo fundamental durante todo o desenvolvimento do sistema foi a reprodutibilidade das amostras. No regime de colimação, somos capaz de testar tal reprodutibilidade, mesmo que apenas parcialmente, durante o próprio processo de produção medindo visualmente a largura da "trilha" de material e a rapidez com que ela se forma*.

É por tais razões que nos restringimos a este regime durante o trabalho.

\subsection{Resultados para nanopartículas de Cu e SmCo}

Além do Co, Cu e SmCo foram utilizados no gerador de nanopartículas. Através de diversas análises, concluímos que há a formação de nanopartículas com tamanhos próximos dos das NPs de Co e em condições parecidas de operação. Estes resultados estão ilustrados a seguir.

NPs de Cu tem diversas aplicações, principalmente na área de plasmônica e fotônica. SmCo é um material extensivamente usado na produção de imãs permanentes devido a sua altíssima anisotropia. Utilizamos, para este estudo, um alvo com a estequiometria de $\mathrm{SmCo}_{5}$

\footnotetext{
* Notamos que quando a trilha se forma no tempo certo, todo o resto parece estar em ordem e os resultados são reprodutíveis.
} 


\subsubsection{Cobre}

Para as NPs de $\mathrm{Cu}$, poucas informações foram obtidas pois poucas análises foram realizadas. A figura 3.21 ilustra imagens de SEM de nanopartículas de $\mathrm{Cu}$ produzidas nas condições padrões de operação, $30 \mathrm{~W}$ e $85 \mathrm{sccm}$ e depositadas sobre um substrato de carbono. Destas, a semelhança com as nanopartículas de Co é evidente. Pelo fato das medidas terem sido realizadas com SEM, foi inviável fazer uma análise estatística do tamanho das NPs.

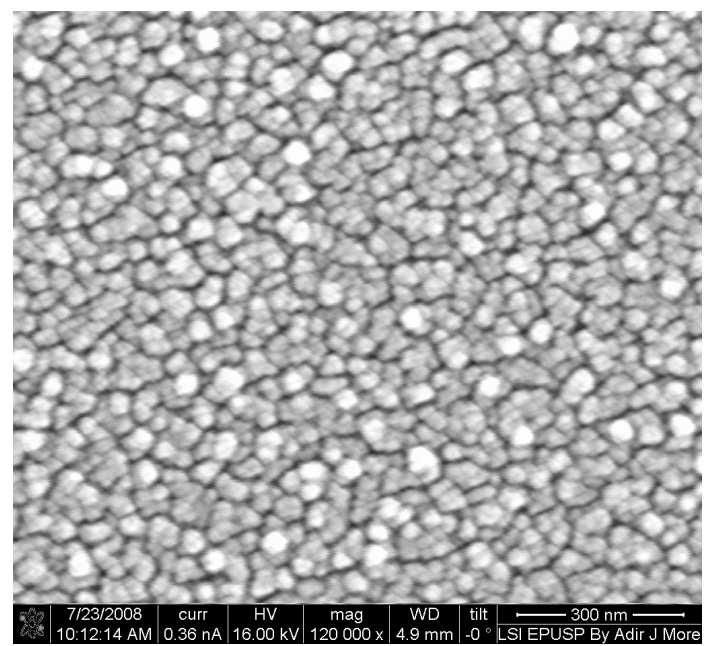

(a)

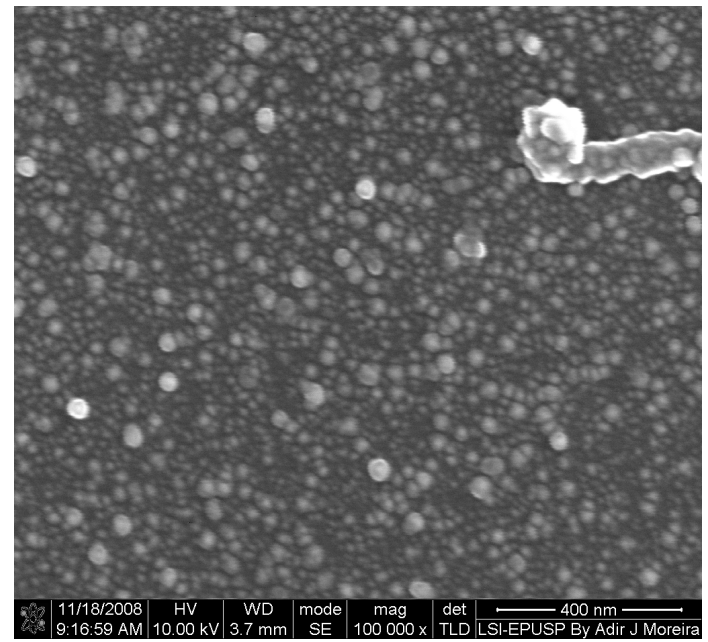

(b)

Fig. 3.21: imagens de SEM em diferentes magnificações de nanopartículas de Cu produzidas nas condições padrões de utilização: 30 W e $85 \mathrm{sccm}$.

A principal diferença que pode ser notada nestas imagens quando comparadas com as imagens de SEM de NPs de Co, por exemplo as da figura 3.13, é o maior empacotamento dos objetos. Isto pode ser atribuído ao fato do $\mathrm{Cu}$ não ser magnético o que faz com que o alinhamento das NPs seja menor.

\subsubsection{SmCo}

Passando para o SmCo, amostras foram produzidas utilizando um alvo de $\mathrm{SmCo}_{5}$. (ficha 8). Os substratos utilizados nestas amostras foram Si para SEM, XRD e VSM e 
grades de Cu para TEM. O fluxo utilizado foi menor, de $45 \mathrm{sccm}$, e as potências foram de $10 \mathrm{~W}((\mathrm{~A})$ e $(\mathrm{B}))$ e $50 \mathrm{~W}(\mathrm{C})$. A razão pela qual diminuímos os valores de potência e fluxo foi pois notamos que, mesmo com estes valores reduzidos, ainda estávamos no regime de colimação e procuramos então, investigar se ainda havia a formação das NPs com estes parâmetros.

Em particular, as amostras (B) e (C) foram produzidas com o substrato fixado sobre um pequeno imã, cujo intuito era alinhar magneticamente as NPs conforme elas fossem sendo depositadas no substrato.

Imagens de SEM e TEM podem ser vistas na figura 3.22 onde a formação das NPs é clara. Além disso, por serem mais fortemente magnéticas (como será visto a seguir), nota-se também uma fortíssima diminuição no empacotamento do material (figura 3.22 (a)).

\section{FICHA 8}

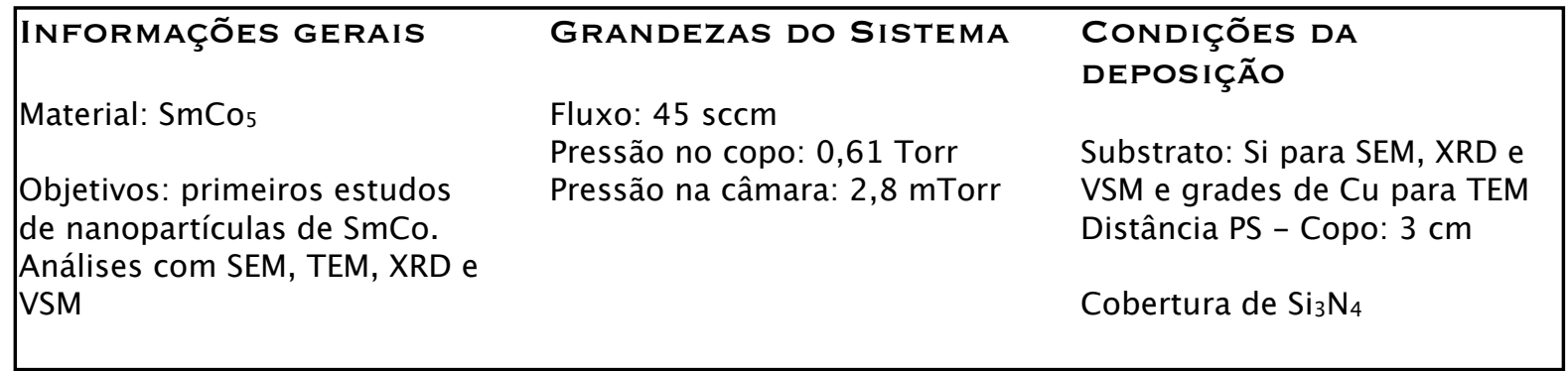

\begin{tabular}{|c|c|c|c|c|c|c|}
\hline $\begin{array}{c}\text { Amos- } \\
\text { tra }\end{array}$ & $\begin{array}{c}\text { Potência } \\
(\mathbf{W})\end{array}$ & $\begin{array}{c}\text { Corrente (mA)/ } \\
\text { Voltagem (V) }\end{array}$ & $\begin{array}{c}\text { Tempo } \\
(\mathbf{m i n})\end{array}$ & $\begin{array}{c}\text { Porta- } \\
\text { substrato }\end{array}$ & Utilização \\
\hline A & 10 & $60 / 155$ & 5 & girando & SEM/TEM \\
\hline B & 10 & $60 / 155$ & 10 & parado & XRD/VSM \\
\hline C & 50 & $400 / 150$ & 10 & parado & SEM/XRD/VSM \\
\hline
\end{tabular}

Como a comparação entre as amostras 8 (A) ou (B) (10 W) e 8 (C) (50 W) foi feita por SEM, não foi possível quantificar as variações nos tamanhos das partículas, mesmo elas aparentando serem maiores. Mas, considerando a variação por um fator 5 na po- 
tência, seria natural de se esperar um aumento por um fator 1,7 no tamanho. Visualmente, isso parece razoável.

A figura 3.23 ilustra quatro curvas de histerese para as amostras 8 (B) e (C), dentro e fora do plano. A curva 3.23 (a) corresponde a amostra 8 (B) (10 W) e a curva 3.23 (b) a amostra $8(\mathrm{C})(50 \mathrm{~W})$.

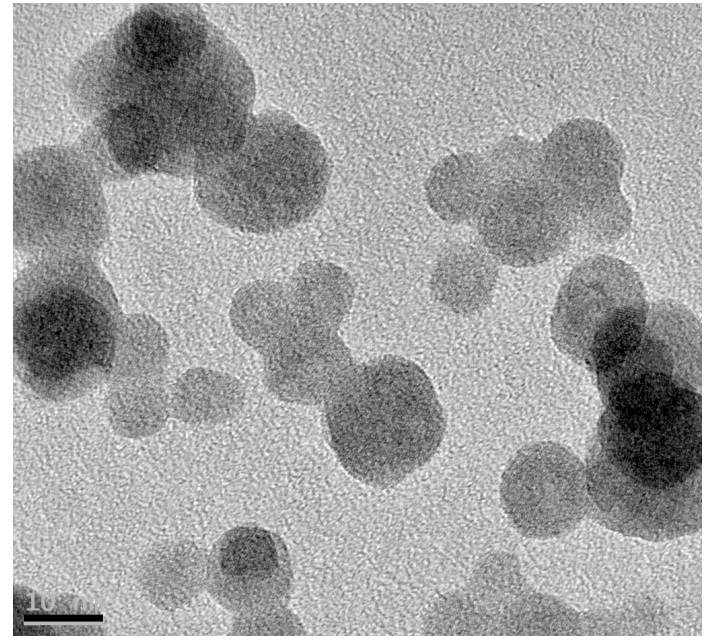

(a)

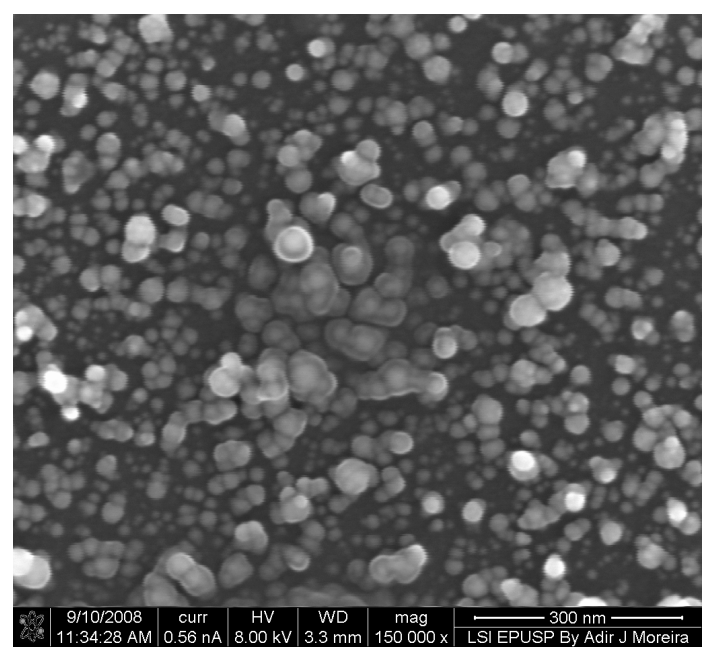

(c)

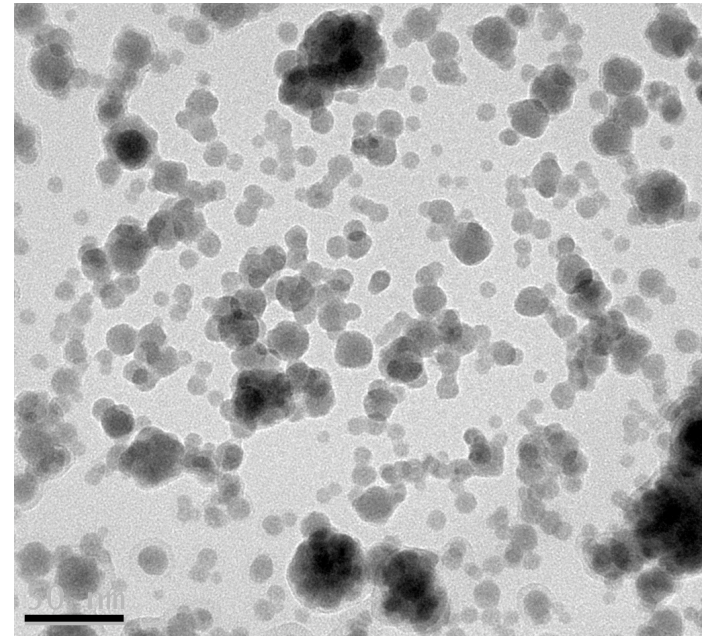

(b)

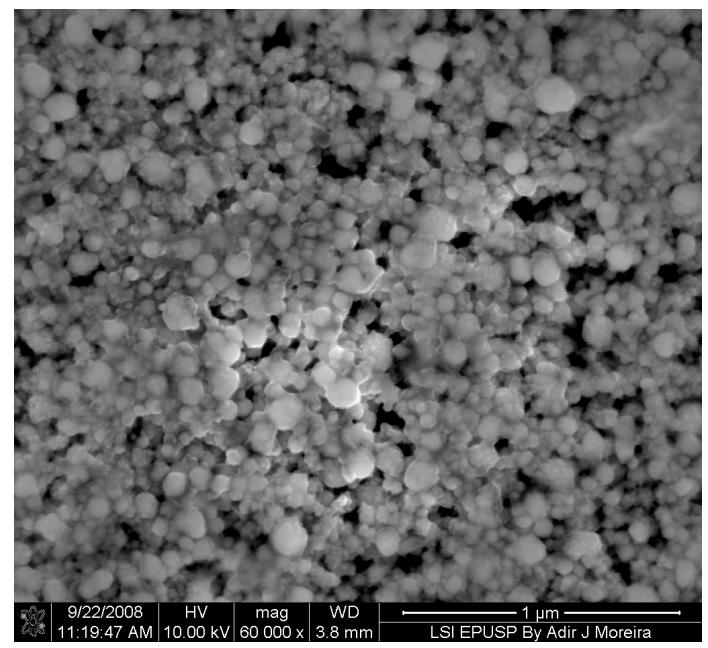

(d)

Fig. 3.22: imagens de SEM e TEM para as amostras 8. (a) e (b) imagens de TEM e (c) imagem de SEM para a amostra $8(A)$ preparada com $10 \mathrm{~W}$ e $45 \mathrm{sccm}$. (d) imagem de SEM para a amostra 8 (C) preparada com $50 \mathrm{~W}$ e $45 \mathrm{sccm}$.

É possível observar nestas imagens que há uma diferença muito grande nas propriedades magnéticas da amostra produzida com $10 \mathrm{~W}$ e da amostra produzida com 50 W. Estas mudanças estão condizentes com o aumento no tamanho dos objetos. 
Na figura 3.23 (b) é possível observar a existência de uma assimetria na curva fora do plano. Nota-se também que o campo aplicado de 20 kOe não foi suficiente para simetrizá-la, indicando a presença de uma alta anisotropia induzida pelo imã durante a sua produção. Isso indica que o campo coercivo, que já é razoavelmente alto, pode ser ainda maior. Esta alta anisotropia mostra que o caráter metálico das nanopartículas foi preservado, mesmo para o SmCo cuja taxa de oxidação é bastante elevada. Medidas posteriores com uma bobina supercondutora indicaram a necessidade de um campo de cerca de 50 kOe para remover a assimetria da curva de histerese.

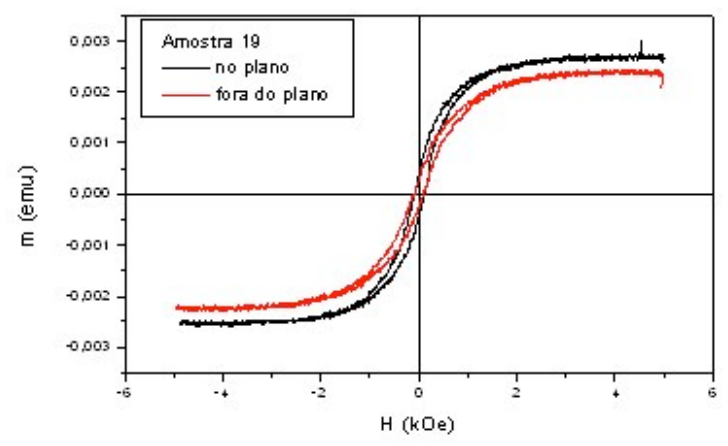

(a)

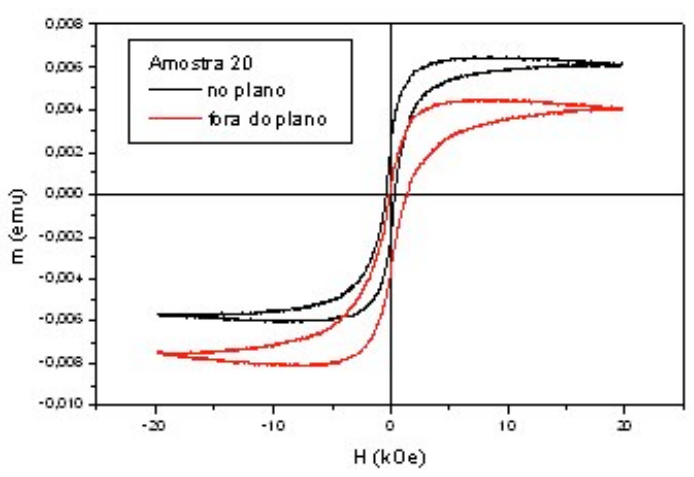

(b)

Fig. 3.23: curvas de histerese obtidas para as amostras 8. (a) relativa a amostra (B) e (b) relativa a amostra (C).

Finalmente, passando para uma análise estrutural das NPs de SmCo, a figura 3.24 ilustra dois difratogramas obtidos para as amostras 8 (A) (indiferente da (B) estruturalmente) e 8 (C). Os picos em torno de $30^{\circ}$, que estão presentes em ambos os gráficos, são do Si utilizado com substrato.

Neste gráfico nota-se novamente a diferença entre as amostras com $10 \mathrm{~W}$ e $50 \mathrm{~W}$. A amostra com $50 \mathrm{~W}$ é altamente cristalina ao passo que a com $10 \mathrm{~W}$ nem um pouco. Além disso, na amostra com $50 \mathrm{~W}$ nota-se uma estrutura híbrida de $\mathrm{SmCo}_{5}$ e $\mathrm{Sm}_{2} \mathrm{Co}_{17}$. Finalmente, pela fórmula de Scherrer, obtivemos um diâmetro médio de $20 \mathrm{~nm}$ para a amostra relativa a $50 \mathrm{~W}$. Este resultado também está condizente com as projeções feitas anteriormente da dependência do tamanho com a potência.

Estes resultados preliminares do SmCo já servem para situar-nos no problema e nos ajudarão a desenvolver melhores amostras. 


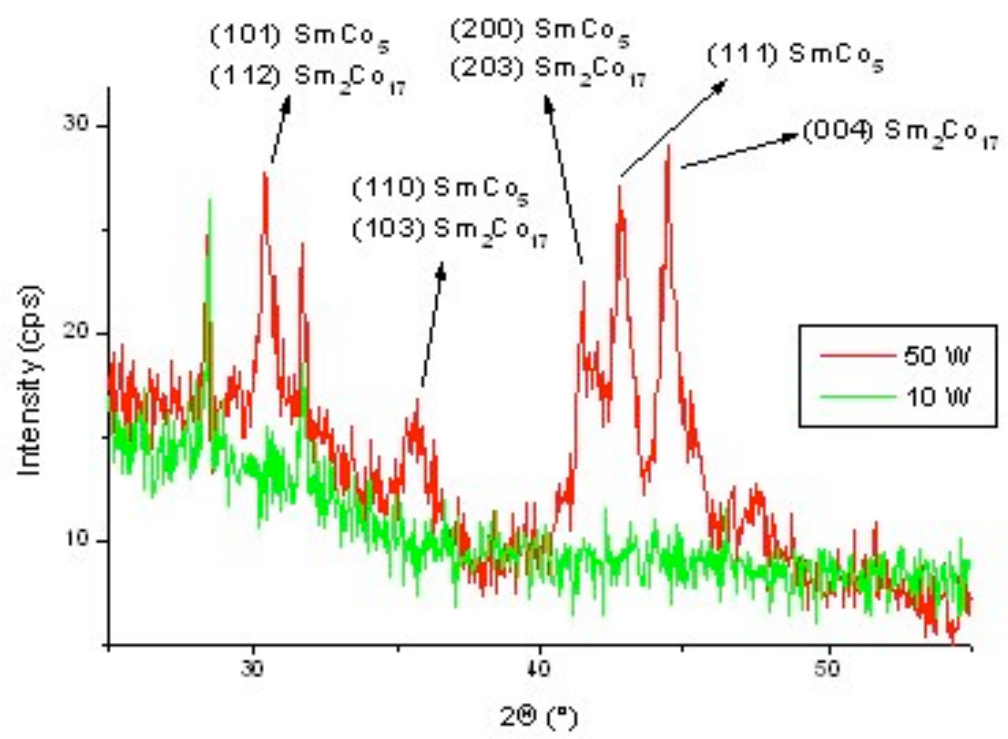

Fig. 3.24: difratogramas para as amostras $8(A)(10 \mathrm{~W})$ e $(C)(50 \mathrm{~W})$. 


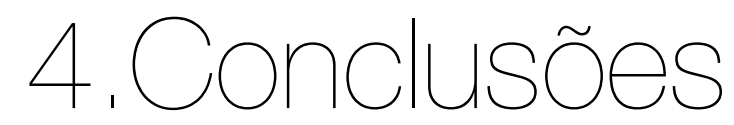

Este trabalho teve como foco o desenvolvimento de um gerador de nanopartículas cuja maior vantagem é poder produzir NPs de diferentes materiais com a mesma metodologia. O sistema foi produzido como uma adaptação não destrutiva de um sistema de "magnetron sputtering" sendo possível a codeposição das NPs com outros materiais.

O princípio de desenvolvimento do sistema é bastante simples. Ele está relacionado com a condensação do vapor atômico, produzido pelo "sputtering", através de colisões com os átomos de Ar presentes na câmara de condensação (denominada de copo), colocada sobre o alvo do material de interesse.

O copo possui $15 \mathrm{~cm}$ de comprimento e $10 \mathrm{~cm}$ de diâmetro e é selado, exceto por uma abertura de $2 \mathrm{~mm}$ em sua extremidade. O substrato é fixado a alguns centímetros desta abertura. Existem duas formas de depositar o material: com o substrato parado, onde todo o material que sai do copo fica depositado nele e com o substrato girando em torno do eixo do porta-substratos, o que faz com que a deposição ocorra esporadicamente a cada volta.

No entanto, fomos capazes de desenvolver uma metodologia para colimar as nanopartículas dentro do copo transformando a deposição em um feixe colimado de material e aumentando exponencialmente a taxa de deposição. Consequentemente, aumentamos também a velocidade com que as amostras eram preparadas.

Para explicar o processo de condensação e a colimação de material, um modelo fenomenológico foi desenvolvido. Este descreve razoavelmente bem as grandezas do nosso sistema e prevê também os resultados obtidos. 
Neste modelo, o fluxo determina a quantidade de Ar na câmara e a potência a quantidade de Co. Há então uma competição entre estas duas grandezas para que ocorra de forma eficiente os processos de colimação e condensação. Quando o fluxo é alto, a potência determina o diâmetro médio dos objetos seguindo uma raiz cúbica. Quando este não é o caso, as variáveis tem de ser ponderadas e o resulta não é tão trivialmente previsível.

Um outro foco do trabalho, relacionado com o desenvolvimento do sistema em si, foi a caracterização morfológica, estrutural e magnética de nanopartículas de cobalto. Este elemento foi escolhido devido as diversas aplicações com as quais ele pode ser utilizado.

Determinamos condições padrões de utilização do equipamento que correspondiam a valores que maximizassem as taxas de deposição sem degradar as peças do sistema. Os valores correspondiam a $30 \mathrm{~W}$ de potência aplicada ao alvo e 85 sccm de fluxo de gás. Da caracterização morfológica, concluímos que não é trivial modificar o tamanho das NPs, mesmo variando significativamente o fluxo e a potência.

Através de análises estatísticas das imagens de microscopia eletrônica de transmissão (TEM) concluímos que o diâmetro médio das nanopartículas gira em torno de $10 \mathrm{~nm}$ com uma dispersão de aproximadamente $13 \%$. Destas imagens foi possível também observar a influência do fluxo na taxa de deposição, corroborando o nosso modelo.

Através de medidas de retro-espalhamento Rutherford (RBS) foi possível realizar medidas da distribuição da espessura de NPs ao longo da amostra. Estas foram realizadas para o substrato parado e girando. Em ambos os casos comprovamos que a espessura tem um máximo no centro e decai seguindo uma distribuição Gaussiana.

Para o substrato parado, a taxa de deposição no centro foi de $75 \mathrm{~nm} / \mathrm{min}$ nas condições padrões de operação. Este valor é cerca de 50 vezes maior que a taxa de deposição do cobalto na mesma potência em um sistema de "sputtering".

No caso do substrato girando, este valor se reduziu para 3,6 $\mathrm{nm} / \mathrm{min}$, uma diminuição de um fator 20 com relação ao substrato parado. Utilizar o substrato girando é 
de interesse pois mesmo este valor ainda é um pouco elevado quando comparado a deposições usuais do "sputtering".

Medidas de difração de raios X mostraram que as NPs são nanocristalinas não apresentando nenhum pico de difração. Imagens em alta magnificação de TEM também mostraram objetos compostos de NPs menores. Estes resultados estão de acordo com o nosso modelo de que as aglomerações ocorrem, em média, entre objetos de tamanhos próximos.

Um estudo das propriedades magnéticas das NPs foi realizado. Neste foi possível concluir que as NPs não apresentam eixos preferenciais de magnetização, o que era esperado devido a forma como os objetos são depositados no substrato.

Finalmente, NPs de $\mathrm{Cu}$ e SmCo foram produzidas em condições parecidas as padrões de operação. Observamos, através de SEM e TEM, a formação dos aglomerados com tamanhos próximos dos de Co. Estes resultados ilustram a universalidade do processo de condensação.

Atualmente, o sistema pode ser considerado estável e altamente reprodutível. As amostras são produzidas com facilidade e com versatilidade. Podemos utilizar qualquer substrato que desejarmos, fazer amostras a baixas e altas temperaturas, codepositar com matrizes dielétricas ou metálicas, preparar diversas amostras idênticas simultaneamente e produzir amostras de controle que possuem tudo (substrato e codeposições) menos as NPs.

\section{Perspectivas futuras e colaborações envolvendo este trabalho}

A principal desvantagem deste sistema, até o momento, é a ausência de um controle sobre o tamanho das NPs. Este seria de enorme interesse e será portanto, um dos focos do nosso trabalho nos anos subseqüentes. Para obter tal controle pretendemos, além de dar continuidade às investigações sobre a influência do fluxo e da potência, trocar o gás utilizado na condensação por uma mistura de Ar e He tornar possível a va- 
riação do comprimento do copo de condensação. Pretendemos também resfriar este último com $\mathrm{N}_{2}$ líquido para melhorar a termalização do vapor atômico.

Com relação a cristalinidade das amostras, acreditamos que a melhor solução para resolver este problema seja o uso de tratamentos térmicos, tanto in situ através de lâmpadas conectadas ao porta-substrato, quanto ex situ através de fornos específicos. Pretendemos também desenvolver um dispositivo para homogeneizar a deposição do material em áreas maiores.

Temos o interesse de produzir NPs com diversos outros materiais. Entre estes, podemos mencionar NPs de metais nobres como Au e Ag e NPs magnéticas de ligas de FePt, CoPt e SmCo como as de maior interesse a curto prazo.

Ao emberçar estas NPs em matrizes diversas, o leque de possibilidades é enorme. Apenas para nanopartículas de cobalto, isso já nos rendeu uma série de colaborações, algumas já em andamento e outras ainda a serem iniciadas. Entre elas podemos mencionar:

I. Com Aurore Rudolf e Jean Philippe Ansermet da École Polytechnique Fédérale de Lausanne (EPFL) na Suiça, estudando efeitos de ressonância nuclear magnética (NMR) para detecção de spins de cobalto em sistemas com NPs de Co codepositadas com uma matriz de $\mathrm{Cu}$;

II. Com Mario Norberto Baibich da Universidade Federal de Santa Catarina, estudando efeitos de magnetoresistência em amostras com NPs de Co codepoistadas com Cu;

III. Com Antonio Carlos Seabra, Mariana Pojar e Simone Trippe da Escola Politécnica da Universidade de São Paulo (EPSUP), Luis Sampaio do Centro Brasileiro de Pesquisas Físicas (CBPF) e Narcizo Marques do Argonne National Laboratory (ANLAB) nos EUA, estudando a coexistência (ou não) da supercondutividade e do magnetismo em filmes com NPs de Co codepositadas com $\mathrm{Nb}$. 
IV. Com Daniel Cornejo e Leonardo Alonso do LMM-IFUSP estudando interfaces ferromagnéticas/anti-ferromagnéticas em filmes com NPs de Co codepoistadas com óxido de níquel.

V. Com Néstor Emilio Massa da Universida Federal de La Plata na Argentina estudando efeitos de dinâmica eletrônica em filmes com NPs de Co através de espectroscopia ótica no infravermelho (FTIR).

Todas estas colaborações são razoavelmente recentes e até então, nenhum trabalho foi publicado.

O meu projeto de doutorado, a ter inicio em sequência, terá como foco a produção de amostras denominadas de "spring magnets", que são compostas de um filme fino magnético codepositado com NPs também magnéticas. Estudaremos as situações de NPs magneticamente duras em uma matriz mole e NPs moles em uma matriz dura. 


\section{Bibliografia}

[1] G. Binnig, H. Rohrer, Ch. Gerber e E. Weibel, Physical Review Letters, 50, 120 (1983)

[2] A. K. Geim e K. S. Novoselov, Nature Matererials, 6, 183 (2007)

[3] Ch. Gerber e H. P. Lang, Nature Nanotechnology, 1, 3 (2006)

[4] T. M. Whitney, P. C. Searson, J. S. Jiang e C. L. Chien, Science, 261, 1316 (1993)

[5] I. M. L. Billas, A. Châtelain e W. A. de Heer, Science, 265, 1682 (1994)

[6] M. N. Baibich, J. M. Broto, A. Fert, F. Nguyen van Dau, F. Petroff, P. Eitenne, G. Creuzet, A. Friederich e J. Chazelas, Physical Review. Letters, 61, 2472 (1988)

[7] G. Binasch, P. Grünberg, F. Saurenbach e W. Zinn, Physical Review B, 39, 4828 (1989)

[8] P. Gambardella, S. Rusponi, M. Veronese, S. S. Dhesi, C. Grazioli, A. Dallmeyer, I. Cabria, R. Zeller, P. H. Dederichs, K. Kern, C. Carbone, H. Brune, Science, 300, 1130 (2003)

[9] S. Sun, C. B. Murray, D. Weller, L. Folks e A. Moser, Science, 287, 1989 (2000)

[10] Y. Sun e Y. Xia, Science, 298, 2176 (2002)

[11] A. S. Edelstein (editor) e R. C. Cammarata (editor), Nanomaterials: Synthesis, Properties and Applications. IOP Publishing Ltd, 1996.

[12] Y. Bao, A. B. Pakhomov e K. M. Krishnam, Journal of Applied Physics 97, 10J317 (2005)

[13] B. H. Liu, J. Ding, Z. Y. Zhong, Z. L. Dong, T. White e J. Y. Lin, Chemical Physics Letters 358, 96 (2002)

[14] J. Zhang e L. Gao, Materials Research Bulletin 39, 2249 (2004)

[15] A. H. Pfund, Phys. Rev. 35, 1434 (1930) 
[16] N. Yukawa, M. Hida, T. Imura, M. Kawamura, Y. Mizuno, Metallurgical and Materials Transactions B, 3, 887 (1972)

[17] J. M. Qiu e J. P. Wang, Applied Physics Letters, 88, 192505 (2006)

[18] S. Tanemura, K. Kajino, L. Miao, S. Koide, M. Tanemura, S. Toh, K. Kaneko e M. Mori, The European Physics Journal D, 34, 79 (2005)

[19] Y. Xu, Z. G. Sun, Y. Qiang, D. J. Sellmyer, Journal of Magnetism and Magnetic Materials, 266, 164 (2003)

[20] S. Bisht, G. Feldmann, S. Soni, R. Ravi, C. Karikar, Am. Maitra e An. Maitra, Journal of Nanobiotechnology, 5, 1477 (2007)

[21] D. Depla (editor) e S. Mahieu (editor), Reactive Sputter Deposition (Springer Series in Materials Science), Springer 2008.

[22] D. Phokharatkul, Y. Ohno, H. Nakano, S. Kishimoto e T. Mizutani, Applied Physics Letters, 93, 053112 (2008)

[23] C. Petit, A. Taleb e M.-P. Pileni, Advanced Materials, 3, 259 (1998)

[24] S. I. Woods, J. R. Kirtley, S. Sun e R. H. Koch, Physical Review Letters, 87, 137205 (2001)

[25] M. M. Deshmukh, S. Kleff, S. Guéron, E. Bonet, A. N. Pasupathy, J. von Delft e D. C. Ralph, Physical Review Letters, 87, 226801 (2001)

[26] R. Morel, A. Brenac, P. Bayle-Guillemaud, C. Portemont e F. La Rizza, The European Journal of Physics D, 24, 287 (2003)

[27] O. Schubert, J. Becker, L. Carbone, Y. Khalavka, T. Provalska, I. Zins e C. Sönnichsen, Nanoletters, 8, 2345 (2008)

[28] A. Polman, Science, 322, 868 (2008)

[29] A. Moser, K. Takano, D. T. Marguiles, M. Albrecth, Y. Sonobe, Y. Ikeda, S. Sun e E. Fullerton, Journal of Physics D, 35, 157 (2002)

[30] J. A. Bain e W. F. Egelhoff Jr., Applied Physics Letters, 88, 242508 (2006)

[31] C.-B. Rong, Y. Li e J. P. Liu, Journal of Applied Physics, 101, 09K505 (2007) 
[32] C. N. Chinnasamy, J. Y. Huang, L. H. Lewis, B. Latha, C. Vittoria e V. G. Harris, Applied Physics Letters, 93, 032505 (2008)

[33] F. X. Gu, R. Karnik, A. Z. Wang, F. Alexis, E. Levy-Nissenbaum, S. Hong, R. S. Langer e O. C. Farokhzad, NanoToday, 2, 14 (2007)

[34] S. Nonose, Y. Sone, K. Onodera, S. Sudo e K. Kaya, J. Phys. Chem. 94, 2744 (1990)

[35] A. I. Korchagin, N. K. Kuksanov, A. V. Lavrukhin, S. N. Fadeev, R. A. Salimov, S. P. Bardakhamov, V. B. Goncharov, A. P. Suknev, E. A. Paukshits, T. V. Larina, V. I. Zaikovskii, S. V. Bogdanov e B. S. Bal'zhinimaev, Vacuum 77, 485 (2005).

[36] R.-P. Methlinga , V. Senz, E.-D. Klinkenberg, Th. Diederich, J. Tiggesbäumker, G. Holzhüuter, J. Bansmann e K.H. Meiwes-Broer, The European Journal of Physics D, 16, $173(2001)$

[37] S. H. Baker, S. C. Thornton, K. W. Edmonds, M. J. Maher, C. Norris e C. Binns, Review of Scientific Instruments, 71, 3178 (2000)

[38] C. G. Granqvist e R. A. Buhrman, Journal of Applied Physics, 47, 2200 (1976)

[39] B. Briehl e H. M. Urbassek, Journal of Vaccuum Science and Technology A, 17-1, 256 (1999)

[40] J. Bansmann, S. H. Baker, C. Binns, J. A. Blackman, J.-P. Bucher, J. Dorantes-Dávila, V. Dupuis, L. Favre, D. Kechrakos, A. Kleibert, K.-H. Meiwes Broer, G. M. Pastor, A. Perez, O. Toulemonde, K. N. Trohidou, J. Tuailoon e Y. Xie. Surface Science Reports, 56, 189 (2005).

[41] M. Ohring, The Materials Science of Thin Films, Academic Press Inc, 1992

[42] A. Ledo-Suárez, L. Rodríguez-Sánchez, M. C. Blanco e M. A. Lópes-Quintela, Physica Status Solidi, 6203 (2006)

[43] A. M .Schwartzberg, T. Y. Olson, C. E. Tally e J. Z. Zhang, Joirnal of Physical Chemistry C, 111, 16080 (2007)

[44] Y.-J. Zhang, Y. Zhang, Z.-h. Wang, D. Li, T.-u. Cui, W. Liu e Z.-d. Zhang, European Journal of Inorganic Chemistry, 13, 2733 (2008) 